University of Tennessee Health Science Center

UTHSC Digital Commons

\title{
Language Skills, Oral Narrative Production, and Executive Functions of Children Who Are Deaf or Hard of Hearing
}

Hyejin Park

University of Tennessee Health Science Center

Follow this and additional works at: https://dc.uthsc.edu/dissertations

Part of the Speech and Hearing Science Commons

\section{Recommended Citation}

Park, Hyejin , "Language Skills, Oral Narrative Production, and Executive Functions of Children Who Are Deaf or Hard of Hearing" (2014). Theses and Dissertations (ETD). Paper 198. http://dx.doi.org/10.21007/ etd.cghs.2014.0238.

This Dissertation is brought to you for free and open access by the College of Graduate Health Sciences at UTHSC Digital Commons. It has been accepted for inclusion in Theses and Dissertations (ETD) by an authorized administrator of UTHSC Digital Commons. For more information, please contact jwelch30@uthsc.edu. 


\title{
Language Skills, Oral Narrative Production, and Executive Functions of Children Who Are Deaf or Hard of Hearing
}

\begin{abstract}
This study assessed the language skills, oral narrative abilities, and executive functions (EFs) of children who are deaf or hard of hearing $(\mathrm{DHH})$ and normal hearing $(\mathrm{NH})$, and examined the differences between two groups as well as the relationships between oral narrative production and EFs.

Eleven children who are $\mathrm{DHH}$ and ten who are $\mathrm{NH}$, between 9 and 11 years of age, participated in the study. All of the children in the DHH group had bilateral hearing losses ranging from moderate through profound, and had no other diagnosed social, emotional or intellectual problems. All had more than 4 years 10 months of hearing experience with hearing aids or cochlear implants, used oral communication, and were educated in mainstreamed classrooms. The $\mathrm{NH}$ group included typically developing children with no diagnosed social, emotional or intellectual problems. Language ability was assessed by a standardized test and narrative microstructure analysis. Narratives were elicited through story retell and story generation, and measured their organization structures. EFs were assessed two ways. One was through parent report and the other was through performance based measures.
\end{abstract}

Results of the language assessments indicate that even though scores on the standardized language test were significantly different between groups, the language ability of the DHH group as assessed through microstructure analysis was generally comparable to their $\mathrm{NH}$ peers, and that they used their language knowledge appropriately at the discourse level. Their language ability was related to the well organized story structure in the story retell condition more than in the story generation condition. The macrostructure narrative analysis showed that the $\mathrm{DHH}$ group understood and produced age-appropriate story grammar and complete episodes, but had some problems in using their knowledge when making up their own stories. Their problems in presenting the logical relations of episodes on the story generation condition indicate that the $\mathrm{DHH}$ group may not fully understand the temporal and causal relationships between characters and events.

The correlations that were found between narrative structures and EFs with the DHH group support the idea that problems in narrative organization may be associated with EFs for this population. Although some relations were found between narrative macrostructures and EFs with the NH group, more EFs were implicated in the organization of narrative structures especially in story generation with the DHH group. This result indicates that EFs may have a greater influence on narrative organization for children who are $\mathrm{DHH}$ than those who are $\mathrm{NH}$. Although the sample is limited and the results preliminary, the findings also suggest that the narrative problems seen in children who are $\mathrm{DHH}$ should be considered from both linguistic and cognitive perspectives in assessment and treatment.

Document Type

Dissertation

Degree Name

Doctor of Philosophy (PhD)

Program

Speech and Hearing Science

Research Advisor

Ilsa E. Schwarz, Ph.D. 


\section{Keywords}

deaf and hard of hearing, executive function, language, narrative

\section{Subject Categories}

Communication Sciences and Disorders | Medicine and Health Sciences | Speech and Hearing Science 
Language Skills, Oral Narrative Production, and Executive Functions of Children Who Are Deaf or Hard of Hearing

\author{
A Dissertation \\ Presented for \\ The Graduate Studies Council \\ The University of Tennessee \\ Health Science Center \\ In Partial Fulfillment \\ Of the Requirements for the Degree \\ Doctor of Philosophy \\ From The University of Tennessee
}

By

Hyejin Park

May 2014 
Copyright (@ 2014 by Hyejin Park. All rights reserved. 


\section{DEDICATION}

To my parents

who are the eternal mentors in my life 


\begin{abstract}
This study assessed the language skills, oral narrative abilities, and executive functions (EFs) of children who are deaf or hard of hearing (DHH) and normal hearing $(\mathrm{NH})$, and examined the differences between two groups as well as the relationships between oral narrative production and EFs.
\end{abstract}

Eleven children who are DHH and ten who are NH, between 9 and 11 years of age, participated in the study. All of the children in the DHH group had bilateral hearing losses ranging from moderate through profound, and had no other diagnosed social, emotional or intellectual problems. All had more than 4 years 10 months of hearing experience with hearing aids or cochlear implants, used oral communication, and were educated in mainstreamed classrooms. The NH group included typically developing children with no diagnosed social, emotional or intellectual problems. Language ability was assessed by a standardized test and narrative microstructure analysis. Narratives were elicited through story retell and story generation, and measured their organization structures. EFs were assessed two ways. One was through parent report and the other was through performance based measures.

Results of the language assessments indicate that even though scores on the standardized language test were significantly different between groups, the language ability of the DHH group as assessed through microstructure analysis was generally comparable to their NH peers, and that they used their language knowledge appropriately at the discourse level. Their language ability was related to the well organized story structure in the story retell condition more than in the story generation condition. The macrostructure narrative analysis showed that the DHH group understood and produced age-appropriate story grammar and complete episodes, but had some problems in using their knowledge when making up their own stories. Their problems in presenting the logical relations of episodes on the story generation condition indicate that the DHH group may not fully understand the temporal and causal relationships between characters and events.

The correlations that were found between narrative structures and EFs with the DHH group support the idea that problems in narrative organization may be associated with EFs for this population. Although some relations were found between narrative macrostructures and EFs with the NH group, more EFs were implicated in the organization of narrative structures especially in story generation with the DHH group. This result indicates that EFs may have a greater influence on narrative organization for children who are DHH than those who are NH. Although the sample is limited and the results preliminary, the findings also suggest that the narrative problems seen in children who are DHH should be considered from both linguistic and cognitive perspectives in assessment and treatment. 


\section{TABLE OF CONTENTS}

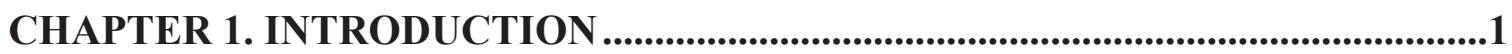

Rationale for the Present Study ...........................................................................

Purpose of the Present Study ...............................................................................

Organization of the Remaining Chapters...............................................................

CHAPTER 2. LITERATURE REVIEW .....................................................................4

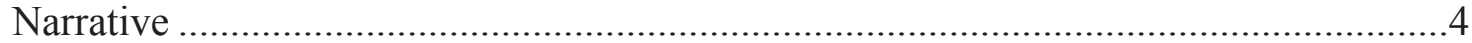

Oral Narrative Discourse and Language Development ............................................4

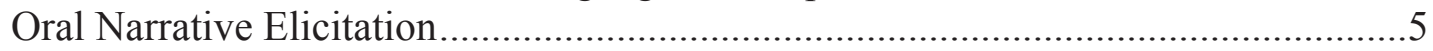

Oral Narrative Analysis...................................................................................

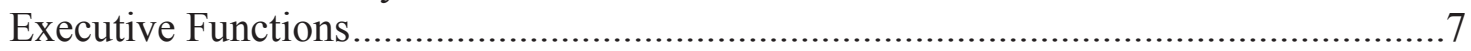

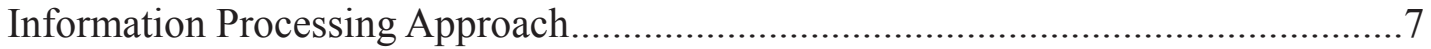

Executive Functions .................................................................................. 7

Tests of Executive Functions .......................................................................... 10

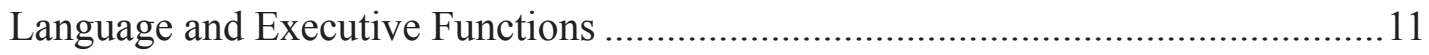

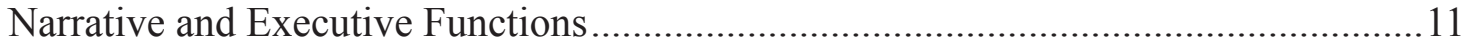

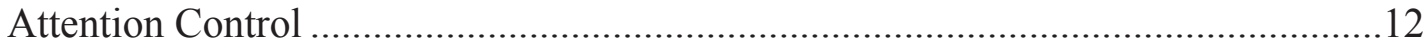

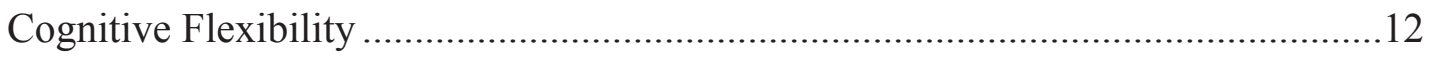

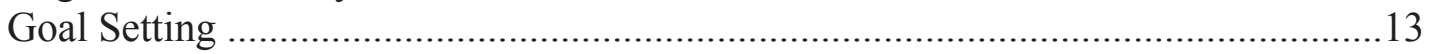

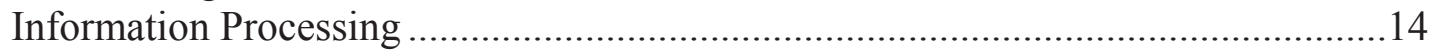

Executive Functions Studies Using the BRIEF ................................................... 14

Children Who Are Deaf or Hard of Hearing.............................................................. 15

Children Who Are DHH and Oral Narratives .........................................................15

Children Who Are DHH, Language, and Executive Functions ...............................17

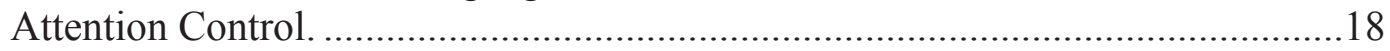

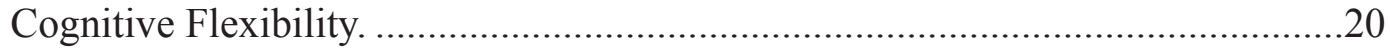

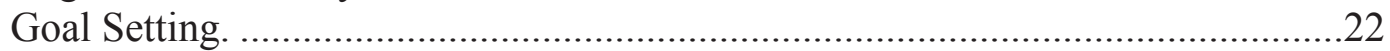

Information Processing ..................................................................................23

Executive Functions Studies Using the BRIEF. ...............................................24

Children Who Are DHH, Narrative Skills and Executive Functions.......................26

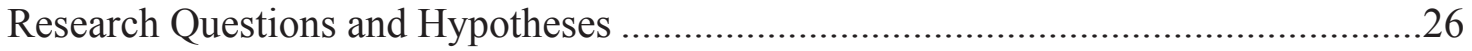

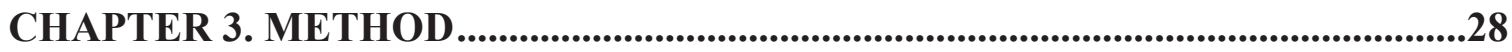

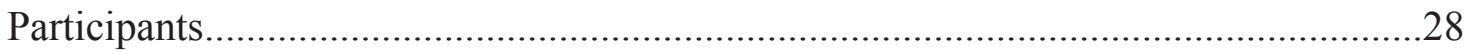

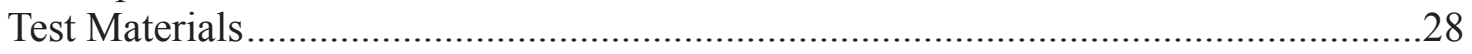

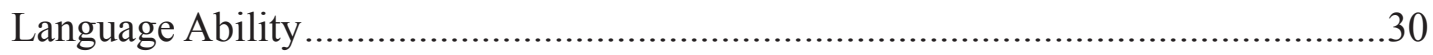

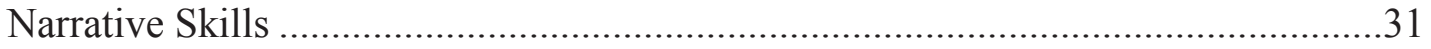

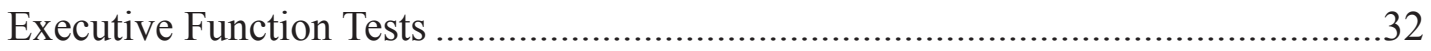

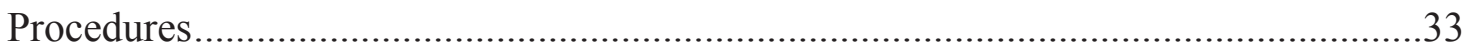

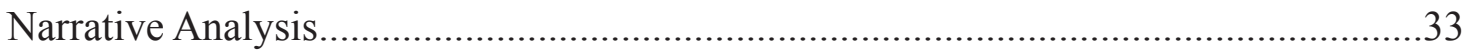

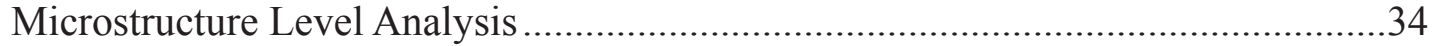

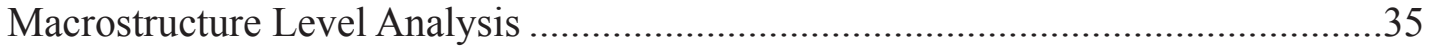

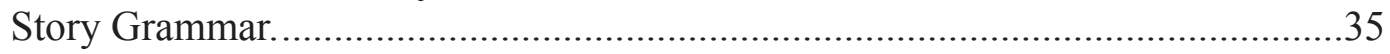




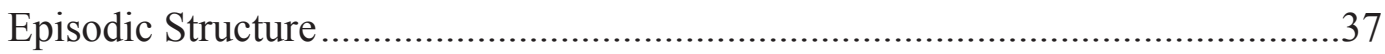

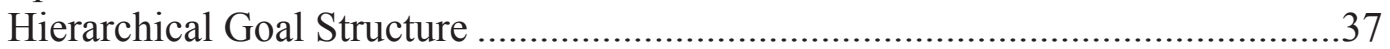

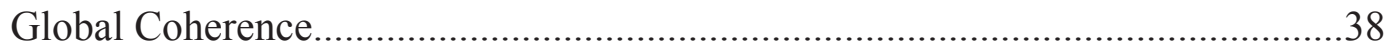

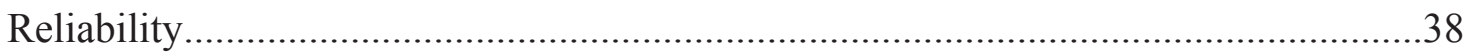

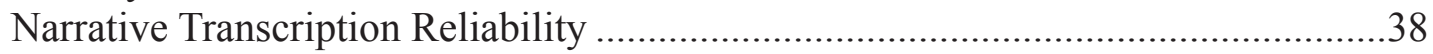

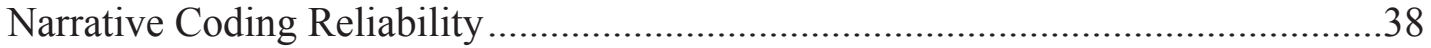

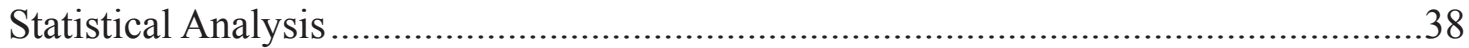

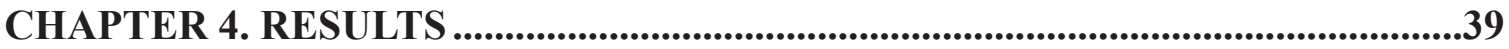

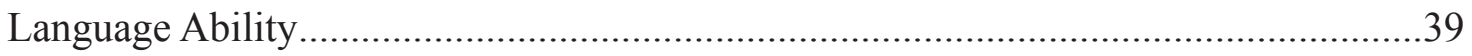

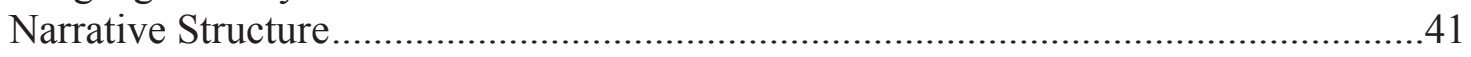

Story Grammar Analysis ...............................................................................41

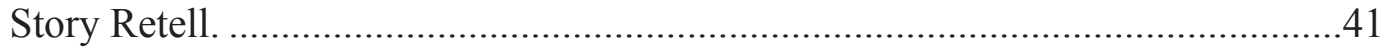

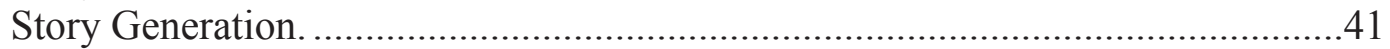

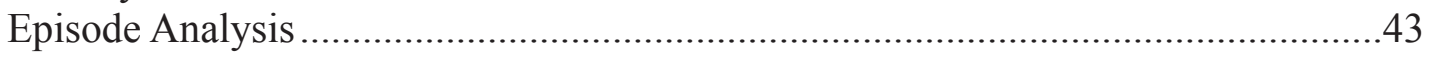

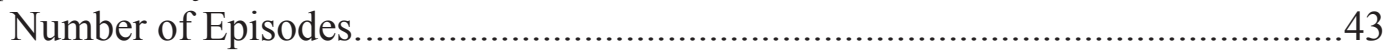

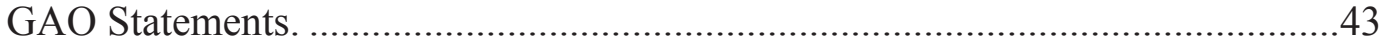

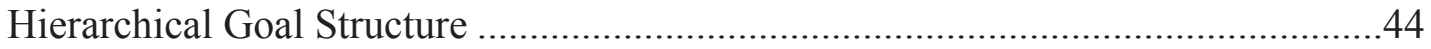

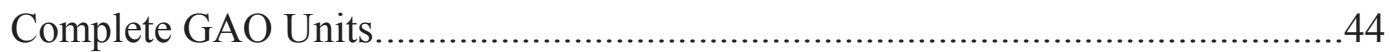

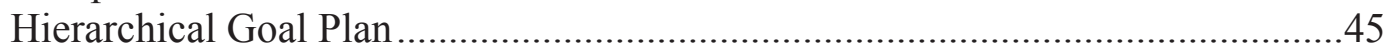

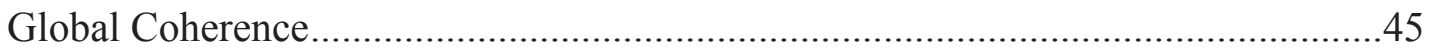

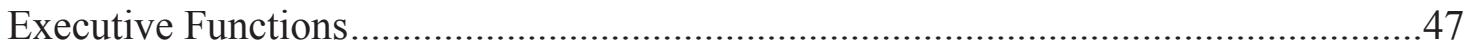

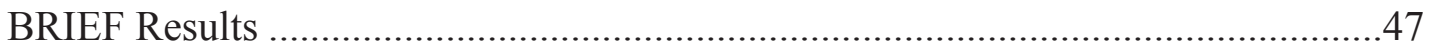

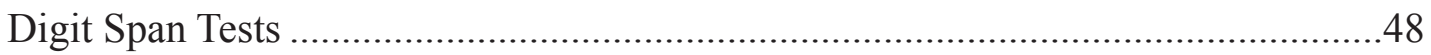

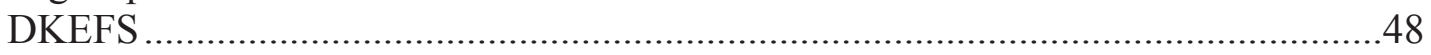

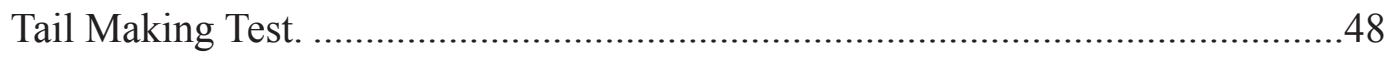

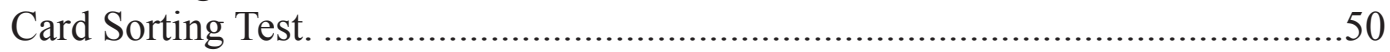

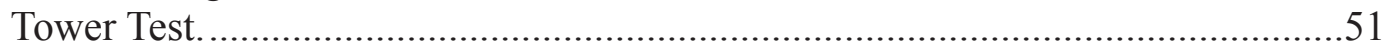

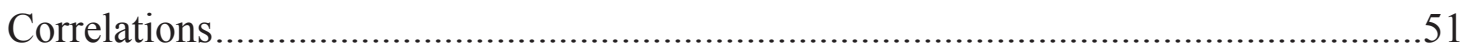

Relations between the CELF-IV and Narrative Microstructure Analysis...................51

Relations between Narrative Structure and Language Ability .....................................53

Relations between Narrative Structure and EFs …………....................................53

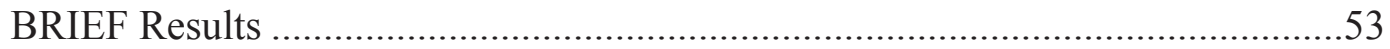

DKEFS and Digit Span Results .....................................................................53

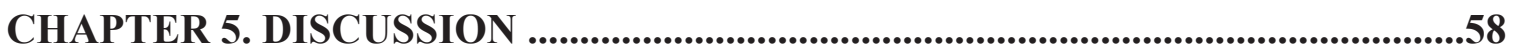

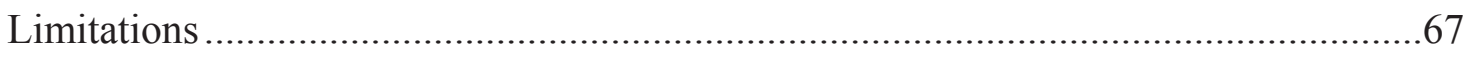

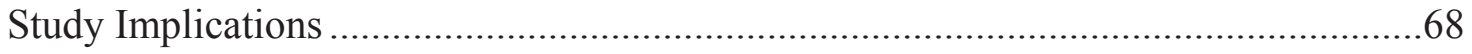

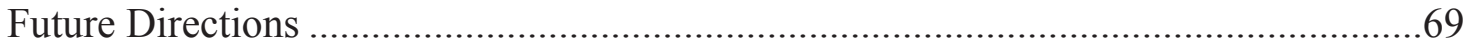

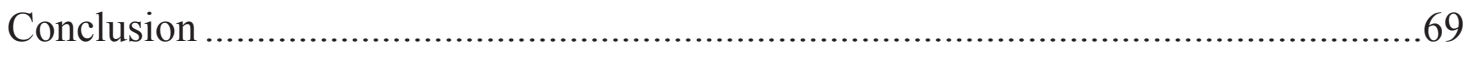

LIST OF REFERENCES .....................................................................................71

APPENDIX A. GOAL PLAN FOR "FROG WHERE ARE YOU?” '...........................92

APPENDIX B. EXAMPLE OF NARRATIVES............................................................93 


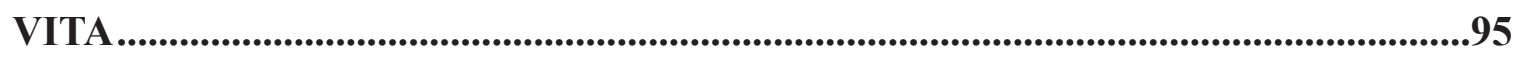




\section{LIST OF TABLES}

Table 3-1. Information about the participants in the $\mathrm{DHH}$ and $\mathrm{NH}$ groups ............... 29

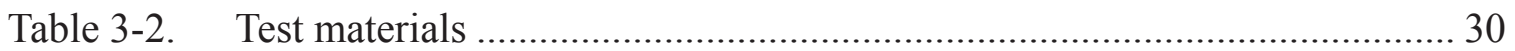

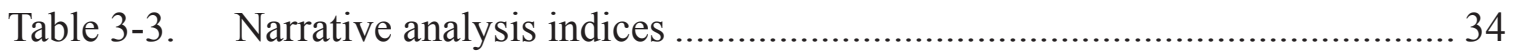

Table 3-4. Definition of story grammar categories ............................................ 36

Table 4-1. Core language subtest scores from the CELF-IV ................................. 40

Table 4-2. Microstructure level analysis of narrative production .............................. 40

Table 4-3. Mean, SD, and range of number of episodes in story retell and story

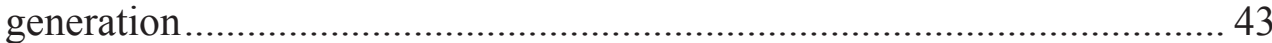

Table 4-4. Correlation coefficients for CELF-IV standard scores and microstructure analysis with the DHH and NH group ........................... 52

Table 4-5. Correlation coefficients between language and narrative structures for story retell and story generation with the $\mathrm{DHH}$ and $\mathrm{NH}$ group ................ 54

Table 4-6. Correlation coefficients between narrative structures and the BRIEF for story retell and story generation with the $\mathrm{DHH}$ and $\mathrm{NH}$ group ................ 55

Table 4-7. Correlation coefficients between narrative structure and the DKEFS for story retell and story generation with the $\mathrm{DHH}$ and $\mathrm{NH}$ group ................. 56 


\section{LIST OF FIGURES}

Figure 4-1. Story grammar component results for story retell ............................... 42

Figure 4-2. Story grammar component results for story generation.......................... 42

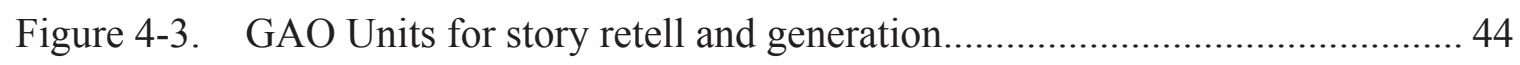

Figure 4-4. Complete and incomplete GAO Units for story retell and story generation.

Figure 4-5. Hierarchical goal plan means for the story retell and story generation ...... 46

Figure 4-6. Cohesive conjunctions used in story retell and story generation............... 46

Figure 4-7. The mean percentile scores for GEC, BRI, and MI of the BRIEF ............ 47

Figure 4-8. The mean percentile scores for GEC, BRI, MI, and the subtests of the

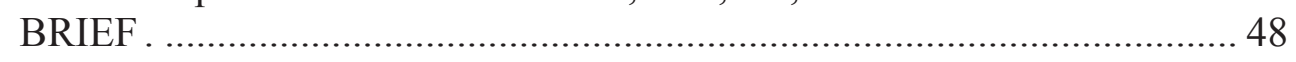

Figure 4-9. Mean standard scores for DS total, and DSF and DSB score ................... 49

Figure 4-10. The mean standard scores for Trail Making completion time .................. 49

Figure 4-11. Mean standard scores for the card sorting, sorting description combined, and sorting description contrast scores of the DKEFS .......................... 50

Figure 4-12. Mean standard scores for the achievement, and rule violation tasks of the DKEFS TOWER test ................................................................... 51 


\section{LIST OF ABBREVIATIONS}

BRI

BRIEF

CELF

CIs

$\mathrm{DHH}$

DKEFS

DSB

DSF

EFs

GAO

GEC

HAs

MI

MLUm

NEPSY

$\mathrm{NH}$

SALT

SD

SLI

TTR

WM
Behavioral Regulation Index

Behavior Rating Inventory of Executive Function

Clinical Evaluation of Language Fundamentals

Cochlear Implants

Deaf or Hard of Hearing

Delis Kaplan Executive Function System

Digit Span Backward

Digit Span Forward

Executive Functions

Goal-Attempt-Outcome

Global Executive Composite

Hearing Aids

Metacognitive Index

Mean Length of Utterance in morpheme

Neuropsychological Assessment

Normal Hearing

Systematic Analysis of Language Transcript

Standard Deviation

Specific Language Impairments

Type Token Ratio

Working Memory 


\section{CHAPTER 1. INTRODUCTION}

\section{Rationale for the Present Study}

As a result of technological advances in hearing aids (HAs) and cochlear implants (CIs), state mandates for newborn infant hearing screening, and improvements in early speech and language interventions, the literature now reports that the oral language abilities of many children who are deaf or hard of hearing (DHH) closely resemble that of their normal hearing $(\mathrm{NH})$ peers (Geers \& Sedey, 2011). Although this trend is positive, a significant number of children who are DHH continue to show delays in language development (Geers, 2004; Geers \& Sedey, 2011; Niparko, Tobey, Thal, Eisenberg, Wang, Quittner, \& Fink, 2010; Schorr, Roth, \& Fox, 2008; Svirsky, Robbins, Kirk, Pisoni, \& Miyamoto, 2000). These deficits are particularly evident in advanced language skills such as reading, writing and narrative discourse (Geers, Nicholas, \& Sedey, 2003; Spencer, Barker, \& Tomblin, 2003).

Difficulty with oral narrative discourse is particularly unfortunate because it has been shown to predict the development of reading and writing skills as well as the quality of social interactions (Boudreau, 2008; Crais \& Lorch, 1994; Feagan \& Farran, 1981; Roth, 1986). Although the importance of both oral and written narrative discourse skills have been demonstrated through research studies, the nature of deficits in this area, particularly for children who are DHH, is not well understood. The limited research that has been conducted on the narrative discourse skills of children who are DHH has mainly focused on written narrative development (Asker-Árnason, Ibertsson, Wass, Wengelin, \& Sahlén, 2010; Crosson and Geers, 2001), or the words or sentences used in oral narratives (Tomblin, Spencer, Flock, Tyler, \& Gantz, 1999; Weiss and Johnson, 1993). Other aspects of narrative discourse such as narrative structure have rarely been explored.

Analysis of the structure of narrative discourse is important because it shows the structural and content relationships that exist within stories (Griffith, Ripich, \& Dastoli, 1986). It also provides opportunities to evaluate the use of temporal sequencing and causal relationships within a story. Narrative structure analysis has been shown to be an excellent tool for examining linguistic and cognitive abilities (Hudson \& Shapiro, 1991; Norbury \& Bishop, 2003). This is because both language and cognitive skills are needed to produce a narrative in which temporal sequencing and causal relationships are well organized.

A few recent studies that have explored cognition and narrative discourse indicate that problems with narrative discourse may be at least partly related to deficits in executive functions (EFs) (Bates, 2012; Ketelaars, Jansonius, Cuperus, \& Verhoeven, 2012; Mar, 2004). Executive functions (EFs) are considered to be primarily responsible for coordinating activities within the cognitive system. Although many studies have investigated EFs, the nature of this construct is debated. In general, EFs have been assumed to serve as an umbrella term that incorporates a collection of interrelated processes responsible for purposeful, goal-directed behavior (Gioia, Isquith, \& Guy, 
2001). Studies have shown that EFs develop around three years of age, with several domains of EFs developing separately (Anderson, Anderson, Northam, Jacobs, \& Mickiewicz, 2002).

Numerous studies have demonstrated that there is a relationship between EFs and language and narrative skills in children with normal hearing $(\mathrm{NH})$, specific language impairment (SLI), Attention Deficit Hyperactivity Disorder (ADHD), autism, and other disorders. As a whole, deficits in areas of EFs have been found in children with language problems, and EFs and language are assumed to be influenced by each other even though the direction of influence has not been clearly evident. For children who are DHH, the link between narrative discourse skills and EFs is not well researched, limiting our ability to describe how the two might be related with this population.

Recently, some researchers have investigated EFs to help explain the oral language problems seen in children who are DHH, especially those with cochlear implants (CIs). In spite of the dramatic improvements in language development for many children who use CIs, wide individual differences still exist in their speech and language outcomes (Geers \& Sedey, 2011). It is important to note that even after accounting for the conventional predictors associated with demographic, medical, and device factors, a substantial and clinically significant degree of unexplained variability and individual differences in speech and language outcomes still remain in children with CIs, which are not observed in their normal hearing, typically developing peers (Harris, Kronenberger, Gao, Hoen, Miyamoto, \& Pisoni, 2012).

Pisoni and Geers (2000) have suggested that individual differences in speech and language outcomes in children with prelingual hearing impairments may reflect underlying differences in central auditory processing and related cognitive functions such as the EFs of attention and working memory. In an investigation of this hypothesis, they found that children who are DHH have deficiencies in verbal working memory and processing speed, and that these can predict vocabulary knowledge and general language performance. These results suggest that the individual differences in children who are DHH using CIs represent systematic underlying differences in several core elementary neurocognitive processes that influence performance in a wide range of traditional speech and language outcomes (Fagan, Pisoni, Horn, \& Dillon, 2007; Conway \& Pisoni 2008).

\section{Purpose of the Present Study}

The potential importance of cognitive factors such as EFs to the development of narrative discourse skills of children who are DHH is evident. However, our current knowledge about how EFs relate to narrative discourse is limited. For this reason, it is important to initiate investigations using standardized as well as non-standardized measures to explore how narrative discourse and EFs are related in children who are $\mathrm{DHH}$. There is the potential to reveal important predictors of language skills as well as new sources of individual differences in clinical outcomes with this population. Furthermore, research on EFs may provide the basis for new cognitive and behavioral 
therapies for children with CIs or hearing aids (HAs), particularly to assist children who do not demonstrate significant improvements in spoken language skills with traditional treatments. For these reasons, this study is designed to explore the relations between EFs and oral narrative performance in children who are DHH using oral language.

\section{Organization of the Remaining Chapters}

In Chapter 2, the literature investigating narrative language and EFs is summarized, what has been explored, how the studies were designed, and what we currently know about EFs, narrative discourse, and the relationship between them is provided. Following this, the relevant research on narrative production and EFs that has been conducted with children who are DHH is described. This chapter concludes with the research questions and hypotheses developed for this investigation. In Chapter 3, the design of this investigation is described. The results of the present study and a discussion of the results are presented in Chapters 4, and 5, respectively. 


\section{CHAPTER 2. LITERATURE REVIEW}

\section{Narrative}

\section{Oral Narrative Discourse and Language Development}

Oral narrative discourse refers to the multiple spoken productions of fictional or real events that temporally unfold (Engel, 1995). The use and understanding of oral narratives are critical in carrying out everyday activities, and in understanding new information at home and in school. Oral narrative skills have been found to be associated with literacy ability (Klecan-Aker \& Caraway, 1997), and a valid predictor of long term language skills (Botting, 2002; Cain \& Oakhill, 1996; Crosson \& Geers, 2001). Thus, oral narratives are a substantial communicative tool, essential for academic achievement, communicative effectiveness and social interaction (Bliss, Covington, \& McCabe, 1999).

Production of a good oral narrative requires high-level linguistic and cognitive abilities (Reilly, Losh, Bellugi, \& Wulfeck, 2004; Paul, Hernandez, Taylor, \& Johnson, 1996). In order to understand and produce oral narratives, children need to sequence events, understand relationships between cause and effect, create a cohesive structure for the event, use precise vocabulary, and structure a narrative according to story schemata (Paul, Hernandez, Taylor, \& Johnson, 1996). As a consequence, in order to produce narratives, the integration of linguistic and cognitive knowledge is necessary (Hudson \& Shapiro, 1991). In producing a narrative, children use linguistic knowledge to convey information about the characters, events, and the sequence of the events of narratives, as well as consider how to tell the narratives so they are appropriate to the audience. At the same time, children use cognitive knowledge to infer the motivation and goals of characters' actions, and logically construct and organize the relations between events to reach the intended theme of the narrative (Holck, Sandberg, \& Nettelbladt, 2011).

Given the characteristics of oral narratives, it is clear that narratives provide an opportunity to assess how language is organized and used to express complex ideas in a social context (Coelho, 2002). Norbury and Bishop (2003) argue that oral narrative analysis is a good way to assess linguistic, pragmatic and cognitive abilities. Many investigators have agreed with this and suggested that oral narrative ability may provide a better indicator of children's linguistic ability than what is measured by traditional language tests (Botting, 2002). As a language assessment tool, the examination of a child's ability to produce an oral narrative can synthetically provide critical information about child's current language skills in syntax, morphology, vocabulary, and phonology within naturalistic discourse level contexts. In this regard, the collection and analysis of an oral narrative can be viewed as a highly efficient approach to language assessment. 


\section{Oral Narrative Elicitation}

In the research literature, oral narrative assessments have typically been presented in the form of either a story generation or story retell task with or without pictures. The form of the task can influence children's narrative performance. Story generation tasks usually require children to tell a story about a single picture or about a real life experience. Because of the nature of the task, it has been regarded as a good reflection of the natural form of discourse and representative of spontaneous communication ability at a discourse level (Hudson \& Shapiro, 1991). However, story generation tasks may be difficult for children because there is little or no external support to help make up the narratives. Another disadvantage of story generation tasks is that their production be affected by a child's motivation to produce or complete a story. If there is no motivation for a child to produce a narrative with a wide range of story components, the story may not be able to be a good reflection of their narrative skills (Hudson \& Shapiro, 1991; Leinonen, Letts, \& Smith, 2000)

An alternative to narrative assessment using a story generation is a story retell task, which can be administered with or without picture supports. In a story retell task, a child listens to a story and is then asked to tell the story back. One advantage of a story retell task is that the content and structure of the story is familiar to the examiner. This makes analysis of the narrative more reliable and easier to complete. A story retell task is also less demanding than a story generation tasks (Boudreau, 2008). According to Holck et al. (2011) oral narratives elicited through story retell tasks are longer in length and have a more complete episode structure. They also contain fewer inaccurate grammatical structures and more grammatical morphemes than narratives produced through story generation tasks. Boudreau (2008) also found that story retell tasks with the support of pictures resulted in more context-dependent utterances.

The type or content of stories used to elicit oral narratives varies across studies described in the research literature. For story generation, familiar events such as a birthday party or visit to the dentist have typically been used. Some investigators have also used the Test of Narrative Language (Gillam \& Pearson, 2004), which is a normreferenced narrative test. This test includes one story retell task without pictures and two story generation tasks with pictures. For story retell, the picture story book 'Frog, Where Are You?' (Mayer, 1969) has been most widely used.

\section{Oral Narrative Analysis}

The two paradigms used to analyze oral narratives include the analysis of the narrative microstructure and the analysis of the narrative macrostructure. Microstructure analysis provides information regarding how a child's developing language forms (words, sentences) are used to express narrative functions. Thus, oral narrative microstructure analysis describes linguistic properties, such as the number of words and sentences, the overall grammatical complexity, and the way in which specific cohesive devices (e.g. conjunctions) are used to link words and sentences. In order to analyze narrative 
microstructure, a transcript of a child's story is usually parsed first into smaller units, most often T-Units. A T-Unit refers one independent clause and any dependent phrases and clauses. Then, the transcript is analyzed to determine such features as percentage of complex T-Units, mean number of words per an utterance, use of specific phrase and clause structure, and percentage of grammatically correct T-Units (Justice, Bowles, Kaderavek, Ukrainetz, Eisenberg, \& Gillam, 2006). Measures of narrative microstructure are viewed as providing general approximates of a child's expressive language ability within a naturalistic and functional context.

Narrative macrostructure refers to the general, global characteristics of an oral narrative, such as the story structure. Macrostructure assessment is based on the perspective that children's narrative abilities are influenced by their "mental representations of events and the verbalizations of such scripts" (Berman, 1995). There are three ways to examine narrative macrostructure, which include traditional story grammar analysis, episodic analysis, and hierarchical goal structure analysis. Story grammar analysis is most widely used. Episodic analysis and hierarchical goal plan analysis are based on the more general story grammar analysis, and focus on either the episodic structure (episodic analysis) or hierarchical goal plan of the narrative (hierarchical goal structure analysis).

Story grammar analysis is a common method used to analyze the organization of an oral narrative. According to Stein and Glenn's (1979) theoretical framework, a story grammar consists of six components; setting, initiating event, internal responses, attempts, direct consequences, and reactions. Story grammar analysis examines if these components emerge in a narrative. These components are subject to developmental growth and Berman (1988), and Bamberg and Damard-Frye (1991) found considerable increases in story length from the preschool through school age years. According to Peterson \& McCabe (1983), by age 6, children can produce oral narratives that typically consist of complete episodes including initiating events, motivating states, attempts, and consequences in their narratives.

Episodic analysis is also based on Stein and Glenn's (1979) story grammar components. This analysis focuses on identifying the individual episode structures within the narrative, which are composed of goals resulting from internal responses, attempts, and the direct consequences of achieving a goal (Liles, 1987; Merritt \& Liles, 1987). These three components form a complete Goal-Attempt-Outcome (GAO) Unit (Stein \& Glenn, 1979). If one or two components are missing, the GAO Unit is incomplete.

Hierarchical goal structure analysis focuses on the hierarchical organization of narratives. This analysis identifies a hierarchical goal structure in narratives and the relationships among goals or episodes. Hierarchical goal structure analysis differs from story grammar analysis because the Goal is separated from the Internal Response. After identifying each story grammar component, the Goals are identified as either superordinate or subordinate. Superordinate goals are the ultimate goals that a protagonist wants to attain, and subordinate goals are subgoals used to obtain the ultimate goal or goals. This analysis examines two important devices that children use to organize their 
narratives, which are complete GAO Units and hierarchical goal structures. Both the completeness of the GAO Units and the use of hierarchical goal structures are important for producing coherent narratives. As a consequence, Luo and Timler (2008) argued that this analysis is a sensitive measure of school age children's narrative organization skills. According to Roth and Spekman (1986), and Trabasso and Nickels (1992), typically developing children used greater numbers of complete episodes as well as embedded episodes as their age was increased. By the age of 9, they also used hierarchical goal plans in narratives similar to those produced by adults.

\section{Executive Functions}

\section{Information Processing Approach}

Recently, increasing numbers of researchers have been interested in exploring the relations between language and cognition because such studies may help to find underlying factors that impact developing language, and/or cause language impairments. An information processing approach to cognition is one of the theoretical accounts of this link. It views human cognition and areas such as sensation, perception, attention, memory, language processing, learning, and problem solving as information processing within a large integrated framework (Pisoni and Cleary, 2003). As Montgomery (2002) pointed out, this framework provides for the possibility that language problems can arise because of cognitive or processing factors such as weak linguistic representations, inefficient processing of representations, or a combination of limitations, not only due to problems with language itself. As a consequence, this approach provides for the possibility of developing more appropriate intervention plans or strategies.

An information processing approach has assumed that the human nervous system is an information processor that encodes, stores, and manipulates various types of representations (Pisoni and Cleary, 2003). Although the details of language processing theories vary, the central premise is that there are limited cognitive resources available to process information. When demands for linguistic processing exceed available resources, the processing and/or storage of linguistic information is degraded. Within this perspective, success in language processing is influenced by the ability to actively maintain and integrate linguistic material within the available resources.

\section{Executive Functions}

Executive functions (EFs) can be generally described as the 'higher-level' cognitive processes that organize information, and direct lower-level functions (Stuss \& Levine 2002). Since Neisser (1967) described EFs as "orchestrating more basic cognitive processes during goal oriented problem-solving," a host of models of EFs have been proposed (e.g., Anderson, 1998; Barkley, 1997; Denckla, 1994; Fuster, 1989; GoldmanRakic, 1987; Lyon \& Krasnegor, 1996; Stuss \& Benson, 1986; Welsh \& Pennington, 
1988). Although the specific view and proposed models of the nature of EFs may vary, most researchers would agree that EFs are "an umbrella construct for a collection of interrelated functions that are responsible for purposeful, goal-directed, problem solving behavior." Many researchers investigating EFs view them as a fragmentary structure that includes a set of relatively independent subfunctions. The subfunctions most frequently used and widely investigated in EFs studies and their definitions are as follows. Definitions were adopted from Friedman and Miyake (2004), and St Clair-Thomson and Gathercole (2006).

1. Attention is the ability to filter out irrelevant information and focus on specific aspects of the environment in a goal directed manner.

2. Shifting is the ability to switch between sets, tasks, or strategies, i.e., the ability to disengage from an irrelevant task set and initiate a new, more appropriate set.

3. Inhibition is the ability to deliberately suppress dominant, automatic, or prepotent responses in favor of more goal-appropriate responses.

4. Working Memory (WM) is a highly flexible multicomponent information processing system that is used to temporarily store information while it is processed and managed for short periods of time.

5. Updating is the ability to monitor and code incoming information, and to update the content of memory by replacing old items with newer, more relevant, information. Updating concerns the dynamic, goal directed manipulation of memory content. As seen in this definition, updating is closely linked to the notion of working memory (Smith \& Jonides, 1997; Lehto, 1996; Morris \& Jones, 1990).

6. Initiating is the ability to begin a task or activity, as well as independently generate ideas, responses, or problem-solving strategies.

7. Planning and Organizing is the ability to manage current and future-oriented task demands. Specifically, planning is the ability to anticipate future events, set goals, and develop appropriate steps ahead of time to carry out a task or activity. Planning involves imagining or developing a goal or end state and then strategically determining the most effective method or steps to attain that goal. Organizing is the ability to provide ideas or key concepts in appropriate order when learning or communicating information.

8. Self-monitoring is the ability to check on ones own performance during or shortly after finishing a task to ensure appropriate attainment of a goal. This function also includes the ability to keep track of the effect a person's behavior has on others.

As defined in the literature, some EFs are similar or related to each other, but, so far, there is no assessment tool designed to test each specific function. In addition, the 
role of each area and how it relates to and influences another is still under investigation. In the midst of exploring how EFs are organized, some investigators have categorized these domains through factor analysis of variables. For example, Anderson (2002) proposed a model of EFs having four distinct domains including specific functions in each domain based on factor analytic studies and clinical neuropsychological knowledge. According to Anderson (2002), the domains and their specific subfunctions include the following. Descriptions were adopted from Anderson (2002).

1. Cognitive flexibility. This refers to the ability to shift between response sets or different thoughts, learn from mistakes, devise alternative strategies, divide attention, and process multiple sources of information at the same time. In this model, working memory is a component of cognitive flexibility.

2. Goal setting. This domain incorporates that ability to develop new initiatives and concepts, as well as the ability to plan actions and approach tasks efficiently and strategically.

3. Attentional control. This domain includes the capacity to selectively attend to specific stimuli and inhibit prepotent responses, and the ability to focus attention for a prolonged period. Attentional control also involves the regulation and monitoring of actions so that plans are executed in the correct order, errors are identified, and goals are achieved.

4. Information processing. Information processing refers to fluency, efficiency and speed of output. The information processing domain reflects the integrity of neural connections and the functional integration of frontal systems, and can be evaluated by the speed, quantity and quality of output.

According to Anderson (2002), these executive domains are considered to have distinct functions, but in order to execute certain tasks they operate together in an integrative manner.

In a language processing approach, EFs are considered to be primarily responsible for the coordination of activity within the cognitive system. There are a number of models of language processing, however, those proposed by Baddeley and colleagues (Baddeley, 1986; 1998; Gathercole \& Baddeley, 1993) and Just, Carpenter, and colleagues (Daneman \& Carpenter, 1980; Just \& Carpenter, 1992) have been most influential in language disorders research (Ellis-Weismer \& Thordardottir, 2002). According to Baddeley and colleagues, EFs operate within a framework of available resources so language comprehension and production reflect the availability of cognitive resources such as memory or attention to complete tasks. 


\section{Tests of Executive Functions}

As seen in the theoretical debate surrounding the make-up of EFs, there is an assumption that EFs require various cognitive abilities. However, given the dynamic essence of EFs, precisely assessing EFs has been very challenging (Denckla, 1994). For this reason, finding an assessment that will be highly sensitive and efficaciously specify EFs is an actively ongoing exploration (Baron, 2004). So far, there is no singular test battery that measures EFs. Performance based tests and a behavior rating scale are most frequently used independently or together.

Traditionally, the tasks that have been used to measure EFs include performance based tasks, such as the Wisconsin Card Sorting Test (WCST; Heaton, Chelune, Kay, \& Curtiss, 1993), the Tower of Hanoi (TOH; Welsh, 1991), the Tower of London (TOL; Shallice, 1982, Anderson, Anderson, \& Lajoie, 1996; Krikorian, Bartok, \& Gay, 1994), and the Trail Making Test (TMT; Reitan \& Wolfson, 1992), which have not been standardized nationwide.

More recently, Delis, Kaplan, \& Kramer (2001) have developed the Delis-Kaplan Executive Function System (DKEFS). The DKEFS consists of nine subtests that measure verbal and nonverbal executive functions. The subtests include a Trail Making Test, Verbal Fluency Test, Design Fluency Test, Color-Word Interference Test, Sorting Test, Twenty Question Test, Word Context Test, Tower Test, and Proverb Test. Each subtest is designed to be administered individually or along with other DKEFS subtests depending on the assessment needs of an examiner. The DKEFS provides normative and qualitative data with norms for ages 8 through 89 years from a national sample. Most of the tests are updated versions of commonly used stand-alone tests of EFs, lengthened to avoid ceiling and floor effects.

Observation of everyday behavior has been recently used as a complementary measure to assess EFs. Particularly for children, everyday behavior is a means to observe routine use of EFs. This methodology provides the rationale for the recently developed and standardized Behavior Rating Inventory of Executive Function (BRIEF: Gioia, Isquith, Guy, \& Kenworthy, 2000; Isquith, Gioia, \& Espy, 2004). The BRIEF is a behavior inventory designed to measure behavioral aspects of EFs in the form of a questionnaire for parents and teachers of school-age children between the ages of 5 and 18 years. The Parent and Teacher Form of the BRIEF each contain 86 items within eight scales that measure different aspects of EFs. The eight scales are divided into two broader indexes, the Behavioral Regulation Index (BRI) and the Metacognition Index (MI). The indices combine to provide an overall score, the Global Executive Composite (GEC). The Behavioral Regulation Index (BRI) is comprised of the Inhibit, Shift, and Emotional Control scales. The Metacognitive Index (MI) is comprised of the Initiate, Working Memory, Plan/Organize, Organization of Materials, and Monitor scales. The BRIEF has been widely used for the clinical or research purposes independently or together with performance based tests (Baron, 2000). The BRIEF and performance based tasks are considered to provide unique information (Anderson, 2002). Therefore, when administered together, information from both behavior and performance assessments can 
help to describe children's executive control competence.

\section{Language and Executive Functions}

Although the direction of influence between EFs and language processes is vague, there is a growing body of research investigating EFs in many areas of language learning with children. There is a demonstrated relationship with vocabulary knowledge (Carlson, 2005; Carlson, Davis, \& Leach, 2005), new vocabulary learning (Dempster \& Cooney, 1982; Gathercole \& Baddeley, 1993), language abilities (Ellis Weismer, Evans, \& Hesketh, 1999), Literacy (Gathercole \& Pickering, 2000), sentence reading (Lewis, Vasishth, \& Van Dyke, 2006), language and reading comprehension (Booth \& Boyle, 2009; Booth, Boyle, \& Kelly, 2010; Daneman \& Merikle, 1996; Dempster \& Corkill, 1999; Gathercole \& Pikering, 2000; Palladino, Cornoldi, De Beni, \& Pazzaglia, 2001; Sesma, Mahone, Levine, Eason, \& Cutting, 2009), and learning (Bull, Epsy, \& Wiebe, 2008; Bull, Johnston, \& Roy, 1999; Bull \& Scerif, 2001; Lehto, 1995; Lorsbach, Wilson, \& Reimer, 1996; McLean \& Hitch, 1999; Ozonoff \& Jensen, 1999; Swanson, 1993, 1999; Swanson, Ashbaker, \& Lee, 1996).

In addition to the evidence that demonstrates the important role of EFs in language and literacy acquisition, several studies have documented the negative impact of impaired EFs on language development in children with learning disabilities such as Specific Language Impairment (SLI) (Henry, Messer, \& Nash, 2011; Hoffman \& Gillam, 2004; Hughes, Turkstra \& Wulfeck, 2009; Im-Bolter, Johnson \& Pascual-Leone, 2006; Marton, 2008), Attention Deficit Hyperactivity Disorder (ADHD) (Cohen, Vallance, Barwick, Im, Menna, Horodezky, \& Isaacson, 2000; Purvis \& Tannock, 1997), Autism (Landa \& Goldbergm 2005), and reading disability (Everatt, Warnet, Miles, \& Thomson, 1997; Martinussen \& Tannock, 2006). Overall, these studies have commonly reported on the poorer EFs performance of children with learning disabilities relative to their typically developing peers across response modalities. The results support the premise that EFs such as attention, updating, or working memory can predict language competence and that tasks needing language processing are more difficult for children with learning disabilities.

\section{Narrative and Executive Functions}

In order to produce a coherent narrative, a child must have knowledge of narrative content as well as narrative structures. The content of a narrative relates to knowledge regarding events of the narrative, whereas the structure of narrative refers to how the content is formulated and organized (Berman \& Slobin, 1994). Cognitive abilities like EFs directly contribute to narrative organization (Luo \& Timler, 2008). EFs support the organization of narratives through planning, holding, adding to, and manipulating information as well as monitoring outputs. Several studies have demonstrated the relations between narrative production and EFs with children with or without learning disabilities, which are presented below according to Anderson's (2002) categories of EFs. 


\section{Attention Control}

This domain includes selective attention, self-regulation, self-monitoring, and inhibition. Although little research has been done connecting attention control and narrative development in children, the National Institute of Child Health and Human Development Early Child Care 15 Research Network (NICHD, 2003) assessed the role of EFs in mediating between home environment and language and learning. The results showed that attention and behavioral inhibition accounted for significant variance when linking home environment factors with language and learning in children at the age of 54 months.

In a study by Ketelaars, Jansonius, Cuperus, and Verhoeven (2012), the role of attention on narrative competence was addressed. Seventy-seven, five year old children with pragmatic language impairment (PLI) and 77 five year old children in a typically developing (TD) control group were administered a story retell task using a story book (Dutch adaptation of the Renfrew Bus Story Test; Jansonius-Schultheiss, Borgers, Bruin, \& Stumpel, 2006) to measure narrative ability. The Neuropsychological Assessment (NEPSY, Korkman, Kirk, \& Kemp, 1998) was used to measure planning (goal setting in terms of Anderson's (2002) categorization), selective attention and cognitive flexibility. A digit span subtest of the Kaufman Assessment Battery for Children (Loomis, Holt, Kaufman, \& Kaufman, 2004) was used to measure working memory. The authors created one EFs factor with the four EFs scores. They found a significant correlation between EFs and narrative productivity in the TD group $(r=.30, p<.05)$ and the PLI group $(r$ $=.37, p<.01)$. The story content organization showed marginally significant correlations with the EFs factor $(r=.22, p=.07)$ only in the PLI group. The cohesion of narratives was not significantly correlated with the EFs factor in either group. However, the EFs factor explained $9 \%$ of the variance in narrative productivity over and above language abilities in the PLI group. They noted the group difference between TD and PLI and hypothesized that EFs abilities could be more important for narrative competence in children with delayed language development like the PLI group.

\section{Cognitive Flexibility}

This domain includes working memory, conceptual transition, and feedback utilization. Working memory (WM) is one of the cognitive factors commonly regarded as vital for narrative production, and is thus the most widely investigated among EFs. In a review of the literature, Mar (2004) described the importance of WM in narrative comprehension and production, both as a storage for long-term memory cues as well as an executive function that inhibits irrelevant retrievals and modulates other aspects of the neural network.

The literature has demonstrated the relationship between WM and narrative production in children who are TD, children with ADHD, and children with SLI. For 
example, Milch-Reich, Campbell, Pelham Jr., Connelly, \& Geva (1999) reported that WM problems attributed to the narrative organization difficulties in children with ADHD $(\mathrm{n}=38)$ and without ADHD $(\mathrm{n}=41)$ between 5.9 and 10.3 years of age. Renz, Lorch, Milich, Lemberger, Bodner, \& Welsh (2003) also documented the contribution of WM deficits to narrative skill problems in children with ADHD. The authors investigated cognitive processing in narratives, measured by the wordless story book, 'Frog, Where Are You?' with 66 boys with and without ADHD, ages 9-11 years. The stories produced by the boys with ADHD lacked completion of the overall goal and attempts linked to the goal. Based on Barkley's study (1997) that demonstrated WM and EFs deficits such as planning and organizing, inhibition, and monitoring among children with ADHD, the authors inferred that WM deficits and problems in EFs may contribute to the difficulties these children have in using a sustained goal in narratives. In a related study, Dodwell and Bavin (2008) demonstrated the relationship between WM and narrative skills with six year old children diagnosed with SLI. The authors investigated this relationship using story recall tasks for narrative, and WM (word, digit, and recalling sentence tasks), inhibition, and attention tasks for EFs. The verbal WM measured by recalling sentences was correlated with narrative recall, but digit span had no relation to narrative performance.

Conceptual transition refers to the ability to shift or switch tasks and has been investigated in relation to narrative skills. For example, Hooper, Swartz, Wakely, de Kruif, and Montgomery (2002) investigated the relations between the EFs of inhibition, set shifting, and sustaining, and written narratives with 55 elementary school children (4th and 5 th grade) with and without problems in written expression. A story generation task and various EFs tasks across the 4 domains listed were administered. The authors found significantly poorer performance for children with writing problems on the initiation and set shifting domains. They interpreted this result as showing the importance of EFs in the written language process for elementary school students. In another study, Coelho (2002) reported on the relationship between cognitive flexibility and narrative production with 102 adults with and without brain injuries. The Wisconsin Card Sorting Test (WCST), which is usually assumed to assess cognitive flexibility, was administered to measure EFs and both story generation with a picture and story retell using filmstrips were used to elicit narrative production. The author found modest correlations $(r=.33-.39)$ between the WCST and story retelling, and a weak correlation $(r=.27)$ between the WCST and story generation.

\section{Goal Setting}

The domain of goal setting includes initiation, conceptual reasoning, planning, and strategic organization. The study of this domain has been mainly conducted with children diagnosed with ADHD, because of the suggested contribution of deficits in planning and organization ability to narrative production. For example, Tannock, Purvis, and Schacher (1993) reported that children with ADHD had organization and monitoring problems in their narrative performance and that their poorly organized and less cohesive narrative production may reflect underlying deficits in EFs. Purvis and Tannock (1997) 
examined story retell and language processing abilities in 50 children with ADHD with or without additional reading disability (RD) between the age of 7 to 11 years. The results revealed that children with ADHD exhibited difficulties in organizing and monitoring their verbal productions, and that the difficulty in organizing was reflected in their poor story retelling. Recently, Luo and Timler (2008) investigated narrative organization with 13 children with ADHD and Language impairment (LI) between 8 and 12 years of age, using the Test of Narrative Language (TNL; Gillam \& Pearson, 2004) to elicit narratives. Children with ADHD and LI produced less organized narratives than the TD group in the single-picture task of the TNL. The authors did not administer EFs tests but referenced the potential importance of impaired EFs such as planning in the ADHD group as demonstrated in the previous study (Barkley, 1997). They also indicated that EFs deficits could be indicated by the children's difficulty in narrative organization because higher level planning skills are needed to produce organized narratives.

\section{Information Processing}

The domain of information processing includes efficiency, fluency and speed of processing. No studies investigating information processing related to narrative production were found. However, there have been some studies which investigated information processing speed as related to language problems (Cowan, 1999; Ellis Weismer, Plante, Jones, \& Tomblin, 2005; Jonides, Lacey, \& Nee, 2005; Leonard, Ellis Weismer, Miller, Francis, Tomblin, \& Kail, 2007). These studies have found slower processing in children with language disabilities. For example, Kail (1994) analyzed data across several studies and found that the children with LD showed 33\% slower performance across a range of language and non-language tasks. This was confirmed by Windsor and Hwang (1999), and Miller, Kail, Leonard, and Tomblin (2001). More recently, Leonard, Ellis Weismer, Miller, Francis, Tomblin and Kail (2007) investigated processing speed in children with LD. The latent variable regression analyses indicated that nonlinguistic cognitive speed or general nonlinguistic speed played a significant role in children's language scores as an independent factor. Based on this result, the authors suggested that any comprehensive account of LD should consider that role of motor and cognitive factors that fall outside of typical descriptions of language (e.g., phonology, morphology, syntax, etc.).

\section{Executive Functions Studies Using the BRIEF}

There have been a few studies using the BRIEF to describe executive functions. The BRIEF has its own categories so they are provided here separately from studies that have used performance based tests. Trainor (2012) investigated the relationship between story retelling and EFs, measured by the BRIEF, with typically developing children. The author found that WM and emotional/inhibitory control were significantly related to both sentence length and the information content of narrative. Recently, Lambeth (2012) investigated the relationship between EFs and oral narrative production with 27 schoolage children (fourteen 1 st and thirteen 3 rd grade). The children were assessed using the 
BRIEF, story generation and story retell tasks from the Test of Narrative Language (TNL) to assess EFs and narrative ability, respectively. Language ability was measured using the Peabody Picture Vocabulary Test (PPVT, Dunn \& Dunn, 2007) and the Clinical Evaluation of Language Fundamentals (CELF). The author analyzed the correlation between EFs, language, and narrative, and demonstrated that EFs, such as shifting $(r=-$ $.614)$, WM ( $r=-.485)$, planning and organizing $(r=-.522)$, and monitoring $(r=-.408)$ were related to narrative performance. The author concluded that this result suggests that narrative tasks engage EFs as well as language abilities.

\section{Children Who Are Deaf or Hard of Hearing}

\section{Children Who Are DHH and Oral Narratives}

Children who are DHH are frequently described as having delays in spoken language development. An extensive body of the literature has reported developmental delays in acquiring language competence. Although recent research has documented considerable improvements in speech perception and production skills, vocabulary development, and enhanced syntactic knowledge at the sentence level in children who are DHH and use oral communication (Dawson, Blamey, Dettman, Barker, \& Clark, 1995; Geers \& Moog, 1994; Miyamoto, Svirsky, \& Robbins, 1997; Svirsky et al., 2000; Tomblin, Spencer, Flock, Tyler, \& Gantz, 1999), the overall language performance of children who are DHH still lags behind children with $\mathrm{NH}$.

At a discourse level, relatively few studies have investigated oral narrative skills in children who are DHH (Crosson, \& Geers, 2001; Griffith, Ripich, \& Dastoli, 1990; Weiss, \& Johnson, 1993; Yoshinaga-Itano, 1986). Given the fact that incidental language learning relies heavily upon hearing experience and is one of the requisites for oral narrative development, it would be anticipated that children who are DHH will have some difficulty in oral narrative development (Bamberg \& Damrad-Frye, 1991).

Early research on the narrative skills of children who are DHH focused primarily on syntactic or lexical knowledge (Kretschmer \& Kretschmer, 1994), or the structural analysis of written or signed narratives (Arfé \& Boscolo, 2006), not oral narratives. The studies investigating written or signed narratives with children who are DHH found that these children used fewer prepositions, fewer text-cohesive devices, fewer or omitted adverbs and conjunctions, fewer words per sentence, shorter or incomplete sentences, and less causally cohesive structures than their normal hearing peers (Arfé \& Boscolo, 2006; Griffith, Ripich, \& Dastoli, 1990; King \& Quigley, 1985; Klecan-Aker \& Blondeau, 1990; Marschark, Mouradian, \& Halas, 1994; Spencer, Barker, \& Tomblin, 2003; YoshinageItano \& Snyder, 1985).

More recently, research on the oral narrative skills of children who are DHH have reported similar deficiencies despite the auditory benefit from CIs (Crosson \& Geers, 2000). For instance, Crosson and Geers (2001) studied the narrative skills of 87 children 
between the ages of 8 and 9 who were deaf and used CIs and 28 children with normal hearing (NH). An eight-picture sequence story (Pierce, 1974) was used to elicit story generation. As a group, the children who are deaf showed deficits in narrative skills, such as poor story structure and limited use of conjunctions, compared to children with NH although their language skills improved as a benefit of CIs. Deficiencies were more obvious in the case of children who are deaf and showed poor speech perception skills (below 43\%). The authors found that the narrative scores of children who are deaf were significantly correlated with speech perception (word level, closed set), receptive syntactic knowledge, and reading comprehension skills, but were not significantly correlated with age and nonverbal intelligence (IQ). In addition, the narrative scores contributed unique and significant variance to reading comprehension scores above and beyond IQ and syntactic knowledge in this group. Taken together, these results suggest that oral narrative ability as well as written narrative measures describe an important aspect of linguistic and literacy skill development in children who are DHH (Nikolopuos, Lloyd, Starczewski, \& Gallaway, 2003; Nikolopoulos, Archbold, \& Gregory, 2005; Starczewski \& Lloyd, 1999).

Geers, Nicholas, \& Sedey (2003) investigated language abilities including oral narratives with 181, eight and nine year old children with CIs. An eight-picture-sequence story generation task (Pierce, 1974) used in the study by Crosson and Geers (2001) was employed. The results showed that over half of the children in the CIs group scored within the average range for utterance length, lexical diversity, verbal reasoning, and oral narrative ability. However, fewer than $50 \%$ of this group scored within normal range in the use of bound morphemes. The focus of this study was to describe contributing factors to language ability, thus they did not report on the children's narrative skills in detail. They found that higher nonverbal intelligence, smaller family size, higher socioeconomic status and female gender contributed to language development. However, the age of implantation did not appear as a contributing factor, which is in contrast to the findings of a study reported by Kirk, Miyamoto, Lento, Ying, O’Neill, and Fears (2002). The authors suggested that the difference between the two studies may be due to the fact that the children participating in the Kirk et al. study (2002) were under 6 years old whereas the participants in the Geers et al. study (2003) were 8 to 9 years old. The advantage for children who receive their implantation under 3 years of age may be no longer apparent by eight or nine years of age. Another notable result from this study is that long experience in mainstream classrooms and an emphasis on speech and auditory skills were confirmed as contributing factors to improved language outcomes after other factors had been accounted for.

In a longitudinal study, Huttumen (2008) investigated narrative generation abilities in relation to speech intelligibility with 18 Finnish children between the ages of $2 ; 7$ and 8;4 with CIs. The children were tested pre-implantation, at the hearing age of three, and at the hearing age of five. To assess story generation, children were presented with six different cards with four pictures per card to elicit the story. Significant improvements in narrative abilities were found to occur between three and five years after implantation. Three years after activation of CIs, children produced at least two story grammar categories although the specific categories were not reported. Five years 
after the implantation of CIs, the children with a few exceptions produced stories that contained a complete episode. On average, the story generation abilities of the children with CIs exceeded their hearing age by one year, which was a notable improvement. The authors reported that speech intelligibility and the ability to produce narratives were not significantly associated with each other at the hearing age of five. This result indicated that other factors besides speech intelligibility might be critical to develop narrative skills longitudinally. Unfortunately, the authors did not describe any other factors that may influence narrative performance.

Worsfold, Mahon, Yuen, and Kennedy (2010) investigated narrative production with 89 children who are DHH between the ages of $6 ; 6$ and 10;9 years divided into two groups, early and late identification of hearing loss with the criterion set at 9 months of age. Story retell was elicited using the Renfrew Bus Story Narrative Assessment (Renfrew, 1994) which consists of 12 pictures. The authors reported on the differences between NH and DHH groups on the construct and content analysis of narratives, including fewer sentences, morphological endings and sentences with multiple clauses in the DHH group. These results are similar to those from Crosson and Geers's (2001) study. Furthermore, there were considerable individual differences between children who are DHH and NH, which has been a common finding (Spencer, Barker, \& Tomblin, 2003). Twelve (13.5\%) and $14(15.7 \%)$ of the 89 children who are DHH scored a 0 on narrative structure and content respectively. The early identification group performed better on some measures than the late identification group. The focus of this study was language analysis based on the age of identification of hearing impairment, thus the authors did not report the specifics of narrative analysis outcomes in detail.

As a whole, research on the narrative skills of children who are DHH when compared with $\mathrm{NH}$ peers have found reduced vocabulary and grammatical knowledge, shorter sentences, and poorer construction and content. Even children who are DHH using CIs and having language knowledge comparable to their age-matched peers with $\mathrm{NH}$ often showed comparatively poorer narrative skills. Factors such as nonverbal cognitive abilities, age at onset of deafness, age at implantation, and length of implant experience have been reported to influence the inferior performance and wide individual variation in language outcomes following cochlear implantation (Fryauf-Bertschy, Tyler, Kelsay, Gantz, \& Woodworth, 1997; Harrison, Panesar, El-Hakim, Abdolell, Mount, \& Papsin, 2001; Manrique, Cevera-Paz, Huarte, \& Molina, 2004).

\section{Children Who Are DHH, Language, and Executive Functions}

A review of the interdisciplinary literature on the environmental factors that influence the development of EFs suggests that if language is not developing ageappropriately, it may have a negative effect on the development of EFs (Marschark, 2003). As we know, in spite of advanced technology, many children who are DHH still show delayed spoken language development when compared to their age-matched peers (Geers, Moog, Biedenstein, Brenner, \& Hayes, 2009; Schorr, Roth, \& Fox, 2008). These language delays may have a negative impact on the development of EFs in children who 
are $\mathrm{DHH}$, which in turn has a negative impact on language development because the relationship between language and EFs may be bidirectional (Landa \& Goldberg, 2005; Russell, Saltmarsh \& Hill, 1999). There have been quite a few studies that have examined EFs in children who are DHH although not many of them have investigated EFs in relation to language. They are organized and presented here following Anderson's (2002) EFs categorization.

Attention Control. This domain, according to Anderson (2002), includes selective attention, self-regulation, self-monitoring, and inhibition ability. Attention control is one of the most widely explored areas of EFs in studies with children and adults who are DHH. Most of these studies reported the existence of impaired attention, increased distractibility, high impulsiveness, or deficient self-control in this population. For instance, Kagan (1965) and Campbell and Douglas (1972) reported that children who are DHH tended to be deficient in self-regulation. They conducted the study with children who are DHH in early elementary school (ages 8, 9, and 10 years old), and found that the impulsivity of children who are DHH remains as they mature, whereas the impulsive tendencies of children with $\mathrm{NH}$ become more controlled over time. Their outcomes have been repeatedly documented in later studies (Altshuler, Deming, Vollenweidner, Rainer, \& Tendler, 1976; Barker, Quittner, Fink, Eisenberg, Tobey, Niparko, \& The CDaCI Investigative Team, 2009; Chess \& Fernandez, 1980; Dye, Hauser, and Bavelier, 2008; Eabon, 1984; Harris, 1978; Khan, Edwards, \& Langdon, 2005; Mitchell \& Quittner, 1996; O’Brien, 1985; Parasnis, Samar, \& Berent, 2003; Quittner, Smith, Osberger, Mitchell, \& Katz, 1994; Sporn, 1997).

Recently, Barker et al., (2009) demonstrated a relationship between attention, behavioral problems, and language with 116 children who are DHH between 1.5 and 5 years of age and $69 \mathrm{NH}$ age-matched peers. The Child Behavior Checklist (CBCL, Achenbach \& Rescorla, 2000), videotaped observations, and solitary play were used to evaluate a child's ability to attend. The Reynell Developmental Language Scales (RDLS; Reynell \& Gruner, 1990), and the MacArthur-Bates Communicative Development Inventories (MBCDI; Fenson, Reznick, Bates, Thal, \& Pethick, 1993) were used to measure language ability. Children who are DHH showed more language, attention, and behavioral difficulties, and there was a significant relationship between language, attention, and behavior problems.

Although there have been some studies reporting no difference in attention control ability between DHH and NH groups (Hindley and Kroll, 1989; Kelly, Kelly, Jones, Moulton, Verhulst, \& Sabra, 1993; Marschark \& Everhart, 1999; Surowiecki, Sarant, Maruff, Blamey, Busby, \& Clark, 2002; Tharpe, Ashmead, \& Rothpletz, 2002), issues have been noted in regards to sampling, relevance of degree of hearing loss, and measurement of EFs when reporting group differences (Moeller, 2007). The bulk of the previous evidence showing group differences generally suggests that the impulsivity associated with children who are DHH may be a general behavioral trait linked to the availability of auditory input (Parasnis, Samar, \& Berent, 2003). 
In related studies, the behavioral inhibition/self-regulation skills of children who are DHH have been investigated. Barkley (2001) claims that response inhibition is the prerequisite to self-regulation. Knutson, Ehlers, Wald, and Tyler (2000) suggest that a child's ability to control their behavior, particularly when behavioral inhibition is required, is related to the development of oral language skills. This relationship between inhibition and language ability has been documented in children who are DHH. For example, Horn, Davis, Pisoni, Miyamoto (2004) investigated the relationship between sustained visual attention, behavioral inhibition skills and language outcomes with 47 children with CIs. A vigilance continuous performance task (vCPT) and a visual response delay task (dCPT) were used to measure sustained attention and inhibition skills, respectively. Vocabulary knowledge and receptive and expressive language skills were measured. Whereas vCPT (sustained attention) was not related to any language measure, $\mathrm{dCPT}$ (inhibition) strongly correlated with vocabulary and receptive language skills over 3 years of cochlear implant use. The results also showed that dCPT was related to expressive language at 1 year post implant. The authors interpreted this result to mean that dCPT may be more influenced by subvocal strategies which are related to language measures in children who are DHH, or that the dCPT loads more heavily than vCPT on EFs. This finding suggests that further investigation into EFs is needed. In a follow up study, the authors confirmed this relationship with 88 children with CIs between 2.5 to 8.9 years of age (Horn, Davis, Pisoni, \& Miyamoto, 2005). In preschool-age children with CIs, individuals who are more conservative responders on the CPT showed higher receptive language scores than did individuals with more impulsive response patterns.

A study by Figueras, Edwards, and Langdon (2008) also demonstrated the relationship between inhibition and language in children who are DHH. In this study, the authors explored language skills and EFs with children around 10 years of age with CIs (22), HAs (25), and NH (22). Receptive vocabulary and receptive grammar skills were used to measure language skills, and several subtests of the NEPSY battery (Korkman, Kirk \& Kemp,2007) and Day-Night Stroop test and One-Two tasks (inhibition) (Diamond \& Taylor, 1996; Diamond, Kirk, \& Amos, 2002) were administered to measure EFs. The results showed that the DHH group, regardless of whether they used CIs or HAs, scored lower than the NH group on the tests to assess inhibition ability, with no difference between children with CIs and HAs. However, when vocabulary skills were partialled out, this difference disappeared. The authors interpreted this result to show that the group difference was apparently more reliant on language skill. The results also demonstrated that the global EFs scores were moderately correlated with language for both the $\mathrm{NH}$ and DHH groups ( $r=0.52, p<0.01$, and $r=0.59, p<0.001$, respectively). When the degree of DHH and hearing age were controlled, the global EFs score were strongly correlated with language scores $(r=.71, p<.001)$ in the DHH group.

An investigation by Rhine-Kalback (2004) also supported the relationship between inhibition/self-regulation and language in children who are DHH. The author investigated this relationship with children who are deaf, between the ages of 6 and 14 years of age. The California Picture Vocabulary test (CPVT; Layton \& Homes, 1985), the CELF-Third Edition (CELF-3)-Concept and Directions subtest (Semel, Wiig, \& Secord, 1995), and the Comprehensive Assessment of Spoken Language (CASL)-Pragmatic 
Judgment subtest (Carrow-Woolfolk, 1999) were used to assess language ability. The BRIEF (Gioia et al., 2000), and some performance based measures, such as the ReyOsterrieth Complex Figure Task (RCFT)-Developmental Scoring System (Bernstein \& Waber, 1996), and the Self-Ordered Pointing Task (Archibald \& Kearns, 1999), were used to assess EFs. The author used language as a predictor of EFs. The results showed that language ability predicted performance on working memory and ratings of inhibition by multiple regression analysis. Based on the results, the authors claimed that the children who are DHH who have not yet developed adequate language skills, regardless of sign or spoken language, will have difficulties in self-regulation and social communication. The results confirmed the relationship between language and inhibition/self-regulation in children who are DHH although the causal direction between them as reported in this study remains unclear.

Cognitive Flexibility. The domain of cognitive flexibility includes working memory, conceptual transfer, and feedback utilization. Working memory (WM) is one of the most explored domains of EFs in individuals who are DHH as well as NH. The literature has demonstrated that WM is central to speech perception, language processing and literacy skills (Alloway, Gathercole, Kirkwood, \& Elliott, 2009; Baddeley, 2003; Cane \& Oakhill, 2006; Cowan, 2005; Dempster, 1982; Gathercole \& Baddelet, 1993) in children with NH. Most studies have reported reduced WM performance with children who are $\mathrm{DHH}$ as a group although there are wide individual differences. For instance, Pisoni and Geers (2000) investigated WM measured by digit span with 43 children with CIs between 8 and 9 years of age. The results showed reduced WM span in this population and that WM correlated with vocabulary use, abstract reasoning, and receptive language comprehension as well as speech perception and speech intelligibility scores. The deficits in WM span and the correlations between WM and language abilities have been repeatedly confirmed by an extended number of children who are DHH in later studies across different types of WM tasks (e.g., digit span, nonword span, competing language processing task, and sentence memory), ages, or nations (Dillon, Burkholder, Cleary, \& Pisoni, 2004; Dillon \& Pisoni, 2004; Dunn \& Markwardt, 1989; Engel-Yeger, Durr, \& Josman, 2011; Harris, Kronenberg, Gao, Hoen, Miyamoto, \& Pisoni, 2012; Houston, Beer, Bergerson, Chin, Pisoni, \& Miyamoto, 2012; Ibertsoon, WillstedtSvensson, Radeborg, \& Sahlen, 2008; Kronenberger, Pisoni, Henning, Colson, \& Hazzard, 2011; May-Mederake, \& Shehata-Dieler, 2013; Mitchell \& Quittner, 1996; Pisoni \& Cleary, 2003; Pisoni, Kronenberger, Roman \& Geers, 2011; Watson, Titterington, Henry, \& Toner, 2007; Willstedt-Svensson, Loefqvist, Almqvist, \& Sahlen, 2004).

Recently, Pisoni et al., (2011) documented deficits in WM in 112 adolescents with CIs across 8 years as measured by digit backwards span (DSB) despite language improvements. They found that more than $75 \%$ of the participants with DHH demonstrated improvement in digit span forward (DSF) over an 8 year period while only about $45 \%$ of the same participants demonstrated improvements in DSB. The NH participants showed the same level of improvement in both DSF and DSB. Based on their findings, the authors suggested that DSF (a measure of phonological short-term verbal 
memory) and DSB (a measure of verbal working memory) were dissociated. They also reported that the number of children who fell 1 standard deviation below the normative mean increased from $23 \%$ at elementary school to $38 \%$ at high school. This result indicates that more children showed specific weaknesses and delays in their verbal WM skills. The authors reported that DSB at the elementary level was found to be a stronger predictor of complex language processing measures at the high school level, as measured by the PPVT, CELF, and the Peabody Individual Achievement Test for Reading (Dunn \& Markwardt, 1989), although both DSF and DSB were significantly correlated with all language outcome measures. The authors suggested that this result shows that WM backwards span reflects important underlying core elementary neurocognitive functions and represents potential intervention targets for improving speech and language outcomes in children with CIs.

In a study using the same population as that in the investigation by Pisoni et al., (2011), Geers and Sedey (2011) documented similar results. The 112 participants were tested for language and verbal reasoning skills, and WM (digit span). The results showed that better English language outcomes were associated with longer WM span as well as a shorter duration of deafness prior to cochlear implantation, higher nonverbal intelligence, and higher family socioeconomic status. This result indicates that cognition as measured by WM plays a role in language development.

Set shifting or switching ability has been rarely investigated with children who are DHH. Included in a small number of relevant studies, Surowiecki, Sarant, Maruff, Blamey, Busby, and Clark (2002) investigated visual memory, attention, EFs, and speech and language abilities in 48 children using CIs (24) or HAs (24) between 6 and 14.5 year of age who use oral communication. The Cambridge Neuropsychological Test Automated Battery (CANTAB; Fray, Robins, \& Sahakian, 1996), a nonverbal neuropsychological test battery, was used for assessing attention, EFs (shifting, planning, and WM), and visual memory skills. Vocabulary (PPVT-Revised; Dunn \& Dunn, 1981) and language age (CELF-Preschool; Semel, Wiig, \& Secord, 1992) were used to measure language abilities. Their results revealed no significant differences between children using CIs and HAs on the EFs measures. Bivariate correlation analysis revealed relationships between the EFs subtests and vocabulary and language measures. However, when age was held constant, language skill was not significantly correlated with the EFs subtests including attention, but vocabulary was significantly associated with all the subtests at the level of 0.05. At a significance level of 0.01 with age controlled, only visual memory skills significantly correlated with language skill, and attention and executive functioning skills did not relate to the children's vocabulary or language skills. The authors interpreted these results as showing that differences in visual memory skills may account for some of the variance seen in the language abilities of children using CIs and HAs.

A study by Figueras et al. (2008) used the DKEFS Card Sorting test, which is known to measure set shifting, switching, or cognitive flexibility, with 47 children who are DHH and 22 children with NH. Receptive vocabulary and grammar skills were also measured. The authors reported that the DHH group did not perform as well as the NH group on the Card Sorting test. However, when vocabulary knowledge was entered as a 
covariate in the analysis, the group difference lost its significance, and the global EFs score was correlated with language. Thus, the authors assumed that EFs deficits in children who are DHH may be linked to delayed language acquisition, not an intrinsic consequence of deafness.

Goal Setting. This domain includes initiation, conceptual reasoning, planning, and organization abilities. There have been very few studies exploring goal setting with individuals who have DHH and these investigations report deficits in this domain. For example, Altshuler, Deming, Vollenweider, Ranier, \& Tendler (1976) reported that children who are DHH showed a lack of planning and an inability to consider decisions. This was confirmed by Das and Ojile (1995) who examined the planning ability of 51 students who are DHH and used total communication and 64 students with NH ranging in age from 9 to 15.4 years. The 'Planned Connections' task, and the 'Crack the Code' task were used to measure planning ability. The results showed that children who are DHH not only scored lower than children with $\mathrm{NH}$ but also appeared to be using inadequate strategies and investing less effort compared to children with $\mathrm{NH}$.

The use of inadequate cognitive strategies by children who are DHH has been reported in mainstream settings as well. For instance, Luckner and McNeill (1994) investigated problem solving ability using the 'Tower of Hanoi' with 86 children between 5 and 13 years of age, and found that children who are DHH showed significantly poorer performance than their NH peers. The authors assumed that this difference might be related to their poor language skills, but did not provide evidence to support their assumption. Mousley and Kelly (1998) also used the 'Tower of Hanoi' in their visual and mathematical problem solving study with college students who are DHH. They found that the students who visualized strategies and moves for solving the 'Tower of Hanoi' before beginning the task were more efficient in solving the problem than students who did not.

Some studies have investigated verbal planning ability as a measure of EFs with children who have DHH. For example, Marschark and Everhart (1999) investigated verbal problem solving strategies using a 'Twenty Questions' game with individuals from seven years to college age with and without hearing impairments. The individuals in the DHH group used sign as their primary means of communication. Problem solving strategies adopted by these students were less hierarchical, constraint seeking and less cognitively sophisticated than the NH participants at all ages. The authors assumed that hierarchical structures may be problematic for students with who are DHH. However, a study by Remine, Care, and Brown (2008) reported contrasting results. In this study, the relationship between language ability and verbal and nonverbal EFs was examined using the DKEFS 20 Question test and DKEFS Tower test. Participants included 37 children who are DHH using oral communication between the ages of 12 and 16.09. Language ability was measure by the CELF-3. They found that only the expressive language score contributed to performance on the DKEFS 20 Questions test. Forty-eight percent of the variability in performance on verbal EFs was accounted for by expressive language ability, and there was no significant relationship between language ability and 
performance on the nonverbal EFs assessed by DKEFS Tower test. This finding indicated that nonverbal EFs may be independent from language skills even though they are influenced by each other. In this study, children who are DHH demonstrated average abilities in the use of strategies and problem solving compared with NH peers, which differ from the findings of Marschark and Everhart (1999). The authors suggested that the different communication modes used by individuals in the two studies caused the different results.

Information Processing. The domain of information processing includes efficiency, fluency, and speed of processing. The literature regarding children who are DHH has documented slower nonverbal and verbal processing speed in this population. For example, Das and Ojile (1995) reported deficits in the nonverbal processing ability of children who are DHH. These authors assessed simultaneous and successive processing in 115 children with (51) and without (64) hearing impairments. The Cognitive Assessment System (CAS; Das \& Naglieri, 1989) was used to measure verbal (using grammatical relationship and word series) and nonverbal (using geometric design and color chips) processing ability. They found that at about the age of 10, children who are DHH did not show differences on nonverbal tasks when compared to children with $\mathrm{NH}$. However, there was a significant difference on verbal tasks. When the children were over 12 years of age, the DHH group performed more poorly on both the nonverbal and verbal tasks. They interpreted this result to show that linguistic content may be more important than the processing characteristics (simultaneous or successive) of the tasks (Furth, 1973; Keane \& Kretschmer, 1987).

Fagan, Pisoni, Horn, and Dillon (2007) studied the association between nonverbal processing ability and language. Specifically, they investigated the relationship between nonverbal sensorimotor and visuospatial processes and vocabulary, reading, and working memory (digit span) with 26 children with CIs between the ages of 6-14 years, who received their cochlear implant between the ages of 1 and 6 years. Their results showed significant correlations between standard scores on the Design Copying (DC) subtest of the NEPSY (for visuospatial processing) and standard scores on vocabulary comprehension, reading and WM. These results suggested that visuospatial processing, $\mathrm{WM}$, and language may rely on common underlying cognitive processes and are consistent with several studies that have found global nonverbal performance to be a reliable predictor of verbal performance in children with CIs.

Recent studies with a large number of participants with CIs who used spoken language found slower processing speed in verbal rehearsal tasks. Pisoni, Kronenberger, Roman, \& Geers (2011) measured sentence duration to assess verbal rehearsal speed with 112 adolescents with CIs and their typically hearing peers during elementary and high school over an 8 year period, and found that $\mathrm{NH}$ adolescents have both faster and more consistent verbal rehearsal speeds than the group of adolescents with CIs. In the group with CIs, faster verbal rehearsal speed at the elementary level predicted improvements in WM (digit span forward scores) between elementary and high school. In addition, verbal rehearsal speeds at the elementary level strongly correlated with language scores at the 
high school level $(r=-0.6, p<0.001)$, suggesting that efficiency, speed, and fluency of phonological coding and processing, as reflected by verbal rehearsal speed, likely influences speech-language outcomes. According to Neufeld, Townsend, \& Jetté, (2007), this is because enhancing the amount of phonological information that can be rapidly encoded, processed, and stored in immediate memory, allows the child to perceive, rehearse, and retrieve larger chunks of verbal information per unit of time.

Executive Functions Studies Using the BRIEF. There have been some EFs studies using the BRIEF. The BRIEF has its own categories so these results are again provided separately from other performance-based measurements. In general, studies using the BRIEF parent or teacher questionnaires have revealed differences between children, youth, and adults who are DHH. For example, Rhine (2002) compared schoolage children with and without hearing impairments, and found significantly poorer performance in the DHH group on the inhibition, shifting, and working memory scales of the BRIEF. In a further study, Rhine-Kahlbeck (2004) investigated the correlations between EFs as measured by the BRIEF, the Self-Ordered Pointing task, and ReyOsterrieth Complex Figure Task, the California Picture Vocabulary Test, the Comprehensive Assessment of Spoken Language (CASL; Carrow-Eoolfolk, 1999), the CELF-3, and social skills measured using the Social Skills Rating System; (SSRS, Gresham \& Elliot, 1990). The author found that language development was a significant predictor of EFs and that the scores on the BRIEF scales correlated with the social competence of the children.

Pisoni, Conway, Kronenberger, Henning, and Anaya (2010) conducted a study using the BRIEF with a group of 19 five- to ten-year-old children with CIs and 30 five- to eight-year-old children with NH. Their results revealed that the group means on the Behavioral Regulation Index (BRI), Metacognition Index (MI) and the Global Executive Composite (GEC) scores of the BRIEF were all higher, indicating more problems, for children with CIs than children with $\mathrm{NH}$ although none of them fell within the clinically significant range. In addition, the result revealed poorer performance by the DHH group in shifting, emotional control, inhibition, WM, planning and organization, and organization of material based on the BRIEF scales. The authors interpreted this result as showing evidence that multiple processing systems are linked together in development and that disturbances resulting from hearing loss are not domain-specific and restricted only to hearing and processing auditory signals by the peripheral auditory system.

Recently, Beer, Kronenberger, and Pisoni (2011) conducted a study with 45 children with CIs between the ages of 5.5-18.0. Participants were tested for EFs using the BRIEF and language skills using the CELF-4 (core language score), the PPVT-4, open set word recognition using the Lexical Neighborhood Test (LNT; Kirk, Pisoni, \& Osberger, 1995), and open-set sentence recognition using the Hearing in Noise Test for Children (HINT-C; Nillson, Soli, \& Gelnett, 1996). The authors reported that school-age children with CIs had significantly more EFs difficulties related to working memory, inhibitory control, and behavior regulation than the normative sample, although the observed scores were within normal limits. In addition, children with more difficulty with EFs related to 
working memory showed significantly poorer performance on tests of sentence perception in noise and general language than children with fewer EFs difficulties in this area. However, WM scores did not predict performance of children with CIs on single word recognition, sentence recognition in quiet or receptive vocabulary. This suggests that deficits in EFs are more likely to impact performance on tasks with a high cognitive load, such as listening in noise and general language. The authors suggest that this result provides evidence that a period of early auditory deprivation may result in differences in the development of domain general neurocognitive processes that impact domain-specific areas such as language and speech perception.

In a related recent study, Greiner (2010) investigated the relationship between EFs and language with 33 children with CIs between $6 ; 10$ and 12;6 years of age, and 29 agematched peers with NH. EFs were measured using the BRIEF parent questionnaire and the NEPSY (Korkman, Kirk, \& Kemp, 1998) Tower, Block Construction, and Visual Attention subtests. Language skills were measured using the PPVT-3 (Dunn \& Dunn, 1997). The results showed that there was no group difference on the BRIEF, but the group with CIs did not perform as well as the NH group on all three NEPSY subtests. This suggests that the BRIEF may not be sensitive enough to identify group differences if there are any differences in EFs between DHH and NH groups. On the NEPSY, the DHH group showed more problems in planning, monitoring, self-regulation as assessed using the Tower subtest. They also showed visual attention, and visuospatial processing problems as assessed using Block Construction. The results showed that the Tower test results $(r=0.606, p=0.001)$ and visual attention $(r=-0.905, p=0.001)$ were correlated with language, but not other EFs measures. The author suggested the EFs could be mediating language performance on these particular measures which is why they are showing correlations with language. The influence of age of implantation was also investigated and none of the EFs measures were correlated with age of implantation except the Tower subtest $(\mathrm{r}=0.132, \mathrm{p}=0.470)$, which indicated that planning and organization abilities could be influenced by age of implantation.

Holt, Beer, Kronenberger, Pisoni, and Lalonde (2012) investigated the relations between family environment and language development and EFs with 45 children with CIs. The EFs were measured using the BRIEF Parent Questionnaire, and language skills were measured using the PPVT-4 (Dunn \& Dunn, 2007), the Preschool Language Scale (PLS, Zimmerman, Steiner, \& Pond, 2002) and the CELF-4 (Semel, Wiig, \& Secord, 2003). They reported that children with CIs are delayed in all aspects of language development and have significantly more problem behaviors related to inhibition as demonstrated by scores on the working memory scales, and the overall score (GEC) when compared to the normative sample. This result is consistent with the body of literature describing children with CIs.

Hintermair (2013) investigated the relations between EFs, communicative competence, and behavioral problems with 214 children who are DHH using oral communication. Participants were either from schools for the Deaf $(n=145)$ or general/mainstream schools $(n=69)$. The EFs were measured using a German version of the BRIEF (BRIEF-D). In addition, communicative competence and behavior problems 
were measured with a German version of the Strengths and Difficulties Questionnaire (SDQ-D, Rothenberger \& Woerner, 2004). The results showed significantly more problems with EFs in the group with DHH when compared with the normative sample of children with NH. Increased problems with EFs in the DHH group were connected with a lower level of communicative competence. Further analysis revealed that the DHH group from the general/mainstream schools had better EFs than the children from the schools for the Deaf, suggesting the crucial role of language for EFs development. Furthermore, the EFs and communication competence predicted behavior problems investigated by SDQ-D, such as hyperactivity, and peer relationship problems. Based on these results, the authors suggested that EFs in children who are DHH need increased attention to ensure social and academic success.

\section{Children Who Are DHH, Narrative Skills and Executive Functions}

There are very few studies investigating the influence of EFs on narrative skills with children who are DHH. Asker-Arnason, Ibertsson, Wengelin, and Sahlen (2007) investigated the relationship between phonological short-term memory (PSM) and oral narrative ability with children with CIs. The authors assessed nonword repetition for PSM measurement, and administered story description, retelling, and generation tasks to assess total narrative ability. The results showed a clear link between PSM and total narrative ability. In a related study, Ibertsson (2009) investigated the relationship between working memory and writing skills with seven adolescents who are DHH between the ages of 14 and 19. The Swedish version of the Competing Language Processing Task (CLPT, Gaulin \& Campbell, 1994) was used for general WM measurement, and the story 'Frog, Where Are You?' (Mayer and Mayer, 1975) was used for narrative writing. The results revealed that two of seven participants with poor phonological decoding strategies wrote less elaborate narratives with a higher proportion of content words and lower function words, lower story-grammar scores, and lower general working memory scores. The author did not report correlations, but assumed a relationship between phonological processing, reading, and working memory based on this result.

\section{Research Questions and Hypotheses}

The aim of this study is to examine the language, oral narrative and EFs skills of children who are DHH and use oral communication and compare their results with those of age-matched children with NH to determine if there were any differences between the groups. This study also explores the relationship between the study variables for the children who are DHH and NH. As a result, the study is designed to answer the following research questions.

1. Is there a significant difference between children who are $\mathrm{DHH}$ and use oral communication and children with $\mathrm{NH}$ on tests of language, narrative structure, and EFs? 
2. Are language ability, oral narrative production and EFs related for children who are $\mathrm{DHH}$ and use oral communication and children with $\mathrm{NH}$ ?

For the Group performance, based upon previous studies, it is hypothesized that children who are DHH and use oral communication will have overall lower standardized language test scores and show some deficits in EFs when compared with NH peers. Differences between the groups are also expected to include the language used in narrative productions as well as the organization of narrative structures. Wide individual differences in the DHH group are anticipated based on previous studies. However, it is also expected that many of the children in the DHH group will perform well on the narrative tasks based on a recent study by Huttumen (2008) who reported that children who are $\mathrm{DHH}$ with a hearing age of more than five years produced complete episodes.

For the relations Among Variables, it is also hypothesized that the language used in narrative productions will reflect scores from language standardized testing. This is expected because narratives require both vocabulary and syntactic knowledge to construct a complete sentence as a fundamental of narrative construction. Finally, based upon the mixed results of studies investigating the structure of oral narratives and EFs in children who are $\mathrm{DHH}$, it is hypothesized that if children who are $\mathrm{DHH}$ are able to produce a narrative, but show some problem in narrative organization, their deficits will be more related to EFs than their linguistic competence. It is expected because the coherent narrative structures have been reported to both linguistic and cognitive skills. 


\section{CHAPTER 3. METHOD}

\section{Participants}

Twenty-one children between ages of 9 and 11 participated in this study. The participants were divided into two groups, eleven in the deaf and hard of hearing (DHH) group of 5 boys and 6 girls, and ten in the normal hearing $(\mathrm{NH})$ group of 6 boys and 4 girls. The average age for the DHH group was 10;5 (range 9;1-11;4). The average age for the NH group was 10;4 (range 9:0 - 11;5).

The children in the DHH group had received or were receiving audiological and/or speech and language services through the audiology and speech clinics in Department of Audiology and Speech Pathology, University of Tennessee Health Science Center (UTHSC). All of the children in the DHH group had a bilateral hearing loss. They had been identified before the age of 5 years and their hearing age was greater than 4 years and 10 months $(M=8 ; 8$, range $4 ; 10-11 ; 00)$. All of the children in the DHH group used oral communication, were educated in mainstreamed classrooms, and reported no other disabilities. Five of the 10 children with DHH had a moderate hearing loss, 1 had a moderate to severe hearing loss, 3 had a severe hearing loss, and 2 had a severe to profound hearing loss. All of them had used hearing aids however the two with severe to profound hearing losses had received cochlear implants (CIs).

The children in the NH group were age matched to the DHH group and had been recruited through flyers. All of the children in the NH group had no history of speech or language therapy or other disabilities, and spoke English as their first language. Before participating in the study, the participants and their families were informed about the study and the tests, and signed consent and assent forms approved by the UTHSC Internal Review Board. Detailed information about each of the participants is provided in Table 3-1.

\section{Test Materials}

The data were collected in three areas, which were language, narratives, and EFs, using standardized tests. The test materials were listed in Table 3-2. The CELF-IV and DKEFS were purchased from the publisher, Pearson (http://www.pearsonclinical.com/language/products/100000442/clinical-evaluation-oflanguage-fundamentals-fourth-edition-celf4.html?Pid=015-8037-200, and http://www.pearsonclinical.com/psychology/products/100000618/deliskaplan-executivefunction-system-d-kefs.html?Pid=015-8091-108), and the BRIEF were purchased from PAR (http://www4.parinc.com/Products/Product.aspx?ProductID=BRIEF). 
Table 3-1. Information about the participants in the DHH and NH groups

\begin{tabular}{|c|c|c|c|c|c|c|}
\hline Subject & Gender & $\begin{array}{c}\text { Degree of } \\
\text { Hearing Loss }\end{array}$ & Amplification & $\mathbf{C A}$ & $\begin{array}{c}\text { Hearing } \\
\text { Age }\end{array}$ & Grade \\
\hline HL 1 & M & Moderate & HA / HA & $9 ; 01$ & $5 ; 10$ & 3 \\
\hline HL 2 & M & Moderate & $\mathrm{HA} / \mathrm{HA}$ & $9 ; 04$ & $8 ; 10$ & 3 \\
\hline HL 3 & M & $\begin{array}{l}\text { Severe to } \\
\text { profound }\end{array}$ & $\mathrm{CI} / \mathrm{CI}$ & $9 ; 05$ & $8 ; 05$ & 4 \\
\hline HL 4 & $\mathrm{~F}$ & Severe & HA / HA & $9 ; 11$ & $9 ; 03$ & 4 \\
\hline HL 5 & $\mathrm{~F}$ & Moderate & HA / HA & $10 ; 01$ & $4 ; 10$ & 4 \\
\hline HL 6 & $\mathrm{~F}$ & Severe & HA / HA & $10 ; 08$ & $7 ; 07$ & 4 \\
\hline HL 7 & M & Moderate & HA / HA & $10 ; 10$ & $9 ; 03$ & 5 \\
\hline HL 8 & $\mathrm{~F}$ & Severe & $\mathrm{HA} / \mathrm{HA}$ & $11 ; 01$ & $8 ; 01$ & 5 \\
\hline HL 9 & $\mathrm{M}$ & $\begin{array}{l}\text { Severe to } \\
\text { Profound }\end{array}$ & $\mathrm{CI}$ & $11 ; 02$ & $8 ; 00$ & 5 \\
\hline HL 10 & $\mathrm{~F}$ & Moderate & HA / HA & $11 ; 02$ & $11 ; 00$ & 5 \\
\hline HL 11 & $\mathrm{~F}$ & $\begin{array}{c}\text { Moderate to } \\
\text { Severe }\end{array}$ & HA / HA & $11 ; 04$ & $8 ; 02$ & 5 \\
\hline NN 1 & $\mathrm{~F}$ & & & $9 ; 00$ & & 3 \\
\hline NH 2 & M & & & $9 ; 07$ & & 4 \\
\hline NH 3 & $\mathrm{~F}$ & & & $9 ; 08$ & & 4 \\
\hline NH 4 & M & & & $9 ; 11$ & & 4 \\
\hline NH 5 & M & & & $10 ; 03$ & & 4 \\
\hline NH 6 & $\mathrm{M}$ & & & $10 ; 06$ & & 5 \\
\hline NH 7 & $\mathrm{~F}$ & & & $10 ; 09$ & & 5 \\
\hline NH 8 & $\mathrm{~F}$ & & & $11 ; 02$ & & 5 \\
\hline NH 9 & M & & & $11 ; 04$ & & 5 \\
\hline NH 10 & M & & & $11 ; 05$ & & 5 \\
\hline
\end{tabular}


Table 3-2. Test materials

\begin{tabular}{lll}
\hline \multicolumn{1}{c}{ Area } & \multicolumn{1}{c}{ Category } & \multicolumn{1}{c}{ Test Materials } \\
\hline Language & & CELF-IV Core Language Test \\
Narrative & Story Retell & Frog, Where Are You \\
& Story Generation & Alien (TNL) \\
& & \\
EFs & Observation Based Test & BRIEF - Parent Form \\
& Performance Based Test & DKEFS Trail Making \\
& & DKEFS Card Sorting \\
& & DKEFS Tower \\
& & Digit Span (WISC-III) \\
\end{tabular}

\section{Language Ability}

The CELF-IV Core Language subtests were used to test the general language abilities of the participants. The CELF-IV is an individually administered clinical tool for the identification, diagnosis, and follow-up evaluation of language and communication disorders in students range between 5-21 years old. The Core Language score consists of four subtests and has been reported to be able to evaluate a student's general language ability and whether or not a language disorder is present (Semel, Wiig, and Secord, 2003). The Core Language score includes the subtests: Concepts and Following Directions, Recalling Sentences, Formulated Sentences, and Word Classes for children between ages of 9 and 11 years. These subtests are described below.

1. Concepts and Following Directions: The Concepts and Following Directions subtest of the CELF-4 evaluates "a student's ability to: (a) interpret spoken directions of increasing length and complexity, containing concepts that require logical operations, (b) remember the names, characteristics, and order of objects, and (c) identify from among several choices pictures of objects" (Semel, Wiig, and Secord, 2003, p.18). An examinee is asked to point to pictures of objects in response to a sentence from an examiner's.

2. Recalling Sentences: The Recalling Sentences subtest evaluates "a student's ability to: (a) listen to spoken sentences of increasing length and complexity, and (b) repeat the sentences without changing word meanings, inflections, derivations or comparisons (morphology), or sentence structure (syntax)" (Semel, Wiig, and Secord, 2003, p.25). An examinee is asked to repeat the sentence in the exact same way spoken by the examiner.

3. Formulated Sentences: The Formulated Sentences subtest evaluates "a student's 
ability to formulate complete, semantically and grammatically correct spoken sentences using words that are provided and contextual constraints imposed by illustrations" (Semel, Wiig, and Secord, 2003, p.33). An examinee is given a word with a picture and asked to make a sentence related to the picture using the given word.

4. Word Classes 2: The Word Classes 2 subtest evaluates "a student's ability to understand relationships between semantically related words and to express those relationships" (Semel, Wiig, and Secord, 2003, p.58). An examinee is given four words by an examiner, and asked to pick two related words and explain how they are related.

\section{Narrative Skills}

Narrative Skills were measured by two narrative production conditions, story retell and story generation. For the story retell condition, "Frog, Where Are You?" (Mayer, 1969), which is a 24-page picture book, used to elicit a narrative from participants. This book has been used extensively in narrative research with typically developing children (Bamberg \& Damrad-Frye, 1991; Berman \& Slobin, 1994), children with SLI (Van Der Lely, 1997; Botting, 2002) and children with other disorders (Reilly, Bates, Marchman, 1998). The story is about a boy who had two pets, a dog and a frog. The story starts with when the frog escapes from his jar and runs away. The boy and the dog discover the empty jar in the next morning and search for the frog. During the search they meet many different animals and experience a number of mishaps, but finally they find the frog with a family of his own. They take one of the baby frogs back home.

In order to provide the same experimental conditions across the participants, every picture from the book including the cover, was scanned, saved as a .jpg file and put in a Powerpoint program. The narrative for the script provided in the manual from the Systematic Analysis of Language Transcripts (SALT, Miller \& Iglesias, 2008) was recorded for every page. Participants looked through the picture book via the monitor of a laptop computer, and listened to the recorded narration through two speakers. The pictures and narration were automatically synchronized. The sound level of the speakers were measured using a Davis System 824 Sound Level Meter, made by Larson, and the volume was set to $65 \mathrm{~dB} \pm 3 \mathrm{~dB}$ SPLA. The speakers were placed on the table in front of a participant, at a distance of 4.5 feet from a child's ears.

Before watching and listening to the story, each participant was given the instruction, "Now we are going to listen to the story while we are watching the pictures in this monitor. Then I am going to ask you to tell the story back to me. Are you ready?" After looking at the pictures while listening to the story, the same pictures were shown to the participants via the laptop computer with the instruction, "I would like you to tell the story back to me. You can use your own words. Touch this arrow to turn to the next page. You can start any time you are ready." The story retell produced by the participants was transcribed for analysis. 
For the story generation condition, the Test of Narrative Language (TNL): Alie, which is a single picture task, was used to elicit a narrative. The single picture titled 'Alien' showed the situation of one boy and girl seeing an alien family walking out a spaceship in a park. The girl with a curious expression is leaning her body towards the alien while holding the boy's hand, and the boy has a frightened expression. The participants were asked to think about the story before starting their narrative and begin whenever they were ready. The story generated by the participants was transcribed for analysis.

\section{Executive Function Tests}

In order to EFs measure, both observation based and performance based assessments were used. The Behavior Rating Inventory of Executive Function (BRIEF; Gioia, Isquith, Guy, \& Kenworth, 2000) - Parent Rating was used for observation based assessment of EFs. The BRIEF includes a parent and a teacher questionnaire designed to rate children's behaviors at home or school. The parent rating was used in this study. It has 86 items to measure 8 aspects of executive function. The answers use a three point scale, Never, Sometimes, and Often. The eight scales form two broader indexes, Behavior Regulation (BRI) and Metacognition (MI), and one overall score, the Global Executive Composite (GEC). Parents completed the BRIEF while their children were participating in the tests.

For the performance based assessment, the three subtests of Delis-Kaplan Executive Function System (DKEFS; Delis, Kaplan, and Kramer, 2001), and the Digit Span subtest of the Wechsler Intelligence Scale for Children-third edition (WISC-IV; Wechsler, 2003) were used. The three subtests of the DKEFS administered in the study included Trail Making, Card Sorting, and Tower tests. All tests were scored based on the standard score provided by the manual.

Of the Trail Making, the Number-Letter Switching test was used in this study. In this test children are asked to draw a line switching number to letter, and letter to number, such as 1 to A, A to 2, 2 to B, through 16 to P. A practice item was given to children before the actual test. This test measures nonverbal EFs. The standard score for completion time the task was used in the analysis.

The DKEFS Card Sorting test consists of two card sets with two testing conditions for each set. The first is free sorting and the other is sort recognition. For the free sorting condition, children are asked to sort the cards into two groups, with three cards per group, according to as many different concepts or rules as possible, and to describe the concepts employed to sort the cards. In the sort recognition condition, the examiner sorted the same sets of cards into two groups, with three cards each group, according to test directions. After the examiner sorts the cards, children are asked to identify and describe the rules or concepts used for that sort. Each of the two card sets has a maximum of eight target sorts: three sorts based on verbal-semantic information from the printed words and five based on visual-spatial features or patterns on the cards. This 
test measures both verbal and nonverbal EFs. The standard scores for the correct sorting, the combined description score, and the description contrast score of two description tasks were used in the analysis.

The DKEFS Tower test uses five disks that vary in size from small to large and a board with three vertical pegs. It has 9 tasks using from 2 discs to 5 discs. An examiner places the disks on the predetermined pegs first, and shows a picture of target tower to a child. Then a child moves the disks to build the target tower within given time. When constructing the target towers, children must follow two rules. First, they must move only one disk at a time, and second, they may never place a larger disk over a smaller disk. This test measures nonverbal EFs. The standard scores for achieving the target and for the rule violations were used in the analysis.

The digit span subtest of the WISC-III was used to assess working memory. The digit span test includes of two conditions; digit span forward (DSF) and digit span backward (DSB). In the DSF condition, children were asked to repeat digits in the same order as they were presented, and in the DSB condition, children were asked to repeat digits backward from which the numbers were provided. The standard scores of DSF and DSB were used in the analysis.

\section{Procedures}

All tests were administered in the Language and Literacy Lab in the Department of Audiology and Speech Pathology, University of Tennessee Health Science Center in Knoxville. All participants were individually tested by a native English speaker, who was an undergraduate or graduate student studying Audiology and Speech Pathology. The participants were seated at a table. The examiner and the author sat across the table at the right and left side of the participants. Before beginning the tests, the participants had the study described to them and signed an assent form. The testing started with CELF-IV followed by the digit span tests, 'Frog Where Are You?' story retell, the DKEFS, and the TNL story generation test. A break was provided between 'Frog Where Are You?' and the DKEFS testing. Additional breaks were given according to a child's request or a decision by the examiner or author. In agreement with the participants and their parents, all the test procedures were recorded with a digital video camera (Sony Model No. DCR-PC5) by the author for reliability testing and in order to score and transcribe the stories.

\section{Narrative Analysis}

The two narrative samples, one used for narrative retell and one for generating narratives were collected from each child. The narratives were transcribed from the recorded video by the author. Each story was segmented into T-Units, which consists of a single main clause and any dependent clause (Scott, 1988). The stories were coded for microstructure and macrostructure level analyses, and entered into the Systematic Analysis of Language Transcripts (SALT; Miller and Iglesias, 2008). The analyzed 
indices for micro- and macrostructure analyses were listed in Table 3-3.

\section{Microstructure Level Analysis}

Microstructure analysis considers the internal linguistic structure used in the construction of narratives. In order to analyze the microstructure of narratives, the narratives were coded according to the conventions of the SALT program and entered for analysis. For this study, five indices were included to assess the productivity and complexity of the language used in the narratives. These indices included the following.

1. T-Units. The total number of T-Units in a narrative was counted by the SALT program. A T-unit is "one main clause with all the subordinate clauses and nonclausal phrases attached to or embedded it” (Paul, 2007, p.587). All coordinated clauses using conjunctions such as and, but, and or are separated out into separate T-units. The number of T-Units reflected the narrative length.

2. Mean Length of Utterance in morphemes (MLUm). The number of words and grammatical morphemes used (for example, -s plural, -ed past tense, -ing present progressive $-\mathrm{s}$ 3rd person regular tense, and 's possessive) were coded for analysis according to the conventions of the SALT program. The MLUm reflects a mean length of utterance in terms of words and morphemes used in a narrative produced by a participant.

\section{Table 3-3. Narrative analysis indices}

\begin{tabular}{lll}
\hline \multicolumn{1}{c}{ Analysis } & \multicolumn{1}{c}{ Category } & Index \\
\hline Microstructure & & Number of T-Units \\
& MLUm \\
& & NDW \\
& TTR \\
& SI \\
& & Grammar Errors \\
& & \\
Macrostructure & Story Grammar & Setting, Events, Response, Goal, Attempt, Outcome, \\
& & Ending, and Others \\
& Episode & Number of Episode \\
& & GAO Units \\
& Hierarchical Goal & Complete GAO Units \\
& Structure & Hierarchical Goal Plan \\
& Cohesive Devices & Temporal and Causal Relationship across Episodes \\
\hline
\end{tabular}


3. Number of Different Words (NDW). The number of different words (NDW) used in a narrative was automatically counted from the SALT program. The NDW is a direct index of vocabulary diversity (Paul, 2007, p.477).

4. Type Token Ratio (TTR). The Type Token Ratio (TTR) was calculated by the SALT program. The TTR is an index of "the ratio of different words among the total number of words in a sample narrative" (Paul, 2007, p.476). Thus, a large TTR is an indicator of the vocabulary diversity. However, as the sample length increases, the TTR decreases because fewer different words are used on the same topics.

5. Subordination Index (SI). The segmented T-Units were coded to determine the Subordination Index (SI) following as the conventions of the SALT program. The SI is a measure of syntactic complexity which produces "a ratio of the total number of clauses to the total number of T-Units" (Scott \& Stokes, 1995, p.310). That is the average number of subordinate clauses produced per T-Unit.

6. Grammar Errors. Grammar errors that the children produced in their narratives were coded individually. In order to reflect the various chances to produce grammatical morphemes according to the number of words used in narratives across participants, a ratio of the total number of grammar errors to the total NDW was calculated.

\section{Macrostructure Level Analysis}

To conduct the macrostructure analysis, a narrative structure was assessed in terms of its story grammar, the number of episodes, completeness of episodic structure, and the goal plan hierarchy.

Story Grammar. In order to identify the global narrative organization and the goal structure, each T-Unit in a narrative was coded as one or more of the eight story grammar categories adapted from Stein and Glenn (1979), and Trabasso (1989). The story grammar categories used in the current study include the following: Setting, Event, Response, Goal, Attempt, Outcome, and Ending. The definition of each category is in the Table 3-4.

The 'Others' category was added to the more conventionally use story grammar categories for his study by the author. This category consists of utterances that cannot be assigned to the other story grammar categories and include actions or behaviors of characters other than the protagonist, events that are not related to the theme of the narrative, or conversations between characters to describe characters, situations or something the participants had already included in the narrative. A ratio of each category to the total number of T-units was calculated. 
Table 3-4. Definition of story grammar categories

\begin{tabular}{|c|c|}
\hline Category & Definition \\
\hline Setting & $\begin{array}{l}\text { Statements which provide background information about the characters and the } \\
\text { place and time in which the story happens }\end{array}$ \\
\hline Event & $\begin{array}{l}\text { Statements which describe actions or events that may change or elicit the } \\
\text { character's current goals or behaviors }\end{array}$ \\
\hline Response & $\begin{array}{l}\text { Statements which describe the character's mental states in response to ongoing } \\
\text { events or external responses }\end{array}$ \\
\hline Goal & $\begin{array}{l}\text { Statements which describe the character's plan for addressing the ongoing } \\
\text { events }\end{array}$ \\
\hline Attempt & Statements which describe the character's actions to achieve the goals \\
\hline Outcome & Statements which describe the consequences of the attempts \\
\hline Others & Statements which cannot be assigned to the codes above \\
\hline Ending & $\begin{array}{l}\text { Statements which describe detailed action or ending that is related to the rest of } \\
\text { the story }\end{array}$ \\
\hline
\end{tabular}

Sources: Stein, N. \& Glenn, C. (1979). An analysis of story comprehension in elementary school children. In R. Freedle (Ed.), New directions in discourse processing (pp. 53-120). Norwood, NJ: Ablex; Trabasso, T. (1989). Causal representation of narratives. Reading Psychology, 10, 67-83. 
Episodic Structure. In order to analyze episodic structure, number of episodes and the proportion of GAO unit to the total number of T-unit were analyzed.

1. GAO units: After coding the T-Units, the number of statements used to produce goals, attempts, outcomes were calculated (GAO statements). In order to reflect the various lengths of the narrative produced by each participant, a ratio of the number of GAO statements to the total number of T-Unit was calculated. The proportion of the GAO statements to T-Units indicates how the participant constructed a narrative to convey episodes.

2. Number of Episodes: After each T-Unit was coded into one or more of the story grammar categories, the number of episodes composed of a Goal-AttemptOutcome (GAO) unit was counted. An episode missing one or two components of a GAO unit was still considered to be an episode as well as an episode having three components of a GAO Unit.

Hierarchical Goal Structure. In order to assess hierarchical goal structure of narratives, the complete GAO unit and superordinate goals of narratives were analyzed.

1. Complete GAO Units: After identifying episodic structure, the GAO integrity was examined. A GAO Unit has been considered to be an essential component for an episode to be completed (Stein \& Glenn, 1979). Thus, the GAO Units are categorized as complete and incomplete contingent on whether a Unit includes the three essential components, a goal, an attempt to achieve to the goal, and its direct action. When all three were included, the GAO Unit was categorized as complete. When one or more of these components were missing, it was considered an incomplete GAO Unit. After categorizing the Units, the ratio of the number of complete episodes to the total number of episodes was calculated.

2. Hierarchical Goal Plan: In order to examine whether the children constructed narratives in terms of a goal-plan hierarchy, the existence of superordinate goals and subordinate goals was analyzed. The superordinate goal refers to a goal that the protagonist in a narrative ultimately wants to achieve. The subordinate goal refers a sub-goal that is used to obtain the superordinate goal. In the each narrative, a superordinate goal and subordinate goals were identified and coded as G1 and G2, respectively. When a narrative has both superordinate and subordinate goals, 3 points was given. Two points were given when the narrative had only a superordinate goal and if there was only a subordinate goal, 1 point was given.

The superordinate and subordinate goal plans of the 'Frog Where Are You?' story were analyzed using protocols from Trabasso and Nickels (1992). Hierarchical goal plans for the 'Alien' story were analyzed by the author to match the intention of each participant since it was a story generation task without an idealized frame for a goal plan. The examples of the goal plans for the 'Frog Where Are You?' story used in this study, and narrative coding examples are provided in Appendix A and Appendix B, respectively. 
Global Coherence. In order to examine the coherence of a narrative, the temporal and causal linguistic relationships between episodes and between the story grammar categories in the narratives were analyzed. The number of accurate words and phrases used to conjoin sentences across episodes was counted and a ratio of the total number of conjunctive expressions to the total possible number of conjunctive expressions was calculated.

\section{Reliability}

\section{Narrative Transcription Reliability}

All narrative samples were transcribed by the author and reviewed by a second examiner who was a student from the Audiology and Speech Pathology program to check the accuracy of transcription. The second examiner independently listened to each story while simultaneously examining the transcript for errors. Inter-transcriber agreement was $96 \%$. For the stories produced by participants with $\mathrm{DHH}, 10 \%$ of the transcripts were again examined by another student who was familiar with articulation of children with $\mathrm{DHH}$ to determine if there were any errors that may have resulted from articulation problems. The inter-transcriber agreement with the third examiner was $99 \%$.

\section{Narrative Coding Reliability}

A student from the Audiology and Speech Pathology program, who was blind to the individual participants, scored and coded $10 \%$ of the samples used in the study (i.e. 1 sample from each participant from each group). Inter-rater agreement was 90.5\%.

\section{Statistical Analysis}

An analysis of variance (ANOVA) was used to compare scores for the $\mathrm{DHH}$ and NH groups. When a test category has more than two tasks, a repeated measure ANOVA was used to test simple main effect of each task and an interaction effect between the groups as well as test difference between groups. When there are several tasks without the need to test an interaction effect under a category, multiple analysis of variance (MANOVA) was used for a group comparison. In order to test relations between test areas, correlations were used. All statistical analyses were conducted with IBM SPSS statistics 21 . In order to show effect sizes for the statistical analyses, partial eta squared values are reported. 


\section{CHAPTER 4. RESULTS}

The purpose of this study was to examine the language, narrative production and executive function skills of children with and without hearing impairments, and to determine if there were any differences between the groups. Based upon the literature, it was anticipated that the children who are DHH would not perform as well as their $\mathrm{NH}$ peers. This chapter provides quantitative data regarding language scores, the narrative structures produced through story retell and story generation, and data from parent report and performance based measures of EFs.

\section{Language Ability}

Language ability was assessed in two ways. First, a score from the CELF-IV Core Language subtest was obtained for each participant. Second, results from the microstructure analysis of narratives were determined. The mean standard scores, standard deviation $(S D)$, and range scores from the CELF-IV Core Language subtest and the microstructure analysis of narratives are listed in Table 4-1 and Table 4-2, respectively.

Scores on the Core Language subtest showed that the mean of the DHH group was $98.82(S D=16.588)$, which is close to the standard mean of 100. Individual data showed that two of the eleven participants with DHH scored below one standard deviation of the standard mean, (81 and 70 for these participants). The mean score for the $\mathrm{NH}$ group was $116.20(S D=10.443)$. All of the children in the NH group scored within one standard deviation of the mean or above. A one-way analysis of variance (ANOVA) was conducted to determine if the difference between the two groups was significant. The outcome revealed a main effect for the group, $F(1,19)=8.076, p=.010, \eta_{p}{ }^{2}=.298$, indicating that the score of the $\mathrm{DHH}$ group was significantly lower than that of the $\mathrm{NH}$ group.

Microstructure analysis showed little difference between groups with the exception of grammar errors. A multivariate analysis of variance (MANOVA) was conducted using the average number of T-Units, MLUm, NDW, TTR, SI, and grammar errors across the narratives. Outcome of the MANOVA revealed that the DHH group performed lower than the NH group, $F(6,14)=3.777, p=.019, \eta_{p}{ }^{2}=.618$. Pairwise comparisons indicated that the proportion of grammar errors made by the DHH group was significantly higher than that of the $\mathrm{NH}$ group, $F(1,19)=8.802, p=.008, \eta_{p}{ }^{2}=.317$, whereas there was no difference between the other categories. The DHH group produced a mean of $8.50 \%$ grammatical errors in their narratives whereas the NH group produced the mean of $0.94 \%$ grammatical errors. 
Table 4-1. Core language subtest scores from the CELF-IV

\begin{tabular}{llccc}
\hline Group & \multicolumn{1}{c}{ Language Test } & Mean & SD & Range \\
\hline DHH & Core Language Total & 98.82 & 16.558 & $70-124$ \\
& Concept and Following & 8.73 & 2.83 & $5-12$ \\
& Directions & 9.73 & 2.90 & $4-13$ \\
& Recalling Sentences & 10.64 & 4.39 & $1-16$ \\
& Formulated Sentence & 9.91 & 3.24 & $6-16$ \\
& Word Class & & & \\
& NH & 116.20 & 10.443 & $97-129$ \\
& Core Language Total & 11.30 & 1.83 & $9-14$ \\
& Concept and Following & 12.10 & 2.51 & $8-16$ \\
& Direction & 12.90 & 3.28 & $4-15$ \\
& Recalling Sentences & 14.4 & 2.59 & $10-18$ \\
\hline
\end{tabular}

Table 4-2. Microstructure level analysis of narrative production

\begin{tabular}{llccc}
\hline Group & Microstructure Index & Mean & SD & Range \\
\hline DHH & Number of T-Units & 31.5 & 8.62 & $19.5-46$ \\
& MLUm & 9.92 & 1.73 & $6.73-12.41$ \\
& NDW & 99.55 & 29.09 & $60-163$ \\
& TTR & 0.43 & 0.07 & $0.33-0.62$ \\
& SI & 1.22 & 0.11 & $1.10-1.40$ \\
& Grammar Error & 8.5 & 7.96 & $0.43-27.06$ \\
& & & & \\
& NHH & 30.2 & 4.18 & $24.5-36$ \\
& MLUm & 10.08 & 0.77 & $9.17-11.53$ \\
& NDW & 97.7 & 10.71 & $78.50-114.00$ \\
& TTR & 0.44 & 0.36 & $0.38-0.49$ \\
& SI & 1.23 & 0.87 & $1.12-1.38$ \\
& Grammar Error & 0.94 & 1.21 & $0-3.94$ \\
\hline
\end{tabular}




\section{Narrative Structure}

\section{Story Grammar Analysis}

Story Retell. The means for each of the eight story grammar components from the story retell are presented in Figure 4-1. The overall pattern of change across story grammar components was similar in both groups. However, the DHH group produced proportionately less information across some story grammar components than the $\mathrm{NH}$ group whereas the DHH group produced more than the NH group in the Others category.

A $2 \times 7$ repeated measures ANOVA for group and the seven story grammar categories showed that the lower performance of the $\mathrm{DHH}$ group than the $\mathrm{NH}$ group was not significant, but close to the significant level, $F(1,19)=4.114, p=.057, \eta_{p}{ }^{2}=.178$, and that there was a main effect for the story grammar, $F(6,14)=91.847, p<.0001, \eta_{p}{ }^{2}$ $=.975$, but there was no interaction effect between the group and the story grammar, $F(6$, $14)=1.516, p=.244, \eta_{p}{ }^{2}=.394$. These results indicated that the difference between the groups was not significant, but the differences between the story grammar components were significant.

The Others category was not the story grammar components, but added to analysis in order to categorize statements that were not directly related with a main plot of a narrative. An ANOVA for group of this category revealed that the higher proportion of DHH than the NH group was not significant, $F(1,19)=1.203, p=.286, \eta_{p}{ }^{2}=.060$.

Story Generation. The mean scores for each story grammar component from the story generation task for both groups are presented in Figure 4-2. The overall pattern across categories was similar in both groups. However, a $2 \times 7$ repeated measures ANOVA for group and the seven categories revealed that a lower performance by the DHH group when compared with the NH group were significant, $F(1,19)=9.529, p=.006, \eta_{p}{ }^{2}$ $=.334$. It also showed that there was a difference between story grammar categories, $F(6$, $14)=4.989, p=.006, \eta_{p}{ }^{2}=.681$, but the interaction effect was not significant, $F(6,14)$ $=.653, p=.688, \eta_{p}{ }^{2}=.219$.

The proportion of the Others category to the total number of T-Units was a mean of $29 \%$ for the DHH group and a mean of $13 \%$ for the NH group. However, the difference between groups in this category was not significant, $F(1,19)=3.736, p=.068$, $\eta_{p}{ }^{2}=.164$. 


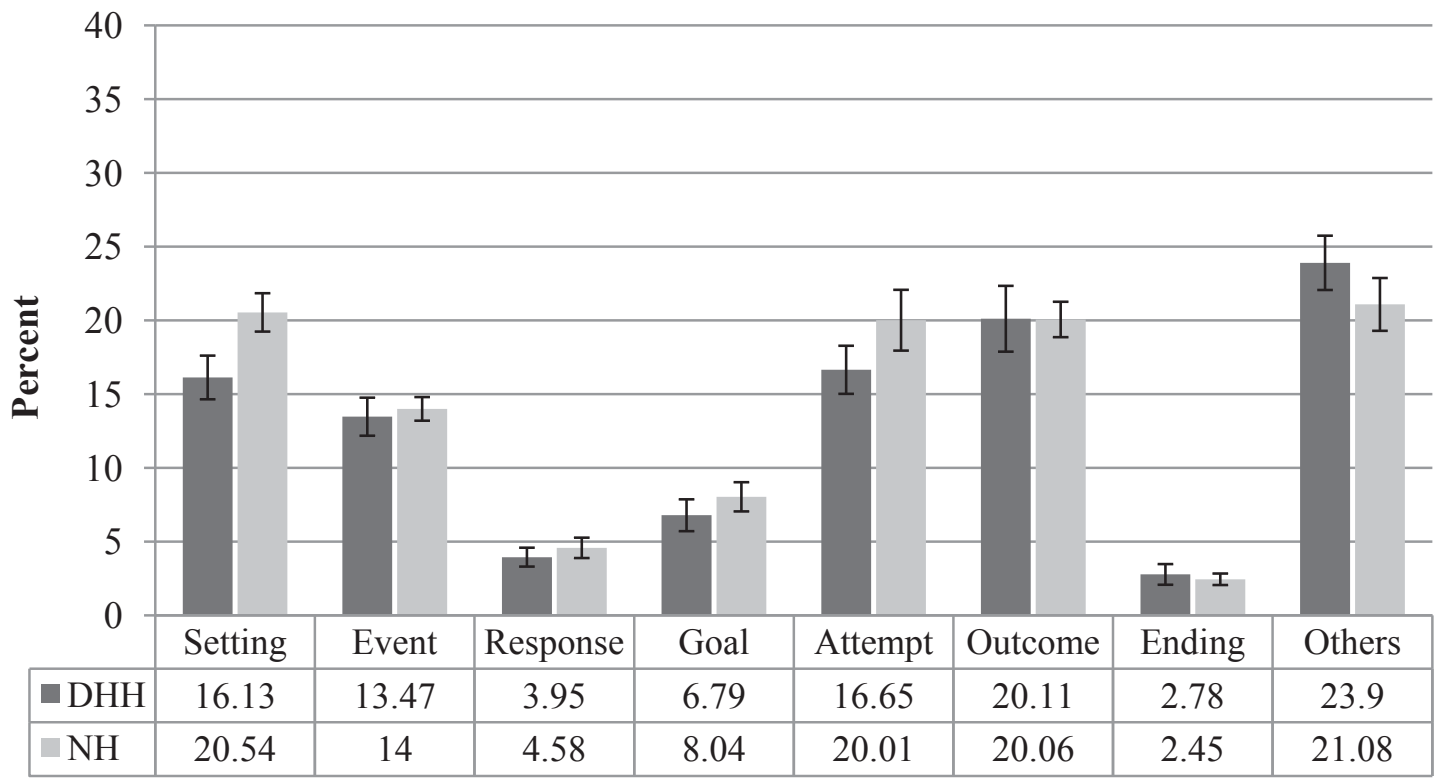

Figure 4-1. Story grammar component results for story retell

* Error bar $=1 S E$

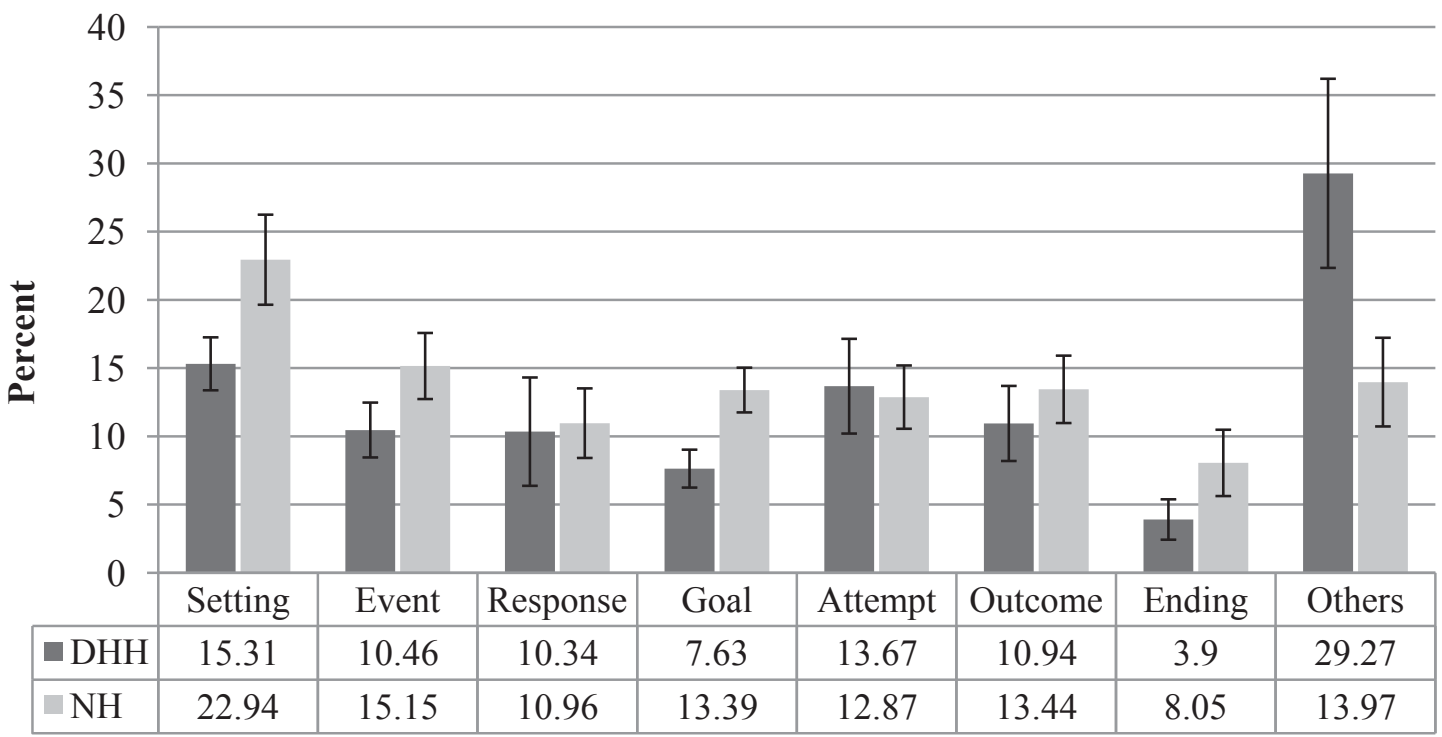

Figure 4-2. Story grammar component results for story generation

*Error bar $=1 S E$ 


\section{Episode Analysis}

Number of Episodes. The number of episodes in the story retell and story generation conditions were counted, and the results for each group are listed in Table 4-3. On average, the DHH group produced slightly fewer episodes than the NH group in the story retell condition, and almost same number in the story generation condition.

However, there was a wide range of scores for both story production conditions. A $2 \times 2$ repeated measures ANOVA revealed that there was no significant difference between the groups, $F(1,19)=.800, p=.382, \eta_{p}{ }^{2}=.040$, but the higher number of episodes in the story retell condition when compared with the story generation condition was significant, $F(1,19)=144.531, p<.0001, \eta_{p}{ }^{2}=.884$. The interaction effect was not significant, $F(1$, 19) $=1.445, p=.244, \eta_{p}^{2}=.071$.

GAO Statements. Statements composed of goals, attempt, or outcomes were compared to the total number of T-Units. The proportion of GAO statements to T-Units was analyzed for both the story retell and story generation tasks. For both story production conditions, the DHH group used a lower proportion of GAO statements compared to the NH group. The performance of both groups is listed in Figure 4-3. Both groups produced more GAO Units in the story retell condition. A 2x2 repeated measures ANOVA for the groups and two story production conditions revealed no group main effect, $F(1,19)=1.278, p=.272, \eta_{p}{ }^{2}=.063$, indicating that a lower performance for the $\mathrm{DHH}$ group compared with the NH group was not significant. For both groups, there was a significantly better performance for the retell condition when compared with story generation, $F(1,19)=4.791, p=.041, \eta_{p}{ }^{2}=.201$. The interaction effect between the groups and story production conditions was not significant, $F(1,19)=.110, p=.744, \eta_{p}{ }^{2}$ $=.006$.

Table 4-3. Mean, SD, and range of number of episodes in story retell and story generation

\begin{tabular}{lllll}
\hline \multicolumn{1}{c}{ Task } & Group & Mean & SD & Range \\
\hline Story Retell & DHH & 6.55 & 1.92 & $2-8$ \\
& $\mathrm{NH}$ & 7.40 & 0.84 & $6-8$ \\
& & & & \\
$\begin{array}{l}\text { Story } \\
\text { Generation }\end{array}$ & $\mathrm{DHH}$ & 2.55 & 1.04 & $0-4$ \\
& $\mathrm{NH}$ & 2.40 & 1.35 & $1-5$ \\
\hline
\end{tabular}




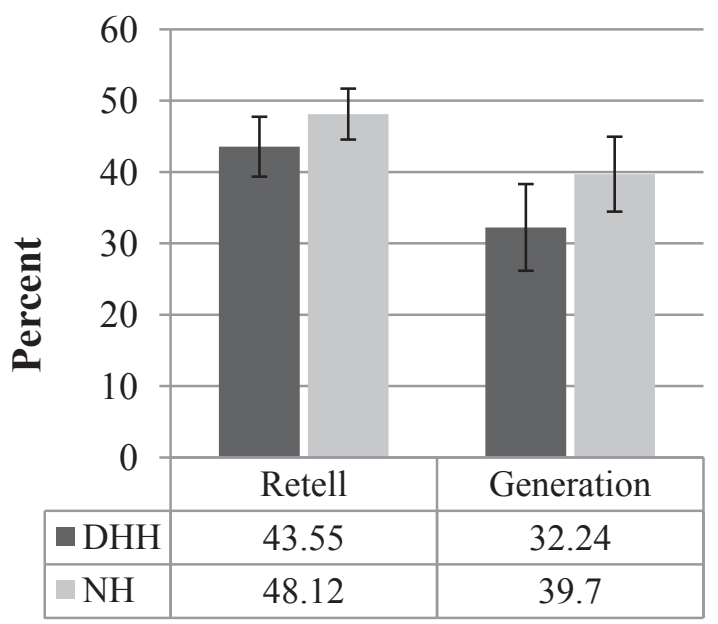

Figure 4-3. GAO Units for story retell and generation

*Error bar $=1 S E$

\section{Hierarchical Goal Structure}

Complete GAO Units. In order to assess how many GAO Units were completely produced in the story retell and story generation conditions, the ratio of complete GAOUnits to the total number of GAO Units was determined. Results are shown in Figure 4-4. The GAO3 score indicates a complete GAO Unit. In other words, the episode includes a Goal, Attempt, and Outcome. An incomplete GAO Unit is scored as GAO2, indicating 2 components or GAO1, indicating one component.

As seen in Figure 4-4, the DHH and NH groups produced a similar proportion of complete and incomplete GAO units with slightly higher number of incomplete GAO Units in the story retell condition. A 2x2 repeated measures ANOVA for group and the complete and incomplete GAO Units (combined GAO2 and GAO1) in the story retell condition revealed no significant difference between groups, $F(1,19)=0.000, p=1.000$, $\eta_{p}{ }^{2}=.000$. However, the higher number of incomplete GAO Units was significant, $F(1$, $19)=60.180, p<.0001, \eta_{p}{ }^{2}=.760$. The interaction effect was not significant, $F(1,19)=$ $0.000, p=.986, \eta_{p}^{2}=.000$.

For the story generation task, the results of a $2 \times 2$ repeated measures ANOVA sho ws no difference between groups, $F(1,19)=.905, p=.353, \eta_{p}{ }^{2}=.045$, or between compl ete and incomplete GAO Units $F(1,19)=1.555, p=.228, \eta_{p}{ }^{2}=.076$. However, the intera ction effect was significant, $F(1,19)=5.208, p=.034, \eta_{p}{ }^{2}=.215$. Pairwise comparisons show that the DHH group produced significantly fewer complete GAO Units than the NH group, $F(1,19)=6.539, p=.019, \eta_{p}{ }^{2}=.256$, whereas there was no difference between $\mathrm{t}$ he group $\mathrm{s}$ in the number of incomplete GAO Unit, $F(1,19)=.511, p=.483, \eta_{p}{ }^{2}=.026$. 


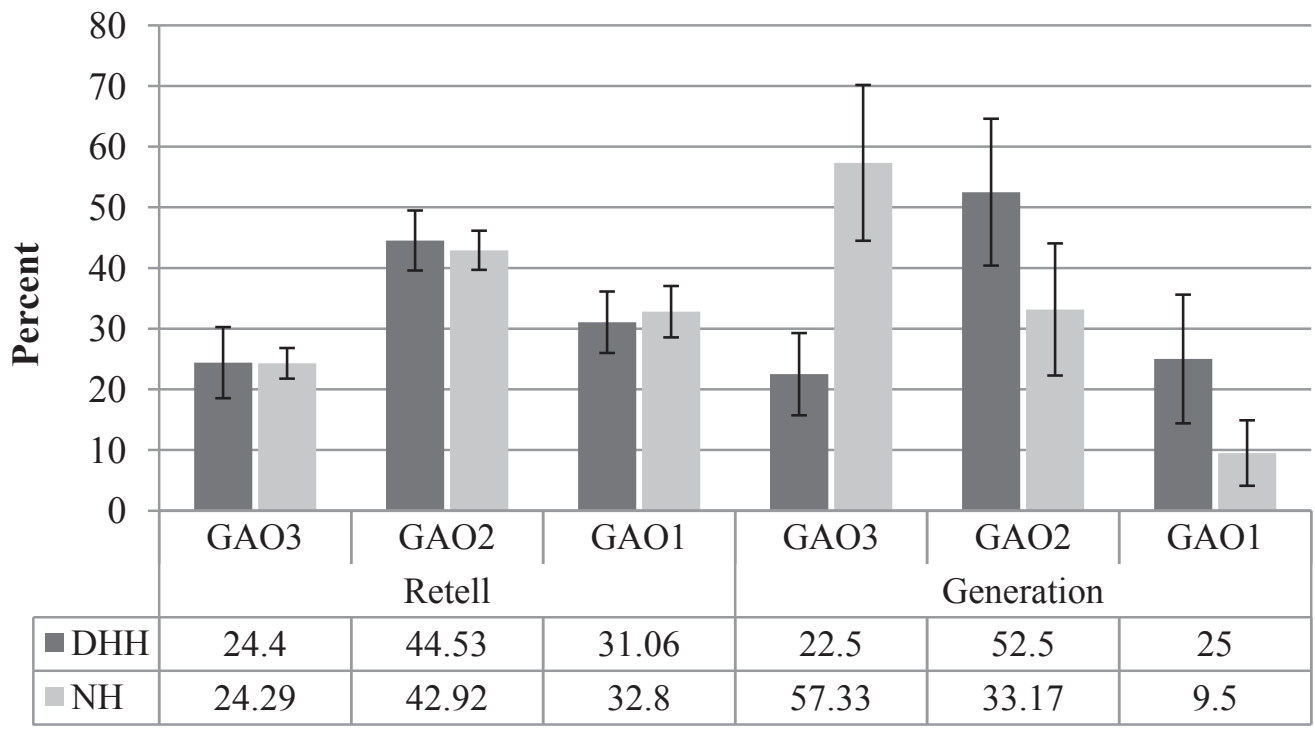

Figure 4-4. Complete and incomplete GAO Units for story retell and story generation

*Error bar $=1 S E$

Hierarchical Goal Plan. The hierarchical goal plans produced in the narratives were analyzed and scores are presented in Figure 4-5. Both groups produced more hierarchical goal plans in the story retell condition than in the story generation condition. In the story generation condition, the DHH group produced fewer hierarchical goal plans than the NH group.

A 2x2 repeated measures ANOVA for group and hierarchical goal plan scores in the two story production conditions revealed no significant difference between groups, $F(1,19)=.856, p=.366, \eta_{p}{ }^{2}=.043$, but a significant main effect for the story production condition, $F(1,19)=74.262, p<.0001, \eta_{p}{ }^{2}=.796$, indicating that both groups produced more hierarchical goal plans in the retelling condition than the generating condition. There was no interaction effect, $F(1,19)=1.479, p=.239, \eta_{p}{ }^{2}=.072$.

\section{Global Coherence}

The cohesive conjunctions used to show the temporal and causal relationships in the story retell and story generation conditions for both groups are presented in Figure 4-6. The $2 \times 2$ repeated measures ANOVA indicates that there was no difference between groups, $F(1,19)=.100, p=.755, \eta_{p}{ }^{2}=.005$, between story production condition, $F(1,19)=.007, p=.932, \eta_{p}{ }^{2}=.000$, or interaction between them, $F(1,19)=.000, p$ $=.993, \eta_{p}^{2}=.000$. 


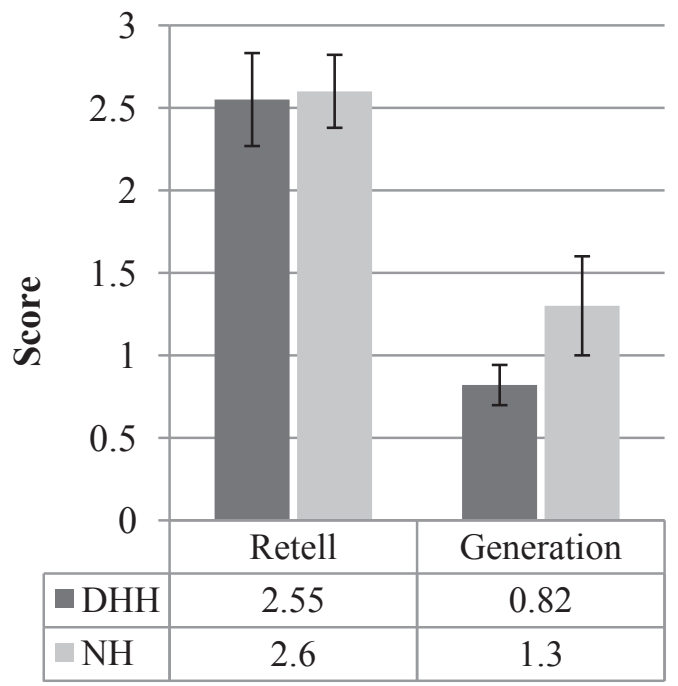

Figure 4-5. Hierarchical goal plan means for the story retell and story generation

* Error bar $=1 S E$

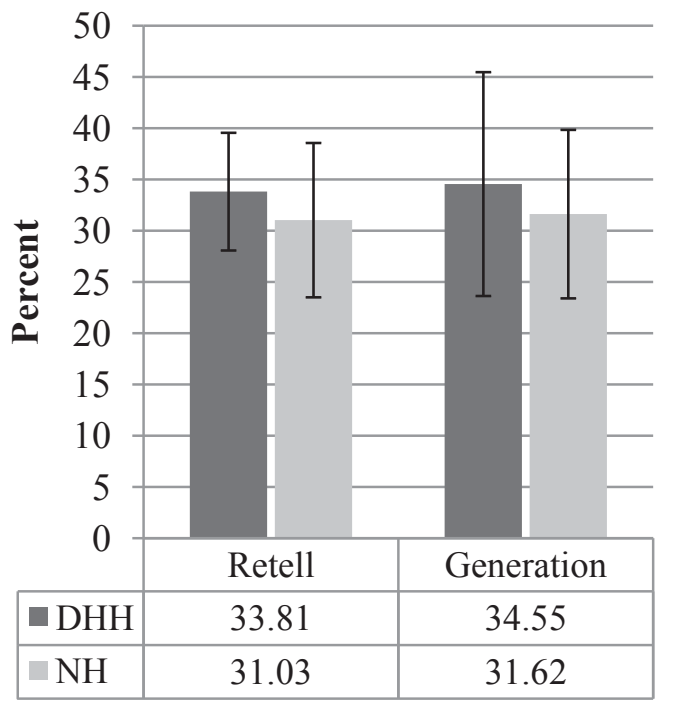

Figure 4-6. Cohesive conjunctions used in story retell and story generation

* Error bar $=1 S E$ 


\section{Executive Functions}

\section{BRIEF Results}

The total index (GEC), two subtotal indices (BRI and MI), and the 8 subtests are presented in Figures 4-7 and 4-8. The DHH group received higher scores than the NH group for all subtotal indices as well as the total index. However, a one way ANOVA with GEC revealed that there was no significant difference in the total index between groups, $F(1,19)=3.991, p=.60, \eta_{p}{ }^{2}=.174$.

A 2x2 ANOVA with group and the two subtotal indices revealed a main effect for group, $F(1,19)=4.519, p=.047, \eta_{p}{ }^{2}=.192$, but no main effect for the type of indices, $F(1,19)=.332, p=.571, \eta_{p}{ }^{2}=.017$, and no interaction effect, $F(1,19)=.233 p=.635$, $\eta_{p}{ }^{2}=.012$, which indicated that the DHH group had more behavior problems than the NH group did.

The MANOVA with the 8 scales also revealed a significant difference between groups, $F(8,12)=3.341, p=.027, \eta_{p}{ }^{2}=.696$. A univariate test indicated a significant difference in the categories 'Initiate', $F(1,19)=5.175, p=.035, \eta_{p}{ }^{2}=214$, 'Plan/Organize', $F(1,19)=14.928, \mathrm{p}=.001, \eta_{p}{ }^{2}=.440$, and 'Monitor', $F(1,19)=6.438$, $p=.020, \eta_{p}{ }^{2}=.253$, which indicating that the DHH group had more problem in these scales.
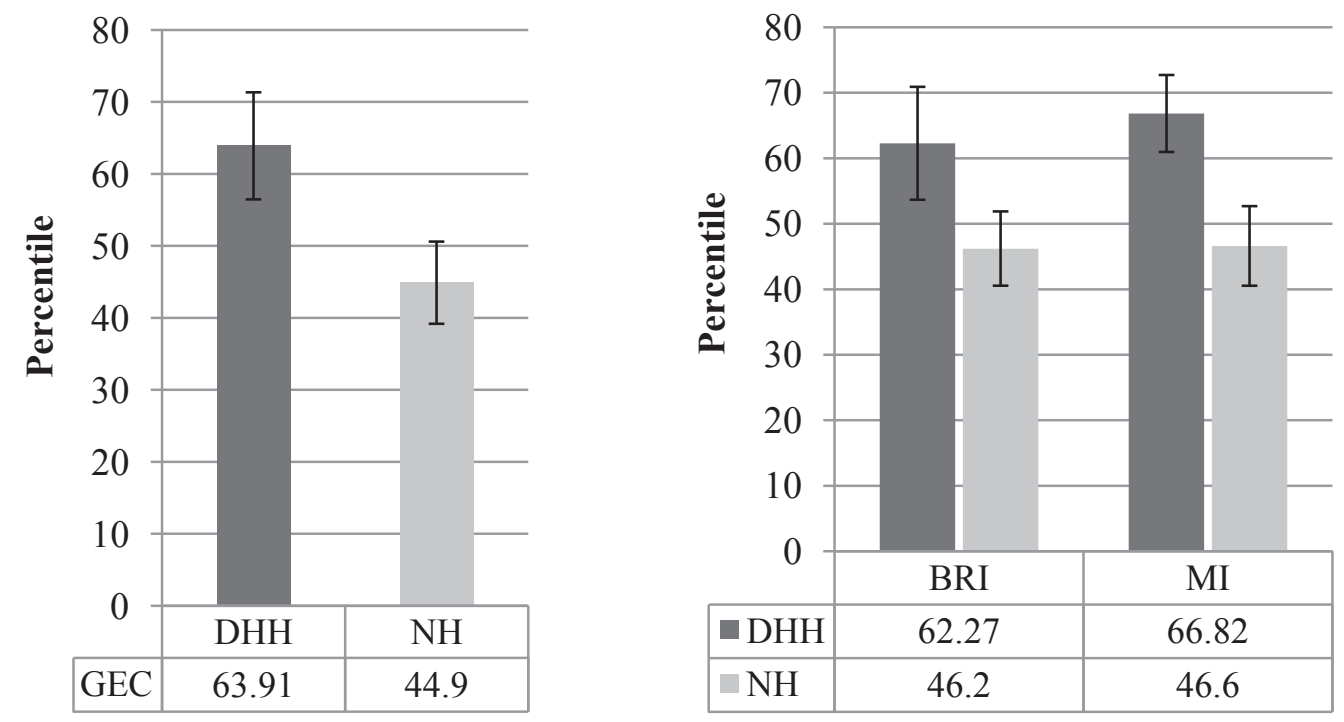

Figure 4-7. The mean percentile scores for GEC, BRI, and MI of the BRIEF

*Error bar $=1 S E$ 


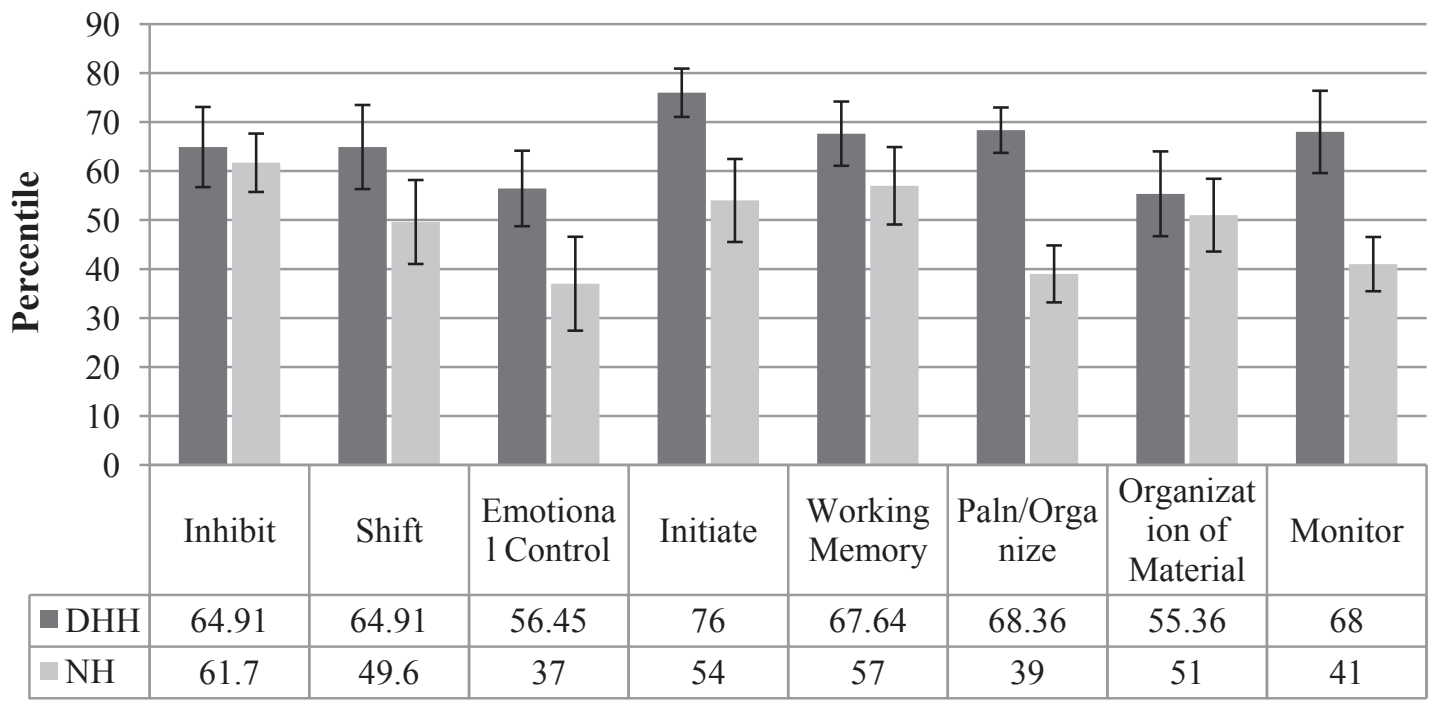

Figure 4-8. The mean percentile scores for GEC, BRI, MI, and the subtests of the BRIEF

*Error bar $=1 S E$

\section{Digit Span Tests}

The DHH group received lower scores than the NH group in the digit span subtests as well as on the total score. However, a one way ANOVA with the total score revealed no difference between the groups on the total score, $F(1,19)=2.791, p=.111$, $\eta_{p}{ }^{2}=.128$. A $2 \times 2$ ANOVA with group and the two subtests (DSF and DSB) also revealed no group main effect, $F(1,19)=1.798, p=.196, \eta_{p}{ }^{2}=.086$, but a significant main effect on the type of subtest, $F(1,19)=4.856, p=.040, \eta_{p}{ }^{2}=.204$. The scores on this test were presented in Figure 4-9.

\section{DKEFS}

Tail Making Test. The mean standard score for completion time on the Trail Making test is presented in Figure 4-10. The DHH group required more time to complete the task. Thus, they received lower scores than the NH group although their mean was still within the -1SD of normative sample $(M=10, S D=3)$. However, a one way ANOVA revealed that there was no significant difference in carrying out this task between the groups, $F(1,19)=.486, p=.494, \eta_{p}{ }^{2}=.025$. 

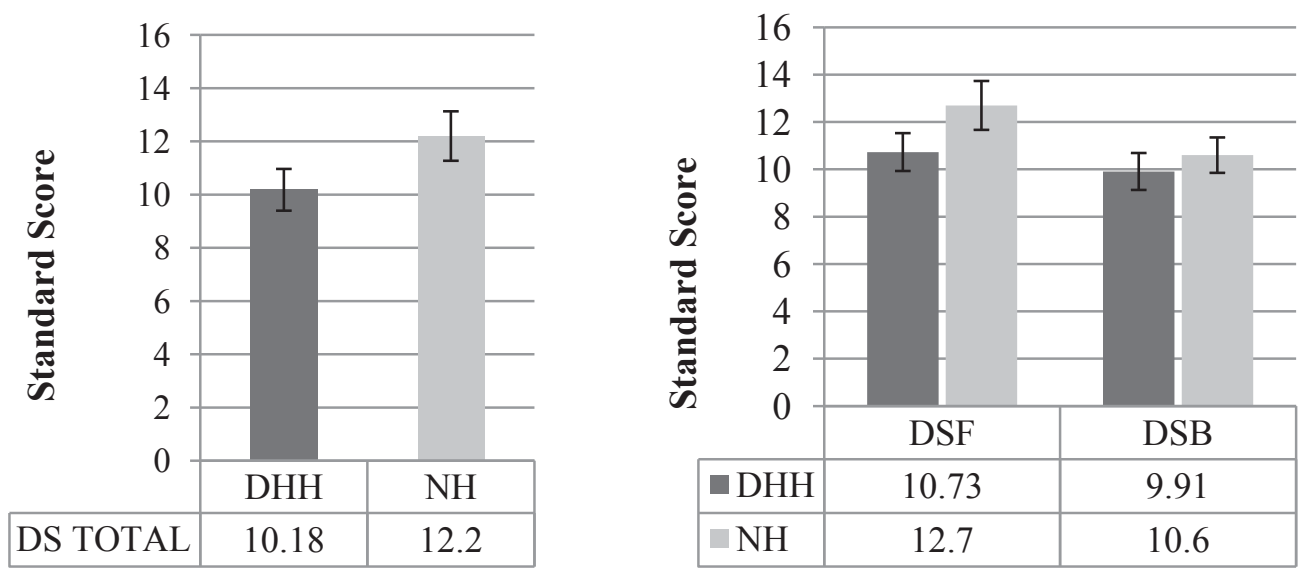

Figure 4-9. Mean standard scores for DS total, and DSF and DSB score

* Error bar $=1 S E$

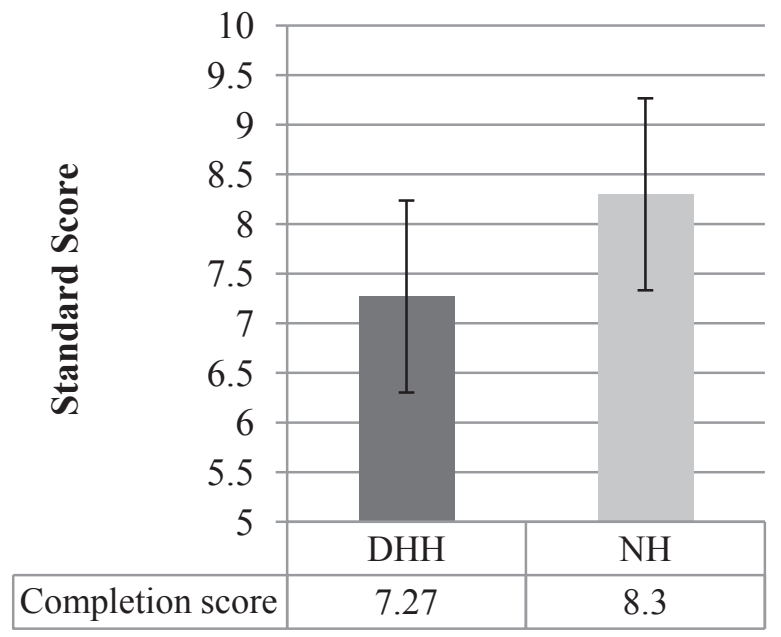

Figure 4-10. The mean standard scores for Trail Making completion time

* Error bar $=1 S E$ 
Card Sorting Test. The mean standard scores for Card Sorting, the Sorting Description combined score, and the Sorting Description contrast score are presented in Figure 4-11. The DHH group scored lower than the NH group on all three scores, especially in Sorting Description Combined score, which was below -1SD of normative sample $(M=10, S D=3)$.

The repeated measures $2 \times 3$ ANOVA for group and the three sorting scores from two tasks revealed a main effect for group, $F(1,19)=12.614, p=.002, \eta_{p}{ }^{2}=.399$, but no main effect for sorting scores, $F(2,18)=.989, p=.391, \eta_{p}{ }^{2}=.099$, indicating that the $\mathrm{DHH}$ group performed lower than the $\mathrm{NH}$ group, and the type of task did not impact on the performance. A significant interaction also had an effect, $F(2,18)=8.051, p=.003$, $\eta_{p}{ }^{2}=.472$. Post hoc analysis with a Bonferroni adjustment indicated that the DHH group scored significantly lower on the Sorting Description combined score, $F(1,19)=16.011$, $p=.001, \eta_{p}{ }^{2}=.457$, but not significantly different on the Sorting task, $F(1,19)=3.316, p$ $=.093, \eta_{p}{ }^{2}=.142$, and on the Description Contrast score, $F(1,19)=1.477, p=.239, \eta_{p}{ }^{2}$ $=.072$, indicating that the $\mathrm{DHH}$ group had more problems in description of sorting rules.

An analysis of covariance of Description Combined score with CELF-IV score as a covariate still revealed the group difference was significant, $\mathrm{F}(1,19)=5.808, \mathrm{p}=.027$, $\eta_{p}{ }^{2}=.244$, indicating that the group difference on this task were independent from the difference of their language competence.

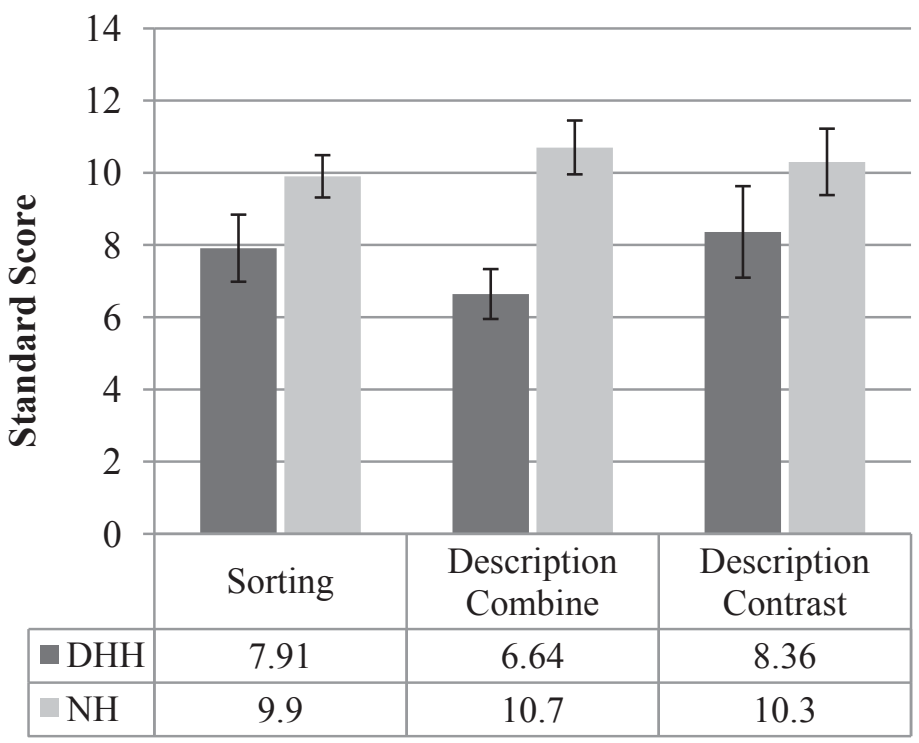

Figure 4-11. Mean standard scores for the card sorting, sorting description combined, and sorting description contrast scores of the DKEFS

* Error bar $=1 S E$ 
Tower Test. The mean standard scores for the achievement and rule violation tasks of the DKEFS Tower test are presented in Figure 4-12. The $2 \times 2$ repeated measures ANOVA revealed no main effect for group, $F(1,19)=.047, p=.831, \eta_{p}{ }^{2}=.002$, for task, $\mathrm{F}(1,19)=.006, \mathrm{p}=.937, \eta_{p}{ }^{2}=0$, and no interaction effect, $F(1,19)=1.063, p=.315, \eta_{p}{ }^{2}$ $=.053$, indicating that there was no difference between the groups in performing the tasks. In fact, all but two participants in each group obtained full scores for rule violation indicating no problems in following the rules for the Tower test.

\section{Correlations}

\section{Relations between the CELF-IV and Narrative Microstructure Analysis}

A correlation analysis was conducted using the standard score from the Core Language subtest of CELF-IV and the microstructure analysis scores for narratives, the number of T-Units, MLUm, NDW, TTR, SI, and Grammar Errors. The correlation coefficients for the DHH and the NH group were listed in Table 4-4.

For the DHH group, the Core Language scores were positively related to the MLUm and the NDW scores and negatively related to Grammar Errors. The number of TUnits and MLUm were related to the NDW. The SI was associated with the MLUm. Grammar errors were negatively related to the MLUm.

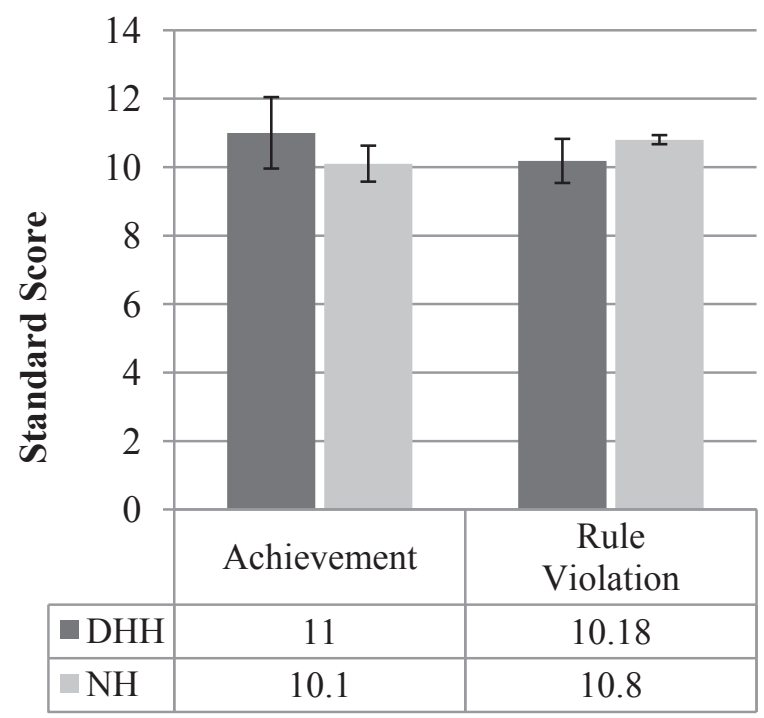

Figure 4-12. Mean standard scores for the achievement, and rule violation tasks of the DKEFS TOWER test

*Error bar $=1 S E$ 
Table 4-4. Correlation coefficients for CELF-IV standard scores and microstructure analysis with the DHH and NH group

\begin{tabular}{lllllllc}
\hline Group & Index & T-Units & MLUm & NDW & TTR & SI & $\begin{array}{c}\text { Grammar } \\
\text { Errors }\end{array}$ \\
\hline DHH & CELF-IV & .386 & $.807^{* *}$ & $.671^{*}$ & -.470 & .360 & $-.780^{*}$ \\
& T-Units & & .374 & $.871^{* *}$ & $-.824^{* *}$ & .033 & -.249 \\
& MLUm & & & $.649^{* *}$ & -.584 & $.715^{*}$ & $-.673^{*}$ \\
& NDW & & & & $-.716^{*}$ & .354 & -.480 \\
& TTR & & & & & -.068 & .501 \\
& SI & & & & & & -.174 \\
& & & & & & & \\
NH & CELF-IV & .431 & -.093 & .169 & -.077 & $-.700^{*}$ & -.335 \\
& T-Units & & -.331 & $.762^{*}$ & -.565 & -.300 & .263 \\
& MLUm & & & -.004 & -.053 & .547 & -.278 \\
& NDW & & & & -.301 & .237 & .252 \\
& TTR & & & & & -.119 & -.209 \\
& SI & & & & & & .181 \\
\hline
\end{tabular}

${ }^{*} p<.05,{ }^{* *} p<.01$ 
For the NH group, the Core Language scores were not related to any narrative microstructure analysis categories except for the SI, which had negatively relation. In this group, the only other association between the microstructure narrative categories was a positive relation between the NDW and the number of T-Units.

\section{Relations between Narrative Structure and Language Ability}

In order to see the relations between language ability and narrative structure, a correlation analysis was run with the CELF-IV, microstructure indices, and the macrostructure indices of GAO Units and complete GAO Units. The correlation coefficients for story retell and story generation with the DHH and $\mathrm{NH}$ groups are provided in Table 4-5. For the DHH group, in story retell, no language abilities were related to the production of GAO Units and all of the language ability indices except the SI were strongly associated with complete GAO Units. However, in story generation, there was no association between language abilities and narrative structures. For the NH group, in story retell, only the NDW was positively associated with complete GAO Units. T-Units also showed a moderate magnitude of correlation in relation with the complete GAO Units but did not reach the significant level $(p=.075)$. In story generation, only the CELF-IV score was negatively related to complete GAO Units.

\section{Relations between Narrative Structure and EFs}

BRIEF Results. In order to examine the relationship between narrative structure and EFs, a correlation analysis was run with the GAO Units, complete GAO Units, and the BRIEF scales. The correlation coefficients for story retell and story generation with the DHH and NH group were listed in Table 4-6. In story retell, for the DHH group, none of BRIEF scales were related to narrative structures. However, in story generation, the Metacognition Index was associated with the production of GAO Units. Of the subscales in the Metacognitive Index, Working Memory and Organization of Materials were significant factors. The Initiate scale was marginally significant $(r=-.588, p=.057)$.

For the NH group, no relationship was found between narrative structure and the BRIEF scales. The relation between Inhibit and the GAO Units was not addressed in the analysis because it has been reported that for this assessment the individual item relative to the higher scales has low reliability (Gioia, Isquith, Guy, \& Kenworthy, 2000).

DKEFS and Digit Span Results. The same correlation analysis was conducted with narrative structure and the performance based tests, DKEFS subtests and Digit Span test. The Description Contrast and Tower Rule Violation scores were excluded in the correlation analysis because there was so little variability in the performance of both groups. The correlation coefficients for story retell and story generation for the DHH and NH group are presented in Table 4-7. 
Table 4-5. Correlation coefficients between language and narrative structures for story retell and story generation with the DHH and NH group

\begin{tabular}{|c|c|c|c|c|c|}
\hline \multirow[t]{2}{*}{ Group } & \multirow{2}{*}{$\begin{array}{l}\text { Language } \\
\text { Index }\end{array}$} & \multicolumn{2}{|c|}{ Story Retell } & \multicolumn{2}{|c|}{ Story Generation } \\
\hline & & GAO Units & $\begin{array}{c}\text { Complete } \\
\text { GAO Units }\end{array}$ & GAO Units & $\begin{array}{l}\text { Complete } \\
\text { GAO Units }\end{array}$ \\
\hline \multirow[t]{7}{*}{$\mathrm{DHH}$} & CELF-IV & .297 & $.710^{*}$ & -.048 & -.159 \\
\hline & T-Units & .190 & $.674^{*}$ & -.235 & .009 \\
\hline & MLUm & .446 & $.711^{*}$ & .274 & -.005 \\
\hline & NDW & .256 & $.732^{*}$ & -.235 & -.098 \\
\hline & TTR & -.515 & $-.680^{*}$ & -.216 & -.257 \\
\hline & SI & .169 & .246 & .168 & -.288 \\
\hline & $\begin{array}{l}\text { Grammar } \\
\text { Errors }\end{array}$ & -.540 & $-.669^{*}$ & -.445 & -.536 \\
\hline \multirow[t]{7}{*}{ NH } & CELF-IV & -.118 & .130 & -.002 & $-.792^{* *}$ \\
\hline & T-Units & -.061 & .587 & -.004 & .031 \\
\hline & MLUm & -.613 & -.368 & .615 & -.007 \\
\hline & NDW & -.026 & $.770^{*}$ & .174 & .118 \\
\hline & TTR & .152 & -.234 & -.099 & -.315 \\
\hline & SI & -.039 & .113 & .323 & .551 \\
\hline & $\begin{array}{l}\text { Grammar } \\
\text { Errors }\end{array}$ & -.165 & .174 & .204 & .329 \\
\hline
\end{tabular}

${ }^{*} p<.05, \stackrel{* *}{p}<.01$ 
Table 4-6. Correlation coefficients between narrative structures and the BRIEF for story retell and story generation with the DHH and NH group

\begin{tabular}{|c|c|c|c|c|c|}
\hline \multirow[t]{2}{*}{ Group } & \multirow[t]{2}{*}{ BRIEF Index } & \multicolumn{2}{|c|}{ Story Retell } & \multicolumn{2}{|c|}{ Story Generation } \\
\hline & & GAO Units & $\begin{array}{c}\text { Complete } \\
\text { GAO Units } \\
\end{array}$ & $\begin{array}{l}\text { GAO } \\
\text { Units } \\
\end{array}$ & $\begin{array}{c}\text { Complete } \\
\text { GAO Units }\end{array}$ \\
\hline \multirow[t]{10}{*}{$\mathrm{DHH}$} & BRI & .068 & .335 & -.371 & -.006 \\
\hline & Inhibit & .043 & .397 & -.477 & -.077 \\
\hline & Shift & .365 & .350 & -.037 & -.013 \\
\hline & Emotional Control & -.226 & .006 & -.345 & .075 \\
\hline & MI & -.268 & .332 & $-.741^{* *}$ & -.431 \\
\hline & Initiate & -.193 & .478 & -.588 & -.292 \\
\hline & Working Memory & -.118 & .006 & $-.715^{*}$ & -.536 \\
\hline & Plan/Organization & .033 & .336 & -.543 & -.489 \\
\hline & Organization Mat. & -.310 & .480 & $-.614^{*}$ & -.400 \\
\hline & Monitor & -.211 & .340 & -.433 & -.018 \\
\hline \multirow[t]{10}{*}{$\mathrm{NH}$} & BRI & .453 & -.027 & .043 & -.422 \\
\hline & Inhibit & $.681^{*}$ & .213 & -.301 & -.059 \\
\hline & Shift & .188 & -.342 & -.010 & -.272 \\
\hline & Emotional Control & .155 & -.042 & .149 & -.291 \\
\hline & MI & -.157 & .227 & .071 & .271 \\
\hline & Initiate & .242 & .200 & -.043 & .057 \\
\hline & Working Memory & -.505 & .116 & -.001 & .255 \\
\hline & Plan/Organization & -.265 & .223 & .308 & .521 \\
\hline & Organization Mat. & -.272 & .124 & .406 & -.016 \\
\hline & Monitor & .114 & -.063 & -.351 & -.474 \\
\hline
\end{tabular}

${ }^{*} p<.05,{ }^{* *} p<.01$ 
Table 4-7. Correlation coefficients between narrative structure and the DKEFS for story retell and story generation with the DHH and NH group

\begin{tabular}{|c|c|c|c|c|c|c|}
\hline \multirow[t]{2}{*}{ Group } & \multirow[t]{2}{*}{ Test } & \multirow[t]{2}{*}{ Task } & \multicolumn{2}{|c|}{ Story Retell } & \multicolumn{2}{|c|}{ Story Generation } \\
\hline & & & $\begin{array}{l}\text { GAO } \\
\text { Units }\end{array}$ & $\begin{array}{l}\text { Complete } \\
\text { GAO Units }\end{array}$ & $\begin{array}{l}\text { GAO } \\
\text { Units }\end{array}$ & $\begin{array}{l}\text { Complete } \\
\text { GAO Units }\end{array}$ \\
\hline \multirow[t]{6}{*}{ DHH } & Digit & DSF & -.438 & .292 & -.274 & -.397 \\
\hline & Span & DSB & -.332 & .114 & -.079 & -.136 \\
\hline & $\begin{array}{l}\text { Trail } \\
\text { Making }\end{array}$ & $\begin{array}{l}\text { Completion } \\
\text { Time }\end{array}$ & .227 & .134 & -.153 & -.078 \\
\hline & \multirow{2}{*}{$\begin{array}{l}\text { Card } \\
\text { Sorting }\end{array}$} & Sorting & -.234 & .384 & -.055 & .175 \\
\hline & & $\begin{array}{l}\text { Description } \\
\text { Combined }\end{array}$ & -.080 & $.650^{*}$ & -.518 & -.094 \\
\hline & TOWER & Achievement & -.528 & .115 & -.280 & -.600 \\
\hline \multirow[t]{6}{*}{ NH } & Digit & DSF & $.662^{*}$ & .432 & -.130 & -.358 \\
\hline & Span & DSB & .514 & .253 & -.555 & -.483 \\
\hline & $\begin{array}{l}\text { Trail } \\
\text { Making }\end{array}$ & $\begin{array}{l}\text { Completion } \\
\text { Time }\end{array}$ & -.431 & -.131 & .075 & -.008 \\
\hline & \multirow{2}{*}{$\begin{array}{l}\text { Card } \\
\text { Sorting }\end{array}$} & Sorting & $.667^{*}$ & .205 & -.551 & -.068 \\
\hline & & $\begin{array}{l}\text { Description } \\
\text { Combined }\end{array}$ & $.636^{*}$ & .096 & -.573 & -.063 \\
\hline & TOWER & Achievement & -.038 & -.099 & .017 & .575 \\
\hline
\end{tabular}


For the DHH group, in story retell, the Card Sorting Description combined score was associated with Complete GAO Units. In story generation, no EFs measures were related with narrative structure.

For the NH group, in story retell, Digit Span Forward, Correct Sorting and the Sorting Description Combined scores of the Card Sorting test were associated with GAO Units production. However, in story generation, no correlations were found between narrative structure and EFs measurements. 


\section{CHAPTER 5. DISCUSSION}

This study investigated the language skills, narrative productions, EFs, and their relations among children who are $\mathrm{DHH}$ and a $\mathrm{NH}$ control group. To extend the research on this topic, two different research questions were developed. These questions were: 1) "Is there a significant difference between children who are DHH and use oral communication and children with NH on tests of language, narrative structure, and EFs?", and; 2) "Are language ability, oral narrative production and EFs related for children who are DHH and use oral communication and children with NH?"

For the first question, based upon previous studies, it was hypothesized that children who are DHH and use oral communication would have overall lower standardized language and EFs test scores when compared with NH peers. Differences between the groups were also expected to include the language used in narrative productions as well as the organization of narrative structures. However, the participants who are DHH with a hearing age of more than five years were expected to be able to produce some complete episodes based on a recent study by Huttumen (2008). Wide individual differences in the DHH group were also anticipated based on previous studies.

As a result of language testing, the DHH group obtained significantly lower scores on the CELF-IV than their NH peers. The average for the DHH group was close to the standard mean, however the total score was lower than the NH group, and there were wide individual differences. This was anticipated as this result is commonly reported in the literature investigating the language skills of children who are DHH (Conway \& Pisoni 2008; Fagan, Pisoni, Horn, \& Dillon. 2007; Geers \& Sedey, 2011; Harris, Kronenberger, Gao, Hoen, Miyamoto, \& Pisoni, 2012). The individual scores on the core language subtest showed that all participants with exception of two in the DHH group scored within the normal range on the receptive and expressive language subtests at the word and sentence level. The participants who are DHH in the current study had been identified with hearing loss between birth and 3 years 2 months of age. Their hearing ages were between 5;10 and 11 years with one exception. The excepted participant has a moderate hearing loss bilaterally and was identified at the age of 5, and, at the time of testing had 4 years 10 months of hearing experience. All participants used digital HAs or

CIs, communicated orally, and were educated in mainstreamed classrooms. Geers and her colleagues reported that early identification, an emphasis on speech and auditory skills, and long experience in mainstream educational settings contributed to improved language competence (Geers, Nicholas, \& Sedey, 2003; Geers \& Sedey, 2011). Thus, these factors were likely to contribute to the generally typical levels of language competence for the participants in the DHH group in the current study.

Unlike the standardized test results, scores from the microstructure analysis showed that language competence was comparable for both groups for story production at a discourse level. On the microstructure indices, which include story length, measured by the number of utterances (number of T-Units), mean length of utterance (MLUm), number of different words (NDW), type token ratio (TTR), simple and complex 
sentences used in the narratives (SI), and the ratio of grammar errors to total number of different words, the DHH group performed similarly to the NH group except in the area of grammar errors.

The performance by both groups on the NDW and MLUm were within the normal mean as estimated from the scores of 250 children between the ages of 9 and 11 years (Justice, Bowles, Kaderavek, Ukrainetz, Eisenberg, \& Gillam, 2006). The mean score for these children was between 79 and 101 for NDW, and between 9.4 and 10.0 for MLUm. Results from this study show that the DHH group was able to use their vocabulary and syntactic knowledge to convey the contents of each narrative at a discourse level as well as their NH peers. The scores also indicate that the DHH group in the current study had overall age appropriate language competence at the word, sentence and discourse levels based upon the narrative production microstructure analysis scores

However, on the Grammar Error index, the DHH group performed significantly lower than the NH group. The individual data showed that they made errors mainly in the use of tense, third person, in the omission or misuse of articles and the relative pronouns who, which, and that, and sometimes in the omission of auxiliaries. Grammar errors made by the NH group were rare and their errors were mostly in tense and a rare occurrence of the misuse of articles. When the two participants in the DHH group who scored below -1 SD from the mean on the standardized language test were excluded from the analysis, the DHH group still had significantly more grammar errors than the NH group. Difficulty in acquiring grammatical morphemes has been reported as one of the featured problems in the DHH population even in long CIs users (Geers Nicholas, \& Sedey, 2003). Recently, Geers, Nicholas, \& Sedey (2003) reported on bound morpheme problems with 8 to 9 year old children using CIs in spite of the fact that more than half of 181 subjects in their study had language scores including utterance length, lexical diversity, and oral narrative ability within the average range of their normal hearing peers. Taken together, the outcome of Grammar Errors showed that, for children who are DHH, the use of grammatical morphemes at a discourse level may be the most difficult area of language to acquire appropriately for their age even though children in the DHH group had relatively typical language competence. Thus, grammatical morpheme knowledge and use should be carefully tracked for school-aged children who are DHH and interventions initiated as needed.

Based on previous studies examining narrative structure, the DHH group was expected to produce some complete episodes but still not perform as well as the NH group. For this reason, the narrative structure analysis results were unanticipated. For the DHH group, performance on narrative organization depended on the narrative production condition and the analysis method. When the narrative macrostructures were analyzed using story grammar components, the $\mathrm{DHH}$ group performance was similar to the $\mathrm{NH}$ group for the proportion of story grammar components in the story retell condition. However, the DHH group produced significantly somewhat less information than their $\mathrm{NH}$ peers in the story generation condition. This result indicates that the DHH group had knowledge of story grammar, and was able to use their knowledge to organize a narrative in the story retell condition. However, their understanding of story grammar may not be 
as stable as it was for the NH group.

More in depth investigation of the story grammar components produced by the DHH group in the story retell condition showed that they produced proportionately less information in the Setting and Attempt categories than the NH group. Even though the group differences were not significant, the $\mathrm{p}$-value was close to the significant level ( $p$ $=.057)$ with a considerable effect size $\left(\eta_{p}{ }^{2}=.178\right)$. In the story generation condition, the DHH group produced less information in more story grammar components such as the Setting, Event, Goal, and Ending categories when compared with their NH peers.

The smaller proportion of Setting components for DHH group indicates that they omitted information about a protagonist or other characters, or the time or place of the narrative. If it was not missed entirely, their use of the component was not as abundant as the NH group. The smaller proportion of Goal components used by the DHH group in story generation shows that they provided less information regarding a protagonist's plan or intention. In a narrative, the goal is motivated from the response to an initial event, and it prompts actions to achieve it. If a goal is omitted, the event or its outcome is not able to be causally related to a whole story or other episodes. The DHH group also produced a proportionately smaller number of Events (especially in story generation) or Attempts (in story retell), which are related to the goal. This outcome indicates that they may have problems in comprehending and/or producing the logical relationships between characters, events, and episodes, and missed some information. It also indicates that their internal story structure regarding temporal and causal relationships may not as stable as that of the NH group (Coelho, 2002). Although the DHH group scored very near their NH peers in language ability as measured through the narrative microstructure analysis, the lack of some story grammar components suggests that they had problems in organizing narrative structures.

The fact that the DHH group produced a larger proportion of the Others category then the NH group in story generation also suggests that their narratives were logically weak. The Others category involves actions or behaviors by other characters, not the protagonist. It also includes events that are not related to a theme of a narrative, or conversations between characters to describe something in detail the participants had already described. Thus, the utterances coded in the Others category were regarded as being only indirectly related to a narrative's main plot. For example, in the story "Frog Where Are You? " there were several minor characters including a dog, bees, a gopher, an owl, and a deer, who participated in some events with or without relation with the boy who was the protagonist. All utterances regarding them without relation with the boy were coded as Others. Thus, this category was proportionately relatively large in both groups in the story retell condition. However, in story generation, this category was coded according to the theme the participants provided in their narratives. The DHH group produced $29 \%$, and the NH group produced $13 \%$ of utterances coded in the Others category. Although the difference between groups was not significant $(p=.068)$, the DHH group produced proportionately more utterances unrelated to the main plot of the narrative which made their narratives less focused. 
Furthermore, the DHH group produced a smaller proportion of the narrative component Ending in the story generation task than the NH group. The Ending of a narrative provides a consequence or reaction related to the outcome of the main goal. However, many participants in the DHH group did not provide enough information to adequately describe a detailed consequence of the events or a conclusion when compared to the NH group. This suggests that the DHH group did not understand the whole story scheme as well as the NH group, and as a result had some problems when they had to make up a narrative.

Episodic analysis focuses on episodic units in narratives rather than the whole story scheme composing the narrative. When the narrative structure was analyzed according to number of episodes and GAO Units, there was no difference between the $\mathrm{DHH}$ and $\mathrm{NH}$ groups even though the DHH group produced slightly fewer GAO Units in both narrative conditions, The similar number of episodes across the groups in the story retell condition showed that the participants were able to construct their narratives with as many episodes as necessary when they had picture support. In contrast, for the story generation task, only one picture was used. Thus, the participants needed to create a story plot by themselves. This difference in the elicitation conditions between the narratives could explain why story generation was more difficult than story retell. Longer story lengths and more episodes in story retell than story generation have been reported in the literature investigating narratives in children (Holck, Sandberg, \& Nettelbladt, 2011; Merritt \& Liles, 1987). In addition, as Leinoene, Letts, and Smith (2000) pointed out, the motivation to produce a narrative is likely to affect the length of narrative. In the instructions, the examiner told the participants to make up a story that was as long and complete as they could, however, the story they developed might not have been elaborate enough for them to produce a complete narrative with a plenty of episodes.

To further examine the GAO Units, the number of complete GAO Units compared to the number of episodes was analyzed. The results revealed that even though the groups produced a similar number of episodes, the DHH group produced a considerably lower proportion of complete GAO Units in the story generation condition. The literature has shown that children are able to produce goals and plans to organize narratives by the age of 5 (Trabasso \& Nickels, 1992). By the ages of 10 to 11 years, around $56 \%$ of the episodes in story generation are complete (Hughes, McGillivary, \& Schmidek, 1997; Roth \& Spekman, 1986). The NH group's performance was very similar to the results of other studies provided in the literature. However, the DHH group's performance was lower. Given that both groups of participants produced a similar ratio of complete GAO Units in story retell, the participants who are DHH were assumed to have intrinsic knowledge of complete episodes, but unable to use this knowledge in a story generation condition as well as the $\mathrm{NH}$ group.

The analysis of complete GAO Units showed that, in the story generation task, the DHH group composed more than $50 \%$ of the episodes without one component. This indicates that the participants in the $\mathrm{DHH}$ group did not provide enough information regarding the logical relationships between the protagonist's motivation or purpose, goal directed actions, and the direct consequence. Given that there was no difference in the 
total number of utterances and total number of episodes between the two groups, this indicates that the DHH group had some problems in organizing and presenting episodes. There may be some reasons for this that include immature or less sophisticated narrative production because of limited language experience, or impairments in their ability to integrate linguistic and cognitive information to form and organize episodes.

With regard to the hierarchical goal plan, the participants in both groups showed similar abilities in the construction of narratives. Both groups showed more hierarchical goal plans in the story retell condition than in story generation. In the story generation condition, most of the participants in both groups produced a superordinate goal. However, among all of the study participants, only two of the children in the NH group constructed their narratives with both superordinate and subordinate goals. All of the other participants just laid out several goals in order instead of constructing narratives with a hierarchical goal plan. Thus, it was difficult to analyze the hierarchical goal plan in narratives produced in story generation. This may be because of the picture that was used to elicit the narrative in the story generation condition. The picture depicted two children seeing a spaceship and the aliens coming out. Given the picture, the use of superordinate and subordinate goal plans was not absolutely necessary in order to construct a narrative.

Finally, The DHH and NH groups showed no difference in their use of cohesive devices to express temporal and causal relationship across episodes. Traditionally, children who are DHH have been reported to use fewer cohesive devices in their narratives (Youshinaga-Itano \& Snyder, 1985; Griffith, Ripich, Dastoli, 1990; KlecanAker \& Blondeau, 1990). However, in a recent study with children using CIs, Crosson and Geers (2001) reported that children having more than 4 years of experience with CIs used cohesive devices similar to those of normal hearing children their age. Nine of eleven participants in the current study used hearing aids, but all had more than four years of hearing experience, and all had been educated using oral language. These factors are likely to have helped the participants acquire the language knowledge needed to use cohesive devices properly.

With regard to language and narrative understanding, the DHH group participants showed age appropriate skills in language knowledge at the word, sentence, and discourse level. However, their narrative organization skills were different depending on the narrative production condition. Although the DHH group organized story structures comparable to their NH peers in the story retell task, they had problems in presenting story structures with logical relationships through story generation. In spite of their language and narrative competence shown in story retell, they still showed some of the problems that have been traditionally reported for children who are DHH (Weiss \& Johnson, 1993; Yoshinaga-Itano \& Downey, 1996). The differences in the results on two story production conditions show that the different narrative conditions provide different information about children's narrative skills. In addition, the differences in performance on language and narrative organization skills in the current study supports that weaknesses in narrative skills were independent of the variance accounted for by weak general language skills (Manhardt and Rescorla, 2002). 
On the EFs tests, the DHH group showed mixed outcomes. On the parental report form from the BRIEF, the DHH group scored higher (indicating more problems) than the $\mathrm{NH}$ group, even though their scores were not within the clinically significant range. The DHH group had more behavior problems than the NH group across all of the scales, which is consistent with the previous research (Beer, Kronenberger, \& Pisoni, 2011; Greiner, 2010; Hintermair, 2013; Holt, Beer, Kronenberger, Pisoni, \& Lalonde, 2012; Pisoni, Conway, Kronenberger, Henning, and Anaya, 2010; Rhine, 2002). The analysis with individual scales revealed that the DHH group had significantly more problems than the NH group in the categories Initiate, Plan/Organization, and Monitor. The literature shows differences in the reports of the individual scales for DHH groups so it is difficult to make comparisons. At present, the differences in the participants ages, the duration of their deafness, communication mode, language skills, or educational settings (Hintermair, 2013; Geers \& Sedey, 2011; Kuntson, Ehlers, Wald, \& Tyler, 2000; Remine, Care, \& Brown, 2008) need to be specified and addressed so that future studies can explore trends in behavior.

On the performance-based tests, the DHH group obtained inconsistent outcomes. For the assessment of working memory as measured by Digit Span, the two groups showed no differences. Further, even though the DHH group scored marginally lower than the NH group, their scores on DSF and DSB were at the normative mean of 10. Given the literature reporting that there is a lower working memory span for children who are $\mathrm{DHH}$ even among long-term users of CIs, the age-appropriate performance of the participants in the current study was unexpected (Pisoni \& Geers, 2000; Pisoni \& Cleary, 2003; Pisoni, Kronenberger, Roman, \& Geers, 2011). The participants in the current study were limited to oral communication users, and, for the most part, had age appropriate language competence as tested by a standardized language test. Given that working memory has been reported to have an association with language ability, this may be a reason for finding a difference from previous large scale studies.

On the DKEFS, the DHH group scored above -1SD of the normative sample, and showed, unexpectedly, no difference from the NH group on all of the subtests except the Description Combined score of the Card Sorting test. The Card Sorting task was designed to measure concept formation and reasoning skills as well as initiate problem solving behavior, and combined verbal and nonverbal EFs. Since numerous EFs contribute to this task, it is difficult to ascertain the reason for the lower performance of the DHH group. However, the DHH group's behaviors during testing may provide some clues. One clear difference between the $\mathrm{DHH}$ and $\mathrm{NH}$ groups was that the participants in the DHH group gave up on the sorting task with fewer trials than the NH group, and provided more 2-1 descriptions such as 'two blue and one yellow and two yellow one blue' instead of searching for a sorting rule that applied to all three of the stimulus cards in each group.

The fewer trials on the Card Sorting task and the lower Description Combined scores indicate that the DHH group had relatively ineffective concept-formation and reasoning skills, and that they were less active in initiating problem solving. The low Sorting Description Contrast score resulted more from the lower sorting recognition description score than the free sorting description score. The DHH participants who 
scored lower on the sorting recognition description task usually stuck to a sorting rule that they had previously employed, and could not move to another sorting rule. It showed that they failed to inhibit previous description responses and undertake flexibility of thinking. This result was consistent with the finding by Figueras, Edwards and Langdon (2008) who also described poor performance on the DKEFS Card Sorting test in children who are DHH using CIs and HAs between the ages of 8 and 12 years. In their study, the lower performance of the DHH group was still significant when the language ability was entered into the analysis as a covariate, which was the same result with the current study. This showed that the EFs related to Card Sorting could not be fully explained by language abilities. Geers and Sedey (2011) reported that children who are DHH had weak reasoning skills compared to their own language skills. They found that the difference between the $\mathrm{DHH}$ and $\mathrm{NH}$ groups in reasoning skills between groups was bigger than that found between groups in language skills. In the present study the lower performance on the Card Sorting test by the DHH group, when compared to the NH group, is likely to reflect deficits in some EFs rather than being caused by their marginally lower language abilities.

On the Trail Making Test, although the DHH group required more time to connect numbers and letters than the NH group, the difference did not reach the significant level. This is an interesting result because this test, like the Card Sorting test, is designed to measure cognitive flexibility, differently from the Card Sorting, with the nonverbal task. The differences in the stimuli used in each test as well as cognitive demands for these tasks may explain the difference in outcomes. The Card Sorting task uses stimuli that require an integration of verbal and cognitive ability whereas the Trail Making test uses numbers and words without context. Thus the task with a higher cognitive load, in this case Card Sorting, may be more impacted by deficits in EFs (Beer, Kronenberger, \& Pisoni, 2011).

The DHH group also performed similarly to the NH group on the Tower test on both the achievement score and rule violation score. This indicates that the DHH group performed as well as the NH group on spatial planning and inhibition which are nonverbal EFs. The literature has reported inconsistent outcomes on this task. The performance within normative range in the current study may reflect the subjects' age and the characteristics of the stimuli. Das and Ojile (1995) found that children who are DHH had an advantage in the nonverbal successive task, but were disadvantaged in the verbal tasks at the age of 10 . Seven of the 11 DHH participants in this study were at or under 10 years of age, so they may still show an advantage in the nonverbal planning task, and, as a result, performed as well as their NH peers.

Outcomes from both the parent questionnaires and the performance-based tests show that the DHH group had some difficulties in EFs while the NH group performed within the normal range across all tests. The areas where the DHH group had difficulties include Initiating, Plan/Organizing, Monitor, Working Memory, Cognitive Flexibility, and Concept Formation. The results from the performance-based measures were inconsistent across the tests. It may be that this reflects the properties of the tests that were used. The $\mathrm{DHH}$ group performed at distinctly lower levels on the verbal tasks while no difference 
was found on the nonverbal tests. This result indicates that the participants who are DHH and use oral communication might show different profiles for EFs depending on whether they are assessed using verbal or nonverbal tasks (Remine, Care, \& Brown, 2008).

The second research question was designed to explore the relations between standardized language scores, narrative production and EF. First, it was anticipated that the language used in narrative productions would reflect scores from language standardized testing. This was expected because good narratives are constructed on the basis of appropriate vocabulary and syntactic knowledge. However, as a result of this study, the associations between the language used in narrative production and language standardized testing were different for the two subject groups. The CELF-IV score was sensitive to the language used in narratives in terms of utterance length, variety of word use, and grammatical accuracy in the DHH group. In contrast, it was not related to most of the microstructure scales for the NH group. It is most likely that this result is an artifact of the lack of variability within the NH group. The NH group had only 10 subjects who scored so consistently high on most measures that the lack of correlations is not surprising.

One unexpected outcome from this analysis was the dissociation of the CELF-IV and SI in the DHH group and the negative relation in the NH group. Bothe groups SI scores were around 1.2 which were lower than the mean (1.5) SI at age of 10 years reported in literature (Scott, 1989). Considering the demonstrated language abilities of the participants in the NH group, this outcome suggests that in the case of children with or without hearing loss at or above 9 years of age who have age-appropriate language abilities, the frequency of complex sentence use in narrative production may be influenced by factors like situation and audience other than their language abilities as measured at word and sentence level (Nippold, 2005; Scott, 2005). Among the microstructure indices, the SI had a relatively strong relation with MLUm in the DHH group and a moderate relation with MLUm in the NH group, but the association in the NH group was not significant $(p=.102)$. The sample size of 10 may not enough to identify this relation and it should be explored in more detail. One interesting result is the association between the number of different words with CELF-IV, story length, and mean length of utterance for the DHH group. This indicates the importance of vocabulary knowledge at a sentence and discourse level for this group. The relation between the number of different words and the story length was also found in the NH group, which indicates the importance of vocabulary knowledge in narrative production in both groups.

It was expected that the microstructure of the narratives would relate to narrative macrostructure, but the relation might be weak. This is because the organization of narrative structure requires cognitive abilities in addition to linguistic abilities. The study results demonstrated that the relationships were different in the subject groups as well as for the story production conditions. For the DHH group, most of the language scales except SI were strongly associated with complete GAO Units in the story retell task, which shows that the logical organization of narrative structure and language ability shared a considerable amount of variance in the story retell condition. In contrast, for the NH group, all the indices of language except T-Units and NDW had low and 
nonsignificant relations with the complete GAO Units in story retell.

In contrast to the results of story retell, no significant relationship was found between microstructure and macrostructure scales in the story generation task for either group except a negative relationship between the CELF-IV Core Language subtest score and the complete GAO Units for the NH group. The individual data showed that two participants who scored higher on CELF-IV Core Language subtest but produced fewer complete GAO Units yielded this correlation. Except for those participants, the other data were scattered. Thus this correlation seems to be influenced by the small amount of variability rather than by a negative relation between language and narrative organization. In the association with the complete GAO Units, the other indices had an overall relatively low and nonsignificant magnitude of correlation coefficients except for Grammar Errors in the DHH group, and SI in the NH group. The absence of significant correlations with low coefficients between the microstructure and macrostructure narrative analyses in story generation indicates that factors other than language ability could influence the construction of complete episodes.

Finally, the relations between narrative structures and EFs were tested. It was hypothesized that if children who are DHH were able to produce a complete narrative, but there was a difference between the groups, the DHH group's performance on the narrative structure organization would be related to EFs. For the story generation task, there was a significant association between GAO Units and EFs as tested on the BRIEF for the DHH group but no association for the NH group. For the DHH group, the MI index of the BRIEF and the GAO Units shared a considerable variance. This result suggests that the EFs included in the MI index, such as Initiate, Working Memory, Plan and Organization, Organization of Materials, and Monitor, may have more influence on narrative structure organization for the $\mathrm{DHH}$ group than the $\mathrm{NH}$ group.

The relationships between narrative structure and EFs as measured by the performance based assessments found some significant associations for the story retell condition. The Description Combined score of the DKEFS Card Sorting was associated with complete GAO Units for the DHH group, and the DSF as well as the Card Sorting and Description Combined scores of DKEFS were associated story retell for the NH group. This result demonstrates that the narrative structure organization for story retell and the EFs measured by the Description score of the DKEFS Card Sorting test, such as Concept Formation and Reasoning, and Cognitive Flexibility share an underlying common variance. The relationship between narrative structure in the story retell condition and Cognitive Flexibility has been demonstrated in the literature (Coelho, 2002; Dodwell \& Bavin, 2008; Ketelaars, Jansonius, Cuperus, and Verhoeven, 2012; Renz, Lorch, Milich, Lemberger, Bodner, \& Welsh, 2003). However, finding no relation between Working Memory and narrative structure for the DHH group was unexpected because the story retell task requires the participants to store the content of a story in order to comprehend it in order to reproduce the story. In addition, this relationship was evident in the BRIEF. This inconsistent result supports that suggestion that the areas of EFs tested by observation based tests and performance based tests are different from each other. 
It was also unexpected that no associations were found with story generation. Most of the correlation coefficients were low or negative. Two possible explanations are provided here. First, the sample size was too small to identify a relationship between narratives and EFs in this condition. There were only 11 or 10 samples, and the performance of the groups was scattered. Second, the EFs assessments used in the present study might not sensitive to subtle common variance between EFs and narratives produced in the story generation condition. The parent report was based on children's behavior, and the tasks in the performance measures were mostly nonverbal tasks. Given that the children showed different performance on verbal and nonverbal tasks, and that the DHH group showed comparable performance to their NH peers on nonverbal EFs tests, increased emphasis on verbal tasks might be likely to show differences in narrative structure organization in the story generation condition.

As a result of exploring the second research question, this study showed that there are differences in the relations between these standard language scores, narrative productions and EFs depending upon the group being assessed and the types of items used for the assessments. Importantly, a relationship was shown between some narrative productions and verbal EFs and this finding should serve to encourage new research in this area.

\section{Limitations}

This study was conducted with 11 children in a DHH group and 10 children in a NH group. The children who participated in this study did so on a volunteer basis and it is possible that these children, especially those in the DHH group, do not represent a crosssection of the DHH population. In this study, all but two of the DHH participants scored within the normal range for language competence and may have been more likely to participate in the study. Participation by children with better skills has been pointed out by Geers and her colleagues as a result of their 8 year longitudinal study with CI users (2011). Moreover, the small sample size of the study may have facilitated correlations between narratives and EFs. A larger sample size in the future will strengthen or refute this result.

An additional limitation is that this study recruited subjects who had no other diagnosed disorders other than hearing impairment, but did not consider environmental factors. The literature investigating language and narrative development has reported that environmental factors have been found to contribute to language and narrative outcomes. These factors include the participants' social economic status (SES) maternal education, or the degree of exposure to narratives (Peterson, 1994, Price, Roberts, \& Jackson, 2006). Using a larger experimental group and considering these factors will provide a more detailed picture of the language and narrative development of children who are DHH.

Another limitation of this study relates to the test materials. Two fictional narratives based on a picture(s) were used to elicit narratives from children. These are both tools widely used in clinics and research studies to elicit narratives. However, a 
single picture condition may not be a particularly effective method to elicit narratives having hierarchically complex goal plan structures. Considering the fact that school-aged children's narratives vary depending on the topic or materials used to elicit the narrative, the influence of different narrative conditions on the elicitation of narrative structures needs to be more thoroughly investigated.

\section{Study Implications}

This study investigated language, narrative structures and EFs with children who are $\mathrm{DHH}$ and $\mathrm{NH}$. It was interesting, and unexpected, to find that the language skills of the DHH group generally fell within the normal range. For this reason, differences in EFs may not necessarily be related to language knowledge. For this study, the macrostructures of narratives produced by the children in the story retell and story generation conditions provided important information about narrative skills. It is interesting to note that significant differences were found between the story retell and story generation conditions across the three analyses. The two story production conditions differed in the existence of a modeled narrative and a story structure support. In the story retell condition, the children reproduced a story they heard and pictures provided support for the story structure. The children in both groups produced longer narratives with more episodes in this condition. Thus, story retell provided information regarding their knowledge of story structure as well as the language used at discourse level. In contrast, the story generation condition where children had to generate their own narrative based on only one picture revealed the children's ability to use their knowledge to organize and produce a narrative. Unfortunately, the frequently used picture condition for the story generation task did not elicit narratives that provided adequate information regarding how the children would structure a self-made narrative. In order to elicit a story generation narrative long enough to provide information about narrative construction ability, a different stimulus picture or pictures should be used.

The narrative macrostructures in this study were analyzed according to story grammar, episodic structure, and hierarchical goal plans. The story grammar analysis provided information about the composition of a story, for instance, how children started or ended narratives, or how an episode began. The episodic structure analysis revealed the logical structure of episodes, for example, why the protagonist decided to do something, what the protagonist wanted, how they tried to accomplish it, the outcome of their actions, and the outcomes impact on the protagonists next behavior. Through the analysis of complete and incomplete episodes, more information about the participants' internal representations of temporal and causal relationships between episodes was found. Unfortunately, the hierarchical goal plan analysis did not provide particularly useful information in this study and may not be a method of analysis to recommend for future studies.

The results of this study provide some information regarding narrative assessment and intervention for children who are $\mathrm{DHH}$. The children in the DHH group produced a smaller number of total episodes and a smaller number of complete episodes. Their 
ability to construct a narrative was associated with EFs, and more EFs were engaged in constructing episodic structures with the DHH group than with the NH group. This result showed that their narrative production problems could be assessed and approached from both language and cognitive perspectives. Speech-language pathologists would agree that narrative problems can have negative consequences on a child's social life and seriously influence academic achievement. Thus, speech-language pathologists and educators should pay attention to EFs problems and extend the content and direction of language assessments with children who are DHH in order to include tests of EFs along with language.

\section{Future Directions}

Both EFs and narrative discourse are known to be important to academic and social skills. EFs serve as an underpinning variable in language development and narratives provide a bridge between oral language and literacy. Both have been reported to develop from young childhood. However, the relationship between EFs and language development, including narrative production, in children who are $\mathrm{DHH}$ has been not actively investigated. The current study demonstrated that even when language skills fall within the normal range, delays or impairments exist in some EFs in school-aged children who are DHH. The study also demonstrated that these problems in EFs are associated with problems in the production of age appropriate narratives. In order to improve the language and literacy skills of children who are DHH, the underlying and possibly reciprocal processes that influence of EFs and language require more investigation from the early stages of language acquisition into adulthood.

In this study, the DHH group showed problems in the logical construction of narratives. The construction of appropriate texts should become even more vital in years beyond elementary school. In particular, the need to understand and use expository text will become paramount. Given the issues found with organizing narrative structures, children who are DHH may show important differences from their normal hearing peers skills in expository text production. However, this topic has been rarely investigated with children who are DHH. Therefore, a study with various types of text at the discourse level, and its relationship to EFs should be investigated.

\section{Conclusion}

In conclusion, following a review of the literature, no study was found that investigated oral narrative production using both microstructure and macrostructure analysis and its relationship to EFs with children who are DHH. This study was designed

to investigate how narrative structures, language, and EFs are related for children who are DHH and a NH comparison group. Narrative and EFs were hypothesized to relate each other.

The group comparisons showed that children who are DHH were able to use their 
language knowledge to retell a narrative as well as their NH peers. However, they had some problems in constructing a logical narrative structure especially in the story generation condition. Their performance was also comparable to the NH group on nonverbal EFs, but lower on the EFs testing that required verbal reasoning. This is in contrast to the NH group that did not show any difference in their performance across all EFs tests. The correlation analysis revealed that the narrative structure from the story retell was associated with verbal EFs performance as well as language competence in both groups. The association of narrative structure with EFs was found in the DHH group in the story generation condition although no correlation was found with language indices. However, the association of narrative structure and EFs was not found in the NH group. These results support the idea that narrative structure organization is related to EFs in school-aged children, and further suggest that EFs might have more influence on organizing narrative structure for children who are DHH than children with NH. The results also suggest that children who are DHH may have some EFs problems even when their language competence has developed within the normal range.

Although the sample size was small, this study outcome provides some information about the narrative development of children who are DHH in terms of their organization of narrative structure, and its relation with EFs. The results of the study also contribute to the literature designed to clarify the underlying process of narrative organization. The EFs problems found in the children who are DHH should be further investigated to explore how EFs may influence language development, the diagnosis of language problems, and language interventions. When we fully understand how hearing loss effects language and cognitive development in children, and how these abilities are interrelated, speech-language pathologists and deaf educators should be able to develop more effective approaches to improve language and enhance academic and social success. 


\section{LIST OF REFERENCES}

Achenbach, T. M., \& Rescorla, L. A. (2000). Manual for the ASEBA preschool forms and profiles. Burlington, VT: University of Vermont, Research Center for Children, Youth, \& Families.

Alloway, T. P., Gathercole, S. E., Kirkwood, H., \& Elliott, J. (2009). The cognitive and behavioral characteristics of children with low working memory. Child development, 80(2), 606-621.

Altshuler, K. Z., Deming, W. E., Vollenweidner, J., Rainer, J. D., \& Tendler, R.(1976). Impulsivity and profound early deafness: A cross cultural inquiry. American Annals of the Deaf, 121, 331-345.

Anderson, P. (2002). Assessment and development of executive function (EF) during childhood. Child Neuropsychology, 8(2), 71-82.

Anderson, V. (1998). Assessing executive functions in children: Biological, psychological, and developmental considerations.Neuropsychological Rehabilitation, 8(3), 319349.

Anderson, P., Anderson, V., \& Lajoie, G. (1996). The tower of London test: Validation and standardization for pediatric populatons. The Clinical Neuropsychologist, 10(1), 54-65.

Anderson, V., Anderson, P., Northam, E., Jacobs, R., \& Mickiewicz, O. (2002).

Relationships between cognitive and behavioral measures of executive function in children with brain disease. Child Neuropsychology, 8(4), 231-240.

Archibald, S.J., \& Kearns, K.A. (1999). Identification and description of new tests of executive functioning in children. Child Neuropsychology, 5(2), 115-129.

Arfé, B., \& Boscolo, P. (2006). Causal coherence in deaf and hearing students' written narratives. Discourse Processes, 42, 271-300.

Asker-Árnason, L., Ibertsson, T., Wass, M., Wengelin, Å., \& Sahlén, B. (2007). Narrative writing assessed with keystroke-logging in children with CI.

Asker-Árnason, L., Ibertsson, T., Wass, M., Wengelin, Å., \& Sahlén, B. (2010). Pictureelicited written narrative, process and product, in 18 children with cochlear implants. Communication Disorders Quarterly, 31 (4), 195-2122.

Baddeley A. (1986). Working Memory. Oxford Univ. Press: Oxford. 
Baddeley, A. (1998). Recent developments in working memory. Current opinion in neurobiology, 8, 234-238.

Bamberg, M., \& Damrad-Frye, R. (1991). On the ability to provide evaluative comments: Further explorations of children's narrative competencies. Journal of Child Language, 18(3), 689-710.

Barker, D. H., Quittner, A. L., Fink, N. E., Eisenberg, L. S., Tobey, E. A., Niparko, J. K. \& CDaCI Team (2009). Predicting behavior problems in deaf and hearing children: the influences of language, attention, and parent-child communication. Development and psychopathology, 21(2), 373-392.

Barkley, R. A. (1997). Behavioral inhibition, sustained attention, and executive functions: constructing a unifying theory of ADHD. Psychological bulletin,121(1), 65-94.

Barkley, R. A. (2001). The executive functions and self-regulation: An evolutionary neuropsychological perspective. Neuropsychology review, 11(1), 1-29.

Baron, I.S. (2000). Test review: Behavior rating inventory of executive function. Child Neuropsychology, 6(3), 235-238.

Baron, S.I. (2004). Delis-Kaplan executive function system. Child Neuropsychology, 10(2), 147-152.

Bates, R.P. (2012). Narrative production and the development o executive function: a study of emergent literacy. Thesis for the Degree of Mater of Arts, San Diego State University.

Beer, J., Kronenberger, W. G., \& Pisoni, D. B. (2011). Executive function in everyday life: Implications for young cochlear implant users. Cochlear implants international, 12(Suppl 1), S89.

Berman, R. A. (1995). Narrative competence and storytelling performance: How children tell stories in different contexts. Journal of Narrative and Life History, 5, 285-313.

Berman, R.A. (1998). On the ability to relate events in narrative. Discourse Processes, 11, 469-497.

Berman, R.A., \& Slobin, D. I. (1994). Relating events in a narrative: A crosslinguistic developmental study. Hillsdale, NJ: Lawrence Erlbaum.

Bernstein, J.H. \& Waber, D.P. (1996). Developmental Scoring System for the ReyOsterrieth Complex Figure Manual. Psychological Assessment Resources, Odessa, Florida, USA. 
Bliss, L. S., Covington, Z., \& McCabe, A. (1999). Assessing the narratives of African American children. Contemporary Issues in Communication Science and Disorders, 26(160-167).

Botting, N. (2002). Narrative as a tool for the assessment of linguistic and pragmatic impairments. Child Language Teaching and Therapy, 18, 1-21

Booth, J. N., \& Boyle, J. M. E. (2009). The role of inhibitory functioning in children's reading skills. Educationai Psychology in Practice, 25(4), 339-350.

Booth, J. N., Boyle, J. M., \& Kelly, S. W. (2010). Do tasks make a difference? Accounting for heterogeneity of performance of children with reading difficulties on tasks of executive function: Findings from a meta-analysis. British Journal of Developmental Psychology, 28(1), 133-176.

Botting, N. (2002). Narrative as a tool for the assessment of linguistic and pragmatic impairments. Child Language Teaching and Therapy, 18(1), 1-21.

Boudreau, D. (2008). Narrative abilities: Advances in research and implications for clinical Practice. Topics in Language Disorders, 28, 99-114.

Bull, R., Epsy, K.A., \& Wiebe, S. (2008). Short-term memory, working memory, and executive function in preschoolers: longitudinal predictors of mathematical achievement at age 7 years. Developmental Neuropsychology, 33(3), 205-228.

Bull, R., Johnston, R.S., \& Roy,J.A. (1999). Exploring the roles of the visual-spatial sketch pad and central executive neuropsychology. Developmental Neuropsychology, 15, 421-442.

Bull, R., \& Scerif, G. (2001). Executive functioning as a predictor of children;s mathematics ability: Inhibition, switching, and working memory. Developmental Neuropsychology, 19, 273-293.

Cain, K., \& Oakhill, J. (1996). The nature of the relationship between comprehension skill and the ability to tell a story. British Journal of Developmental Psychology, 14(2), 187-201.

Cain, K., \& Oakhill, J. (2006). Profiles of children with specific reading comprehension difficulties. British Journal of Educational Psychology, 76(4), 683-696.

Campbell, S. B., \& Douglas, V. I. (1972). Cognitive styles and responses to the threat of frustration. Canadian Journal of Behavioural Science/Revue canadienne des sciences du comportement, 4(1), 30.

Carlson, S. M. (2005). Developmentally sensitive measures of executive function in preschool children. Developmental neuropsychology, 28(2), 595-616. 
Carlson, S. M., Davis, A. C., \& Leach, J. G. (2005). Less Is More Executive Function and Symbolic Representation in Preschool Children. Psychological Science, 16(8), 609-616.

Carrow-Woolfolk, E. (1999). CASL: Comprehensive assessment of spoken language. American Guidance Services.

Chess, S., \& Fernandez, P. (1980). Do deaf children have a typical personality?. Journal of the American Academy of Child Psychiatry, 19(4), 654-664.

Coelho, C.A. (2002). Story narratives of adults with closed head injury and non-braininjured adults: Influence of socioeconomic status, elicitation task, and executive functioning. Journal of Speech, Language, and Hearing Research, 45, 1232-1248.

Cohen, N. J., Vallance, D. D., Barwick, M., Im, N., Menna, R., Horodezky, N. B., \& Isaacson, L. (2000). The interface between ADHD and language impairment: An examination of language, achievement, and cognitive processing. Journal of Child Psychology and Psychiatry, 41(3), 353-362.

Conway, C. M., \& Pisoni, D. B. (2008). Neurocognitive basis of implicit learning of sequential structure and its relation to language processing. Annals of the New York Academy of Sciences, 1145(1), 113-131.

Cowan, N. (1999). An embedded-processes model of working memory. Models of working memory: Mechanisms of active maintenance and executive control, 62101.

Cowan, N. (2005). Working memory capacity. Psychology Press.

Crais, E. R., \& Lorch, N. (1994). Oral narratives in school-age children. Topics in Language Disorders, 14(3), 13-28.

Crosson, J., \& Geers, A. E. (2000). Structural analysis of narratives produced by a group of young cochlear implant users. The Annals of Otology, Rhinology \& Laryngology. Supplement, 185, 118.

Crosson, J., \& Geers, A. (2001). Analysis of narrative ability in children with cochlear implants. Ear \& Hearing, 22, 381-394.

Daneman, M. \& Carpenter, P.A. (1980). Individual defferences in working memory and reading. Journal of verbal learning and verbal behavior, 19, 450-466.

Daneman, M., \& Merikle, P. M. (1996). Working memory and language comprehension: A meta-analysis. Psychonomic Bulletin \& Review, 3(4), 422-433. 
Das, J.P., \& Naglieri, J.A. (1989). Cognitive Assessment System: Experimental edition. New York: Psychological Corp.

Das, J. P., \& Ojile, E. (1995). Cognitive processing of students with and without hearing loss. The Journal of Special Education, 29(3), 323-336.

Dawson, P. W., Blamey, P. J., Dettman, S. J., Barker, E. J., \& Clark, G. M. (1995). A clinical report on receptive vocabulary skills in cochlear implant users. Ear \& Hearing, 16, 287-294.

Delis, D. C., Kaplan, E., \& Kramer, J. (2001). Delis Kaplan Executive Function System. San Antonio, TX: The Psychological Corporation.

Demster, F.N., \& Cooney, J.B. (1982). Individual differences in digit span, susceptibility to proactive interference, and aptitude/achievement test scores. Intelligence, 6, $399-416$.

Dempster, F. N., \& Corkill, A. J. (1999). Interference and inhibition in cognition and behavior: Unifying themes for educational psychology. Educational Psychology Review, 11(1), 1-88.

Denckla, M.B. (1994). Measurement of executive function. In Lyon, G.Reid (Ed), Frames of reference for the assessment of learning disabilities: New views on measurement issues., (pp.117-142). Baltimore, MD, US: Paul H Brookes Publishing, xvii. 650pp.

Diamond, A., Kirkham, N., \& Amso, D. (2002). Conditions under which young children can hold two rules in mind and inhibit a prepotent response. Developmental Psychology, 38, 352-362.

Diamond, A., \& Taylor, C. (1996). Development of an aspect of executive control: Development of the abilities to remember what I said and to "Do as I say, not as I do." Developmental Psychobiology, 29,315-334.

Dillon, C. M., Burkholder, R. A., Cleary, M., \& Pisoni, D. B. (2004). Nonword repetition by children with cochlear implants: Accuracy ratings from normal-hearing listeners. Journal of Speech, Language and Hearing Research, 47(5), 1103-1116.

Dillon, C. M., \& Pisoni, D. B. (2004). Nonword repetition and reading in deaf children with cochlear implants. International Congress Series, Vol. 1273, pp. 304-307.

Dodwell, K., \& Bavin, E. L. (2008). Children with specific language impairment: An investigation of their narratives and memory. International Journal of Language and Communication Disorders, 43, 201-218. 
Dunn, L.M., \& Dunn, L.M. (1981). Peabody Picture Vocabulary Test-Revised. Circle Pines, Minn: American Guidance Service, 1981.

Dunn, L., \& Dunn, D. (1997). Peabody Picture Vocabulary Test (3rd ed.). Circle Pines, MN: American Guidance Service.

Dunn, L., \& Dunn, D. (2007). Peabody Picture Vocabulary Test (4th ed.). San Antonio, Texas: Pearson; 2007.

Dunn, L., \& Markwardt, F. C. (1989).Peabody Individual Achievement Test(Revised ed.). Circle Pines MN: American Guidance Service.

Dye, M. W., Hauser, P. C., \& Bavelier, D. (2008). Visual attention in deaf children and adults. In M.Marschark \& P.C. Hauser (Eds.). Deaf cognition: Foundations and outcomes, 250-263.

Eabon, M. F. (1984). On the Relationship between Impulsivity and Field-Dependence in Hearing-Impaired Children. Paper Presented at the Annual Meeting of the Midwestern Psychological Association (56th, Chicago, IL, May 3-5, 1984).

Ellis Weismer, S. Evans, J., \& Hesketh, L. J. (1999). An examination of verbal working memory capacity in children with specific language impairment. Journal of Speech, Language and Hearing Research, 42(5), 1249-1260.

Ellis Weismer, S., Plante, E., Jones, M., \& Tomblin, J. B. (2005). A functional magnetic resonance imaging investigation of verbal working memory in adolescents with specific language impairment. Journal of Speech, Language and Hearing Research, 48(2), 405.

Ellis Weismer, S., \& Thordardottir, E.T. (2002). Cognition and Language. In P. Accardo, A.Capture, \& B.Rogers (Eds.), Disorders of Language Development (pp. 21-37). Timonium, MD: York Press, Inc.

Engel, S. (1995). The stories children tell: Making sense of the narratives of childhood. New York: Freeman.

Engel-Yeger, B., Durr, D. H., \& Josman, N. (2011). Comparison of memory and metamemory abilities of children with cochlear implant and normal hearing peers. Disability and Rehabilitation, 33(9), 770-777.

Everatt, J., Warner, J., Miles, T. R., \& Thomson, M. E. (1997). The incidence of Stroop interference in dyslexia. Dyslexia, 3(4), 222-228.

Fagan, M. K., Pisoni, D. B., Horn, D. L., \& Dillon, C. M. (2007). Neuropsychological correlates of vocabulary, reading, and working memory in deaf children with cochlear implants. Journal of deaf studies and deaf education, 12(4), 461-471. 
Feagans, L., \& Farran, D. C. (1981). How demonstrated comprehension can get muddled in production. Developmental Psychology, 17(6), 718-727.

Fenson, L., Dale, P. S., Reznick, J. S., Bates, E., Thal, D., \& Pethick, S. (1993). MacArthur-Bates Communicative Development Inventories: user's guide and technical manual. Paul H. Brookes Publishing Company.

Figueras, B., Edwards, L., \& Langdon, D. (2008). Executive function and language in deaf children. Journal of Deaf Studies and Deaf Education, 13(3), 362-377.

Fray, P. J., Robbins, T. W., \& Sahakian, B. J. (1996). Neuorpsychiatyric applications of CANTAB. International Journal of Geriatric Psychiatry.

Friedman, N. P., \& Miyake, A. (2004). The relations among inhibition and interference control functions: a latent-variable analysis. Journal of experimental psychology: General, 133(1), 101.

Fryauf-Bertschy, H., Tyler, R. S., Kelsay, D. M., Gantz, B. J., \& Woodworth, G. G. (1997). Cochlear implant use by prelingually deafened children: The influences of age at implant and length of device use. Journal of Speech, Language and Hearing Research, 40(1), 183-199.

Furth, H. G. (1973). Deafness and learning: A psychosocial approach. Belmont, CA: Wadsworth.

Fuster, J. (1989). The prefrontal cortex: Anatomy, physiology, and neuropsychology of the frontal lobe (2nd ed.). New York: Raven Press.

Gathercole, S. E., \& Baddeley, A. D. (1993). Working memory and language. Lawrence Erlbaum Associates, Inc.

Gathercole, S. E., \& Pickering, S. J. (2000). Working memory deficits in children with low achievements in the national curriculum at 7 years of age.British Journal of Educational Psychology, 70(2), 177-194.

Gaulin, C., \& Campbell, T. (1994). Procedure for assessing verbal working memory in normal school-age children: Some preliminary data. Perceptual and Motor Skills, $79,55-64$.

Geers, A. E. (2004). Speech, language, and reading skills after early cochlear implantation. Archives of Otolaryngology_Head \& Neck Surgery, 130(5), 634.

Geers, A. E., \& Moog, J. S. (1994). Spoken language results: Vocabulary, syntax, and communication. In A. E. Geers, \& J. S. Moog (Eds.), Effectiveness Of Cochlear Implants And Tactile Aids For Deaf Children: The Sensory Aid Study At Central Institute For The Deaf (Monograph issue). Volta Review, 96, 131-150. 
Geers, A. E., Moog, J. S., Biedenstein, J., Brenner, C., \& Hayes, H. (2009). Spoken language scores of children using cochlear implants compared to hearing agemates at school entry. Journal of Deaf Studies and Deaf Education, 14(3), 371385 .

Geers, A. E., Nicholas, J. G., \& Sedey, A. L. (2003). Language skills of children with early cochlear implantation. Ear and hearing, 24(1), 46S-58S.

Geers, A. E., \& Sedey, A. L. (2011). Language and verbal reasoning skills in adolescents with 10 or more years of cochlear implant experience. Ear and hearing, 32(1 Suppl), 39S.

Gillam, R. B., \& Pearson, N. A. (2004). Test of Narrative Language: Examiner's Manual. Pro-ed.

Gioia, G.A., Isquith, P.K., \& Guy, S.C. (2001) Assessment of executive functions in children with neurological impairment. In R.J. Simeonsson \& S.L. Rosenthal, (Eds.), Psychological and developmental assessment: Children with disabilities and chronic conditions (pp.317-356). New York: Guilford Press.

Gioia, G.A., Isquith, P.K., Guy, S.C., \& Kenworthy, L. (2000). Behavior Rating Inventory of Executive Function (BRIEF), Lutz, FL: Psychological Assessment Resources.

Goldman-Rakic PS (1987) Circuitry of primate prefrontal cortex and regulation of behavior by representational memory. In: Plum F, Mountcastle F (eds) Handbook of Physiology, Vol 5. The American Physiological Society, Washington DC, pp $373-517$.

Greiner, L. A. (2010). Measures of executive function in children with cochlear implants. Thesis, University of Iowa.

Gresham, F. M., \& Elliott, S. N. (1990). Social skills rating system (SSRS). American Guidance Service.

Griffith, P., Ripich, D., \& Dastoli, S. (1986). Story structure, cohesion, and propositions in story recalls by learning-disabled and nondisabled children. Journal of Psycholinguistic Research, 15, 539-555.

Griffith, P. L., Ripich, D. N., \& Dastoli, S. L. (1990). Narrative abilities in children with hearing loss: Propositions and cohesion. American Annals of the Deaf, 135(1), 1421.

Harris, R. I. (1978). The relationship of impulse control to parent hearing status, manual communication, and academic achievement in deaf children. American Annals of the Deaf, 123(1), 52-67. 
Harris, M. S., Kronenberger, W. G., Gao, S., Hoen, H. M., Miyamoto, R. T., \& Pisoni, D. B. (2012). Verbal Short-Term Memory Development and Spoken Language Outcomes in Deaf Children With Cochlear Implants. Ear and Hearing.

Harrison, R. V., Panesar, J., El-Hakim, H., Abdolell, M., Mount, R. J., \& Papsin, B. (2001). The effects of age of cochlear implantation on speech perception outcomes in prelingually deaf children. Scandinavian Audiology, 30(2), 73-78.

Heaton, R. K., Chelune, G. J., Talley, J. L., Kay, G. G., \& Curtiss, G. (1993). Wisconsin card sorting test manual: revised and expanded. Odessa: Psychological Assessment Resources.

Henry, L. A., Messer, D. J., \& Nash, G. (2012). Executive functioning in children with specific language impairment. Journal of child psychology and psychiatry, 53(1), $37-45$.

Hindley, P., \& Kroll, L. (1998). Theoretical and epidemiological aspects of attention deficit and overactivity in deaf children. Journal of deaf studies and deaf education, 3, 64-72.

Hintermair, M. (2013). Executive Functions and Behavioral Problems in Deaf and Hardof-Hearing Students at General and Special Schools. Journal of Deaf Studies and Deaf Education. doi:10.1093/deafed/ent003.

Hoffman, L. M., \& Gillam, R. B. (2004). Verbal and spatial information processing constraints in children with specific language impairment. Journal of Speech, Language and Hearing Research, 47(1), 114-125.

Holck, P., Sandberg, A.D., \& Nettelbladt, U. (2011). Narrative ability in children with cerebral palsy. Research in Developmental Disabilities, 32, 262-270.

Holt, R. F., Beer, J., Kronenberger, W. G., Pisoni, D. B., \& Lalonde, K. (2012). Contribution of Family Environment to Pediatric Cochlear Implant Users' Speech and Language Outcomes: Some Preliminary Findings. Journal of Speech, Language and Hearing Research, 55(3), 848-864.

Hooper,S.R., Swartz,C.W., Wakely, M.B., de Kruif, R.E.L., \& Montgomery, J.W. (2002). Executive functions in elementary school children with and without problems in written expression. Journal of Learning Disabilities, 35, 57-68.

Horn, D. L., Davis, R. A., Pisoni, D. B., \& Miyamoto, R. T. (2004). Visual attention, behavioral inhibition and speech/language outcomes in deaf children with cochlear implants. International Congress Series, 1273, 332-335. 
Houston, D. M., Beer, J., Bergeson, T. R., Chin, S. B., Pisoni, D. B., \& Miyamoto, R. T. (2012). The ear is connected to the brain: some new directions in the study of children with cochlear implants at Indiana University. Journal of the American Academy of Audiology, 23(6), 446-463.

Hudson, J.A., \& Shapiro, L.R. (1991). From knowing to retelling: The development of children's scripts, stories, and personal narratives. In McCabe, A. \& Peterson, C. (Eds.), Developing Narrative Structure. Lawrence Erlbaum Associates, Inc. Hillsdale

Hughes, D., McGillivray, L., \& Schmidek, M. (1997). Guide to narrative language: procedures for assessment. Eau Claire, WI: Thinking Publications.

Hughes, D. M., Turkstra, L. S., \& Wulfeck, B. B. (2009). Parent and self-ratings of executive function in adolescents with specific language impairment.International Journal of Language \& Communication Disorders, 44(6), 901-916.

Huttunen, K. (2008). Development of speech intelligibility and narrative abilities and their interrelationship three and five years after pediatric cochlear implantation. International Journal of Audiology, 47. (Supplement 2), S38-S46.

Ibertsson, T. (2009). Cognition and communication in children/adolescents with cochlear implant. Doctoral Dissertation. Lund University, Lund, Sweden.

Ibertsson, T., Willstedt-Svensson, U., Radeborg, K., \& Sahlén, B. (2008). A methodological contribution to the assessment of nonword repetition-a comparison between children with specific language impairment and hearingimpaired children with hearing aids or cochlear implants. Logopedics Phonatrics Vocology, 33(4), 168-178.

Im-Bolter, N., Johnson, J., \& Pascual-Leone, J. (2006). Processing limitations in children with specific language impairment: The role of executive function.Child development, 77(6), 1822-1841.

Isquith, P. K., Gioia, G. A., \& Espy, K. A. (2004). Executive function in preschool children: Examination through everyday behavior. Developmental neuropsychology, 26(1), 403-422.

Jansonius-Schultheiss,K.,Borgers,M.,Bruin,B.D.And Stumpel, H. (2006) Renfrew's Language Scales Dutch Adaptation. Amsterdam: Pro-education, HvA.

Jonides, J., Lacey, S. C., \& Nee, D. E. (2005). Processes of working memory in mind and brain. Current Directions in Psychological Science, 14(1), 2-5.

Just, M.A., \& Carpenter, P.A. (1992). A capacity of comprehension: Individual differences in working memory. Psychological Review, 99, 122-149. 
Justice, L. M., Bowles, R. P., Kaderavek, J. N., Ukrainetz, T. A., Eisenberg, S. L., \& Gillam, R. B. (2006). The index of narrative microstructure: A clinical tool for analyzing school-age children's narrative performances. American Journal of Speech-Language Pathology, 15(2), 177-191.

Kagan, J. (1965).The Matching Familiar Figures Test. Cambridge, MA: Harvard University Press.

Kail, R.(1994). A method of studying the generalized slowing hypothesis in children with specific language impairment. Journal of Speech and Hearing Research, 37,418421.

Keane, K. J., \& Kretschmer, R. E. (1987). Effect of mediated learning intervention on cognitive task performance with a deaf population. Journal of Educational Psychology, 79(1), 49-53.

Kelly, D. P., Kelly, B. J., Jones, M. L., Moulton, N. J., Verhulst, S. J., \& Bell, S. A. (1993). Attention deficits in children and adolescents with hearing loss: A survey. Archives of Pediatrics \& Adolescent Medicine, 147(7), 737.

Ketelaars, M.P., Jansonius, K., Cuperus, J., \& Verhoeven, L. (2012). Narrative competence and underlying mechanisms in children with pragmatic language impairment. Applied Psycholinguistics, 33, 281-303.

Khan, S., Edwards, L., \& Langdon, D. (2005). The cognition and behaviour of children with cochlear implants, children with hearing aids and their hearing peers: A comparison. Audiology and Neurotology, 10(2), 117-126.

King, C. M., \& Quigley, S. P. (1985). Reading and deafness. College-Hill Press.

Kirk, K. I., Miyamoto, R. T., Lento, C. L., Ying, E., O'neill, T., \& Fears, B. (2002). Effects of age at implantation in young children. Annals of otology, rhinology \& laryngology. Supplement, 111(189), 69-73.

Kirk, K. I., Pisoni, D. B., \& Osberger, M. J. (1995). Lexical effects on spoken word recognition by pediatric cochlear implant users. Ear and hearing, 16(5), 470-481.

Klecan-Aker, J. S., \& Caraway, T. H. (1997). A study of the relationship of storytelling ability and reading comprehension in fourth and sixth grade African-American children. International Journal of Language \& Communication Disorders, 32(1), 109-125.

Klecan-Aker, J., \& Blondeau, R. (1990). An Examination of the Written Stories of Hearing-Impaired School-Age Children. Volta Review, 92(6), 275-282. 
Knutson, J. F., Wald, R. L., Ehlers, S. L., \& Tyler, R. S. (2000). Psychological consequences of pediatric cochlear implant use. The Annals of Otology, Rhinology \& Laryngology. Supplement, 185, 109.

Korkman, M., Kirk, U., \& Kemp, S. (1998). NEPSY: A developmental neuropsychological assessment. Psychological Corporation.

Kretschmer, R. R., \& Kretschmer, L. W. (1994). Discourse and hearing-impairment. In D. N. Rippich \& N. A. Creaghead (Eds.), School Discourse Problems (pp. 349-378). San Diego: Singular Publishing.

Krikorian, R., Bartok, J., \& Gay, N. (1994). Tower of London procedure: A standard method and developmental data. Journal of Clinical and Experimental Neuropsychology, 16(6), 840-850.

Kronenberger, W. G., Pisoni, D. B., Henning, S. C., Colson, B. G., \& Hazzard, L. M. (2011). Working memory training for children with cochlear implants: A pilot study. Journal of Speech, Language and Hearing Research, 54(4), 1182-1196.

Lambeth, S., Fahy, M. J., \& Throneburg, R. (2012). Relationship between school-aged executive functions and oral narrative skills. Eastern Illinois University, Doctoral Dissertation.

Landa, R. J., \& Goldberg, M. C. (2005). Language, social, and executive functions in high functioning autism: A continuum of performance. Journal of autism and developmental disorders, 35(5), 557-573.

Layton, T.L., Holmes, D.W. (1985). Carolina Picture Vocabulary Test (fro Deaf and Hearing Impaired) manual. Austin, TX: Pro-Ed.

Lehto, J. (1995). Working memory and school achievement in the ninth form. Educational Psychology, 15, 271-281.

Lehto, J.E. (1996). Are executive function tests dependent on working memory capacity? The Quarterly Journal of Experimental Psychology, 49A(1), 29-50.

Leinonen, E., Letts, C. and Smith, B. R. (2000). Children's Pragmatic Communication Difficulties: Narratives and Story Telling, pp. 92-124. London: Whurr.

Leonard, L. B., Ellis Weismer, S., Miller, C. A., Francis, D. J., Tomblin, J. B., \& Kail, R. V. (2007). Speed of processing, working memory, and language impairment in children. Journal of Speech, Language and Hearing Research, 50(2), 408.

Lewis, R. L., Vasishth, S., \& Van Dyke, J. A. (2006). Computational principles of working memory in sentence comprehension. Trends in cognitive sciences, 10(10), 447-454. 
Liles, B. Z. (1987). Episode organization and cohesive conjunctives in narratives of children with and without language disorders. Journal of Speech and Hearing Research, 30, 185-196.

Loomis, D., Holt, R., Kaufman, J. C., \& Kaufman, A. S. (2004). Kaufman Assessment Battery for Children. Corsini Encyclopedia of Psychology.

Lorsbach, T.C., Wilson, S., \& Reimer, J.F. (1996). Memory for relevant and irrelevant information: Evidence for deficient inhibitory processes in language/learning disabled children. Contemporary Educational Psychology, 21, 447-466.

Luo, F., \& Timler, G.R. (2008). Narrative organization skills in children with attention deficit hyperactivity disorder and language impairment: Application of the causal network model. Clinical Linguistic \& Phonetics, 22, 25-46.

Luckner, J. L., \& McNeill, J. H. (1994). Performance of a group of deaf and hard-ofhearing students and a comparison group of hearing students on a series of problem-solving tasks. American Annals of the Deaf, 139(3), 371-377.

Lyon G.R., and Krasnegor, N.A. (Eds). (1996) Attention, memory, and executive function. Baltimore: Paul H. Brookes.

Manhardt, J., \& Rescorla, L. (2002). Oral narrative skills of late talkers at ages 8 and 9. Applied Psycholinguistics, 23(01), 1-21.

Manrique. M., Cevera-Paz, F.J., Huarte, A., Molina, M. (2004). Advantages of cochlearimplantation in prelingual deaf children before 2 years of age when compared to later implantation. Laryngoscope, 114, 1462-1469.

Mar, R. A. (2004). The neuropsychology of narrative: story comprehension, story production and their interrelation. Neuropsychologia, 42(10), 1414-1434.

Marschark, M. (2003). Interactions of language and cognition in deaf learners: From research to practice. International journal of audiology, 42, S41-S48.

Marschark, M., \& Everhart, V. S. (1999). Problem solving by deaf and hearing children: Twenty questions. Deafness and Education International, 1, 63-79.

Marschark, M., Mouradian, V., \& Halas, M. (1994). Discourse rules in the language productions of deaf and hearing children. Journal of experimental child psychology, 57(1), 89-107.

Martinussen, R., \& Tannock, R. (2006). Working memory impairments in children with attention-deficit hyperactivity disorder with and without comorbid language learning disorders. Journal of Clinical and Experimental Neuropsychology, 28(7), 1073-1094. 
Marton, K. (2008). Visuo-spatial processing and executive functions in children with specific language impairment. International Journal of Language and Communication Disorders, 43, 181-200.

Mayer, M. (1969). Frog, where are you?. New York: Dial Press

May-Mederake, B., \& Shehata-Dieler, W. (2013). Case Report A Case Study Assessing the Auditory and Speech Development of Four Children Implanted with Cochlear Implants by the Chronological Age of 12 Months. Case Reports in Otolaryngology, 2013, 1-10.

McLean, J.F., \& Hitch, G.J. (1999). Working memory impairment in children with specific arithmetic learning difficulties. Journal of Experimental Child Psychology, $74,240-260$.

Merritt, D. D., \& Liles, B. Z. (1987). Story grammar ability in children with and without language disorder: Story generation, story retelling, and story comprehension. Journal of Speech and Hearing Research, 30, 539-552.

Milch-Reich, S., Campbell, S.B., Pelham, Jr., W.E., Connelly, L.M., \& Geva, D. (1999). Developmental and individual differences in children's on-line representations of dynamic social events. Child Development, 70, 413-431.

Miller, J. F., \& Iglesias, A.(2008). Systematic Analysis of Language Transcripts (Research Version 9.1) [Computer software]. Middleton, WI: SALT Software.

Miller, C. A., Kail, R., Leonard, L. B., \& Tomblin, J. B. (2001). Speed of processing in children with specific language impairment. Journal of Speech, Language and Hearing Research, 44(2), 416.

Mitchell, T. V., \& Quittner, A. L. (1996). Multimethod study of attention and behavior problems in hearing-impaired children. Journal of Clinical Child Psychology, 25(1), 83-96.

Miyamoto, R. T., Svirsky, M. A., \& Robbins, A. M. (1997). Enhancement of expressive language in prelingually deaf children with cochlear implants. Acta Otolaryngol (Stockholm), 117, 154-157.

Moeller, M. P. (2007). Current state of knowledge: psychosocial development in children with hearing impairment. Ear and hearing, 28(6), 729-739.

Montgomery, J.M. (2002). Information processing and language comprehension in children with specific language impairment. Topics in Language Disorders, 22, 62-84. 
Morris, N., \& Jones, D. M. (1990). Memory updating in working memory: The role of the central executive. British Journal of Psychology, 81(2), 111-121.

Mousley, K., \& Kelly, R. R. (1998). Problem-solving strategies for teaching mathematics to deaf students. American Annals of the deaf, 143(4), 325-336.

National Institute of Child Health and Human Development Early Child Care Research Network. (2003). Do children's attention processes me-diate the link between family predictors and school readiness? Developmental Psychology, 39,581-593.

Neisser U. 1967. Cognitive Psychology. New York: Appleton-Century-Crofts.

Neufeld, R. W., Townsend, J. T., \& Jetté, J. (2007). Quantitative Response Time Technology for Measuring Cognitive-Processing Capacity in Clinical Studies. In R.W.J. Neufeld (Ed.), Advances in clinical cognitive science: formal modeling of processes and symptoms (p. 207-238). Washington, DC: American Psychological Association.

Nikolopoulos, T. P., Archbold, S. M., \& Gregory, S. (2005). Young deaf children with hearing aids or cochlear implants: early assessment package for monitoring progress. International journal of pediatric otorhinolaryngology, 69(2), 175-186.

Nikolopoulos, T. P., Lloyd, H., Starczewski, H., \& Gallaway, C. (2003). Using SNAP Dragons to monitor narrative abilities in young deaf children following cochlear implantation. International journal of pediatric otorhinolaryngology, 67(5), 535541.

Nilsson, M., Soli, S. D., \& Gelnett, D. J. (1996). Development and norming of a hearing in noise test for children. Los Angeles: House Ear Institute.

Niparko, J. K., Tobey, E. A., Thal, D. J., Eisenberg, L. S., Wang, N. Y., Quittner, A. L., \& Fink, N. E. (2010). Spoken language development in children following cochlear implantation. JAMA: the journal of the American Medical Association, 303(15), 1498-1506.

Nippold, M. A. (2007). Later language development: School-age children, adolescents, and young adults. Pro Ed.

Norbury, C.F., \& Bishop, D.V.M. (2003). Narrative skills of children with communication impairments. International Journal of Language and Communication Disorders, 38, 287-313.

O'Brien, D. H. (1987). Reflection-impulsivity in total communication and oral deaf and hearing children: a developmental study. American annals of the deaf, 132(3), 213-17. 
Ozonoff, S., \& Jensen, J. (1999). Brief Report: Specific executive function profiles in three neurodevelopmental disorders. Journal of Autism and Developmental Disorders, 29, 171-177.

Palladino, P., Cornoldi, C., De Beni, R., \& Pazzaglia, F. (2001). Working memory and updating processes in reading comprehension. Memory \& cognition, 29(2), 344354.

Parasnis, I., Samar, V. J., \& Berent, G. P. (2003). Deaf adults without attention deficit hyperactivity disorder display reduced perceptual sensitivity and elevated impulsivity on the Test of Variables of Attention (TOVA). Journal of Speech, Language and Hearing Research, 46(5), 1166-1183.

Paul, R. (2007). Language disorders from infancy through adolescence: Assessment \& intervention. Elsevier Health Sciences.

Paul, R., Hernandez, R., Taylor, L., \& Johnson, K. (1996). Narrative development in late talkers: Early school age. Journal of Speech and Hearing Research, 39, 1295-1303.

Peterson, C. (1994). Narrative skills and social class. Canadian Journal of Education, 19(3).

Peterson, C., \& McCabe, A. (1983). Developmental Psycholinguistics. Three Ways of Looking at a Child's Narrative. New York: Plenum Press.

Pierce, R. (1974). Look and Laugh. Milwaukee, WI: Western Publishing Inc

Pisoni, D. B., \& Cleary, M. (2003). Measures of working memory span and verbal rehearsal speed in deaf children after cochlear implantation. Ear and hearing, 24(1 Suppl), 106S.

Pisoni, D. B., Conway, C. M., Kronenberger, W., Henning, S., \& Anaya, E. (2010). Executive function, cognitive control, and sequence learning in deaf children with cochlear implants. In M. Marschark \& P.E. Spencer (Eds.), The Oxford handbook of deaf studies, language, and education, 2, 439-458. New York, NY: Oxford University Press.

Pisoni, D. D., \& Geers, A. E. (2000). Working memory in deaf children with cochlear implants: Correlations between digit span and measures of spoken language processing. The Annals of otology, rhinology \& laryngology. Supplement, 185, 92-93.

Pisoni, D., Kronenberger, W., Roman, A., \& Geers, A. (2011). Measures of digit span and verbal rehearsal speed in deaf children following more than 10 years of cochlear implantation. Ear and hearing, 32(1), 60S-74S. 
Price, J. R., Roberts, J. E., \& Jackson, S. C. (2006). Structural development of the fictional narratives of African American preschoolers. Language, Speech, and Hearing Services in Schools, 37(3), 178-190.

Purvis, K. L., \& Tannock, R. (1997). Language abilities in children with attention deficit hyperactivity disorder, reading disabilities, and normal controls. Journal of abnormal child psychology, 25(2), 133-144.

Quittner, A. L., Smith, L. B., Osberger, M. J., Mitchell, T. V., \& Katz, D. B. (1994). The impact of audition on the development of visual attention. Psychological Science, 5(6), 347-353.

Reilly, J., Bates, E., \& Marchman, V. (1998). Narrative discourse in children with early focal brain injury. Brain and Language, 61, 335-375.

Reilly, J., Losh, M., Bellugi, U., Wulfeck, B. (2004). "Frog, where are you?" Narratives in children with specific language impairment, early focal brain injury, and Williams syndrome. Brain and Language, 88, 229-247.

Reitan, R. M., \& Wolfson, D. (1992). Neuropsychological evaluation of older children. Neuropsychology Press.

Remine, M. D., Care, E., \& Brown, P. M. (2008). Language ability and verbal and nonverbal executive functioning in deaf students communicating in spoken English. Journal of deaf studies and deaf education, 13(4), 531-545.

Renfrew C. Renfrew Bus Story Manual: a test of narrative speech. Oxford: Winslow Press, 1994.

Renz, K., Lorch, E. P., Milich, R., Lemberger, C., Bodner, A., \& Welsh, R. (2003). Online story representation in boys with attention deficit hyperactivity disorder. Journal of Abnormal Child Psychology, 31(1), 93-104.

Reynell, J., \& Gruber, C. P. (1990). Reynell Developmental Language Scales: Manual. Western Psychological Services.

Rhine, S.E. (2002). Assessment of executive functioning in deaf and hard of hearing children. Unpublished masters pre-dissertation, Gallaudet University, Washington, District of Columbia.

Rhine Kalback, S. (2004). The assessment of developmental language differences, executive functioning, and social skills in deaf children. Dissertation, the Graduate School of Gallaudet University. 
Roth, F. P., \& Spekman, N. J. (1986). Narrative DiscourseSpontaneously Generated Stories of Learning-Disabled and Normally Achieving Students. Journal of Speech and Hearing Disorders, 51(1), 8-23.

Rothenberger, A., \& Woerner, W. (Hrsg.) (2004). Strengths and Difficulties Questionnaire (SDQ) - Evaluations and applications. European Child and Adolescent Psychiatry, 13, Supplement 2.

Russell, J., Saltmarsh, R., \& Hill, E. (1999). What do executive factors contribute to the failure on false belief tasks by children with autism?. Journal of Child Psychology and Psychiatry, 40(06), 859-868.

Schorr, E. A., Roth, F. P., \& Fox, N. A. (2008). A comparison of the speech and language skills of children with cochlear implants and children with normal hearing. Communication Disorders Quarterly, 29(4), 195-210.

Scott, C. (1988). Spoken and written syntax. In M. Nippold (Ed.), Later language development: Ages 9-19 (pp. 49-96). Austin, TX: Pro-Ed.

Scott, C. (2005). Learning to writie. In H. Catts and A. Kamhi (Eds.). Language and Reading Disabilities ( $2^{\text {nd }}$ edition, p. 233-273). Boston, MA: Allyn \& Bacon.

Scott, C. M., \& Stokes, S. L. (1995). Measures of syntax in school-age children and adolescents. Language, Speech, and Hearing Services in Schools, 26(4), 309-319.

Semel, E., Wiig, E. H., \& Secord, W. A. (1995).Clinical evaluation of language fundamentals(3rd ed.). San Antonio, TX: Psychological Corporation.

Semel, E., Wiig, E.H., \& Secord, W.A. (1992). Clinical Evaluation of Language Fundamentals-Preschool. San Antonio, Tex: The Psychological Corp.

Semel, E., Wiig, E. H., \& Secord, W. A. (2003). Clinical evaluation of language fundamentals, fourth edition (CELF-4). Toronto, Canada: The Psychological Corporation/A Harcourt Assessment Company.

Sesma, H. W., Mahone, E. M., Levine, T., Eason, S. H., \& Cutting, L. E. (2009). The contribution of executive skills to reading comprehension. Child Neuropsychology, 15(3), 232-246.

Shallice, T. (1982). Specific impairments of planning. Philosophical Transactions of the Royal Society of London. B, Biological Sciences,298(1089), 199-209.

Smith, E. E., \& Jonides, J. (1997). Working memory: A view from neuroimaging. Cognitive psychology, 33, 5-42. 
Spencer, L. J., Barker, B. A., \& Tomblin, J. B. (2003). Exploring the language and literacy outcomes of pediatric cochlear implant users. Ear and hearing, 24(3), 236247.

Sporn, M. B. (1997). The assessment of the Test of Variables of Attention with deaf children. Unpublished pre-dissertation project, Gallaudet University, Washington, DC.

St Clair-Thomson H.L., Gathercole, S.E. (2006). Executive functions and achievement in school: Shifting, updating, inhibition, and working memory. The Quarterly journal of experimental psychology, 59, 745-759 .

Starczewski, H., \& Lloyd, H. (1999). Using the stories/narrative assessment procedure (SNAP) to monitor language and communication changes after a cochlear implant: A case study. Deafness \& Education International, 1(3), 137-154.

Stein, N. \& Glenn, C. (1979). An analysis of story comprehension in elementary school children. In R. Freedle (Ed.), New directions in discourse processing (pp. 53-120). Norwood, NJ: Ablex.

Stuss,D.T., \& Benson, D.F. (1986). The frontal Lobes. New York: Raven Press.

Stuss, D.T. \& Levine, B. (2002). Adult clinical neuropsychology: Lessons from studies of the frontal lobes. Annual Review of Psychology, 53, 401-433.

Surowiecki, V., Sarant, J., Maruff, P., Blamey, P., Busby, P., \& Clark, G. (2002). Cognitive processing in children using cochlear implants: the relationship between visual memory, attention, and executive functions and developing language skills. Annals of Otology Rhinology Laryngology Supplement, 189, $119-126$.

Svirsky, M. A., Robbins, A. M., Kirk, K. I., Pisoni, D. B., \& Miyamoto, R. T. (2000). Language development in profoundly deaf children with cochlear implants. Psychological Science, 11, 153-158.

Swanson, H.L. (1993). Executive processing in learning disabled readers. Intelligence, 17, $117-149$.

Swanson, H.L. (1999). Reading comprehension and working memory in learning disabled readers: Is the phonological loop more important than the executive system. Journal of Experimental child psychology, 72, 1-31.

Swanson, H.L., Ashbaker, H., \& Lee, C. (1996). Learning-disabled readers' working memory as a function of processing demands. Journal of Experimental Child Psychology, 61, 242-275. 
Tannock, R., Purvis, K.L., \& Schachar, R.J. (1993). Narrative abilities in children with attention deficit hyperactivity disorder and normal peers. Journal of Abnormal Child Psychology, 21, 103-117.

Tharpe, A. M., Ashmead, D. H., \& Rothpletz, A. M. (2002). Visual attention in children with normal hearing, children with hearing aids, and children with cochlear implants. Journal of Speech, Language and Hearing Research, 45(2), 403.

Tomblin, J. B., Spencer, L., Flock, S., Tyler, R., \& Gantz, B. (1999). A comparison of language achievement in children with cochlear implants and children using hearing aids. Journal of Speech, Language, and Hearing Research, 42, 497-511.

Trabasso, T. (1989). Causal representation of narratives. Reading Psychology, 10, 67-83.

Trabasso, T., \& Nickels, M. (1992). The development of goal plans of action in the narration of a picture story. Discourse Processes, 15, 249-275.

T rainor, K., (2012). Executive functions in preschool children with typical and disordered language. Masters Theses. Paper 757.

Van der Lely, H.K.J. (1997). Narrative discourse in grammatical specific language impaired children: A modular language deficit? Journal of Child Language, 24, 221-256.

Watson, D. R., Titterington, J., Henry, A., \& Toner, J. G. (2007). Auditory sensory memory and working memory processes in children with normal hearing and cochlear implants. Audiology and Neurotology, 12(2), 65-76.

Wechsler, D. (2003). Wechsler Intelligence Scale for Children-WISC-IV. Psychological Corporation.

Weiss, A. L., \& Johnson, C. J. (1993). Relationships between narrative and syntactic competencies in school-aged, hearing-impaired children. Applied Psycholinguistics, 14(1), 35-59.

Welsh, M. C. (1991). Rule-guided behavior and self-monitoring on the Tower of Hanoi disk-transfer task. Cognitive Development, 6(1), 59-76.

Welsh, M. C., \& Pennington, B. F. (1988). Assessing frontal lobe functioning in children: Views from developmental psychology. Developmental neuropsychology, 4(3), 199-230.

Willstedt-Svensson, U., Loefqvist, A., Almqvist, B., Sahlen, B. (2004). Is age at implant the only factor that counts? The influence of working memory on lexical and grammatical development in children with cochlear implants. International Journal of Audiology, 43, 506-515. 
Windsor, J., \& Hwang, M. (1999). Testing the generalized slowing hypothesis in specific language impairment. Journal of speech, language and hearing research, 42(5), 1205.

Worsfold, S., Mahon, M., Yuen, H. M., \& Kennedy, C. (2010). Narrative skills following early confirmation of permanent childhood hearing impairment. Developmental Medicine \& Child Neurology, 52(10), 922-928.

Yoshinaga-Itano, C. (1986). Beyond the sentence level: what's in a hearing-impaired child's story?. Topics in Language Disorders, 6(3), 71.

Yoshinaga-Itano, C., \& Downey, D. M. (1996). The Effect of Hearing Loss on the Development of Metacognitive Strategies in Written Language. Volta Review, 98(1), 97-143.

Yoshinaga-Itano, C., \& Snyder, L. (1985). Form and Meaning in the Written Language of Hearing-Impaired Children. Volta Review, 87(5), 75-90.

Zimmerman, I.L., Steiner, V.G., \& Pond, R.E. (2002). Preschool language scale-4. San Antonio, TX: The Psychological Corporation. 


\section{APPENDIX A. GOAL PLAN FOR "FROG WHERE ARE YOU?"*}

Setting: introduce the protagonist, time, and place

Event: The frog climbed out of the jar and went away through the window.

The boy found that the jar is empty.

Goal 1 (first superordinate goal): the boy wants to get the frog back.

Goal 2 (secondary superordinate goal): The boy wants to find the frog.

Goal3 (subordinate goal): the goal in every single episode

Episode 1: Goal (3) - to find a frog

Attempt - search under clothes

Outcome - not found the frog

Episode 2: Goal (3) -to find a frog / for the frog come back

Attempt - called for the frog

Outcome - not found / not come back

Episode 3: Goal (3) - to find a frog / to see if the frog was there

Attempt - look in the hole on the ground, and/or called in the hole

Outcome - the gopher bit the boy's nose

Episode 4: Goal (3) - to find the frog / to see if the frog was there

Attempt - look in the hole in the tree, and/or call in the hole

Outcome - the owl knocked the boy down, chased him to the rock

Episode 5: Goal (3) - to find the frog / to see if the frog was there

Attempt - climbed the rock and called (for the frog)

Outcome - The deer carried the boy to the cliff and the boy fell in the pond

Episode 6: Goal (3) - to find the frog / to see if there was a frog

Event - hear a familiar sound

Attempt - told the dog to be quiet, crept the log to look behind it

Outcome - find the lost frog and his family including baby frogs

Event - One of the baby frogs jumped towards him, and wanted to be his new pet

Attempt 1 (attempt to get the Goal1): took the baby frog as a new pet

Outcome 1 (from the attempt 1): has a new pet and went home

Ending: said good-bye to his old frog and his family

the boy and dog are happy to have a new pet.

* Modified with permission from Routledge, Taylor and Francis group. Trabasso, T. \& Nickels, M. (1992). The development of goal plans of action in the narration of a picture story. Discourse processes, 15(3), 249-275. 


\section{APPENDIX B. EXAMPLE OF NARRATIVES}

1. Frog Where Are You? (the DHH, 10;8)

C There was/ed a boy who had/ed a pet dog and a pet frog [SI-2][setting].

$\mathrm{C}$ While the boy and his/z dog were/ed sleep/ing, the frog climb/ed out of the jar [SI2][event].

$\mathrm{C}$ and jump/ed out the open window [SI-1][event].

$\mathrm{C}$ The boy and the dog woke/ed up the next morning [SI-1][setting].

$\mathrm{C}$ and they look/ed everywhere [SI-1][A3-1].

$\mathrm{C}$ And the boy open/ed the window [SI-1][A3-2].

$\mathrm{C}$ and look/ed out the window [SI-1][A3-2].

$\mathrm{C}$ and call/ed for frog again [SI-1][A3-2][G3-2infer].

$\mathrm{C}$ Then the jar was/ed too heavy for the dog stay/ed on the window [GEomit/infinitive][SI-1][other].

$\mathrm{C}$ so he fell/ed down [SI-1][other].

$\mathrm{C}$ and mash/ed the jar [SI-1][other].

$\mathrm{C}$ The boy climb/ed out the window to make sure the dog was/ed okay [SI-1] [reaction].

C But the dog was/ed not hurt [SI-1][other].

$\mathrm{C}$ but the jar was/ed smash/ed [SI-1][other].

C Again, the boy call/ed for frog [SI-1][A2][G2].

$\mathrm{C}$ and the dog look for the frog, too [GE-tense][SI-1][other].

$\mathrm{C}$ The boy (called down,) found/ed a hole [SI-1][setting].

$\mathrm{C}$ and call/ed down the hole for his frog [SI-1][G3-3][A3-3].

$\mathrm{C}$ meanwhile the dog was/ed bark/ing at the tree, the hive on the tree [SI-1][other].

C Then a, (pause), something pop/ed up out of the hole [SI-1][O3-3].

$\mathrm{C}$ and bit/ed the boy on the nose [SI-1][O3-3].

$\mathrm{C}$ Meanwhile the dog was/ed shak/ing the tree [SI-1][other].

$\mathrm{C}$ and bark/ing at the bee/s [SI-1][other].

C The dog had/ed knock/ed down the hive [SI-1][other].

$\mathrm{C}$ and the bee/s were/ed angry at the dog for destroy/ing their/z home [SI-1][other].

$\mathrm{C}$ The boy who had not notice/ed the dog had/ed seen/ed a hole in the tree [SI-2][setting].

$\mathrm{C}$ He climb/ed up the tree [SI-1][A3-4].

$\mathrm{C}$ and call/ed down the hole for the frog [SI-1][A3-4][G3-4].

C And owl swoop/ed out of the hole [SI-1][O3-4].

$\mathrm{C}$ and knock/ed the boy down to the ground [SI-1][O3-4].

$\mathrm{C}$ But the dog was/ed chase/ed by angry bee/s [SI-1][other].

C The owl chase/ed the boy all the way to a rock [SI-1][O3-4].

C The boy climb/ed up the rock [SI-1][setting].

$\mathrm{C}$ and hold/ed on to some branch/s [SI-1][setting].

$\mathrm{C}$ so that he $\mathrm{did} / \mathrm{ed} / \mathrm{n}^{\prime} \mathrm{t}$ fall [SI-1].

$\mathrm{C}$ and call/ed for frog [SI-1][A3-5][G3-5].

C But the branch/s were/ed/n't really branch/s [SI-1][setting].

C They were/ed antler/s of a deer [SI-1][setting].

$\mathrm{C}$ The deer ran/ed all the way to a cliff [SI-1][other]. 
C The dog ran/ed with it, too, with the boy on his/z head [SI-1][other].

C The deer stop/ed [SI-1][other].

$\mathrm{C}$ and the boy and (the fro,) the dog fell/ed off the cliff [SI-1][O3-5].

$\mathrm{C}$ and fell/ed onto a pond, right on top of one another [SI-1][O3-5].

$\mathrm{C}$ Then the boy and the dog hear/ed a familiar sound behind the log [SI-1][event].

$\mathrm{C}$ The boy told/ed the dog very quiet [SI-1][A3-6].

$\mathrm{C}$ and then they crept/ed over the $\log [\mathrm{SI}-1][\mathrm{A} 3-6]$.

$\mathrm{C}$ The boy and a dog saw/ed the frog, and the mother with her [SI-1][O3-6][O2].

$\mathrm{C}$ Then the boy and the dog notice/ed a bunch of baby frog [GE-plural][SI-1][O3-6].

C One hop/ed up to the boy [SI-1][event].

$\mathrm{C}$ and it like/ed him [SI-1][event].

$\mathrm{C}$ and (it want to be,) it want/ed to be his/z new frog [SI-1][event].

$\mathrm{C}$ Then the boy took/ed the new frog home [SI-1][A1].

$\mathrm{C}$ the boy and the dog took/ed the new frog home with them [SI-1][O1].

C As the boy walk/ed away he wave/ed to the, his/z old frog and his/z family [SI-

2][Ending].

\section{Alien story (The DHH group, $9 ; 11$ )}

C One day Andy and Max were/ed play/ing, (were playing) in the wood [SI-1][setting].

C And they came/ed out for lunch in the park [SI-1][setting].

$\mathrm{C}$ And then when they were/ed come/ing back, they saw/ed an alienship (with four peo,) four alien come/ing out, and the strange pet come/ing out, too [SI-2][event].

C The ship was/ed just land/ing [SI-1][setting].

C And then Andy want/ed to go see for themselves if they were/ed real or not [SI-2][G1].

C Max would/ed/n't think it was/ed a good idea [GE-omit/conjunction][SI-1][other].

$\mathrm{C}$ He thought/ed, he would/ed can be taken/ed back into space [GE-auxiliary][SI1][other].

C Andy and Max went/ed over there [SI-1][A1].

C And (they start/ed talk/ing about, they start/ed talk/ing about - pause) they start/ed talk/ing about (how do they) how they got/ed here [SI-2][other].

$\mathrm{C}$ and why they were/ed here [SI-1][other].

$\mathrm{C}$ And then (little alien,) the smallest alien (were/ed play,) decide/ed they want/ed to play with the two kid/s [GE-omit/conjunction][SI-1][other].

$\mathrm{C}$ And (they decide/ed,) Andy and Max decide/ed that they could/ed live with them [SI2][G2].

C And then they became/ed best friend with Andy/'s/z family [GE-plural][SI-1][O2].

$\mathrm{C}$ (And they just,) and they knew/ed each other for a few year/s [SI-1][Ending].

$\mathrm{C}$ And then they back into outer space [GE-omit/verb][SI-1][Ending]. 


\section{VITA}

Hyejin Park was born in Seoul, Korea in 1973. She is a certified speech language pathologist in Korea with seven years of experience working with infants, children and adults who are deaf or hard or hearing. Her research focuses on the oral language and literacy development of school-aged children who are deaf and hard of hearing. She has two peer-reviewed publications, three book publications, and eight national conference presentations. She received her Doctor of Philosophy degree from the University of Tennessee Health Science Center, Speech and Hearing Science Program in 2014. 